\title{
Patient-specific fracture risk assessment of vertebrae: A multiscale approach coupling X-ray physics and continuum micromechanics
}

\author{
${ }$ Romane Blanchard $^{1}$, Claire Morin ${ }^{2}$, Andrea Malandrino $^{3}$, Alain Vella $^{4}$, Zdenka Sant $^{4}$, \\ (2. \\ Christian Hellmich ${ }^{1 *}$ \\ ${ }^{1}$ TU Wien- Vienna University of Technology, Institute for Mechanics of Materials and Structures, Karlsplatz, 13/202, \\ 1040 Vienna, Austria \\ ${ }^{2}$ CIS-EMSE, CNRS:UMR 5307, LGF, Ecole Nationale Supérieure des Mines, F-42023 Saint-Etienne, France \\ 4. Institute for Bioengineering of Catalonia, C/ Baldiri Reixac 10-12, 08028 Barcelona, Spain \\ ${ }^{4}$ Mechanical Engineering Department, University of Malta, Tal Qroqq, Msida MSD 2080, Malta
}

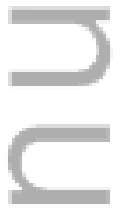

\section{SUMMARY}

While in clinical settings, bone mineral density (BMD) measured by Computed Tomography, remains the key indicator for bone fracture risk, there is an ongoing quest for more engineering mechanicsbased approaches for safety analyses of the skeleton. This calls for determination of suitable material properties from respective CT-data, where the traditional approach consists of regression analyses between attenuation-related grey values and mechanical properties.

We here present a physics-oriented approach, considering that elasticity and strength of bone tissue originate from the material microstructure and the mechanical properties of its elementary components. Firstly, we re-construct the linear relation between the clinically accessible grey values making up a Computed Tomograph, and the X-ray attenuation coefficients quantifying the intensity losses from which the image is actually reconstructed. Therefore, we combine X-ray attenuation averaging at different length scales and over different tissues, with recently identified "universal" composition characteristics of the latter.

This gives access to both the normally non-disclosed X-ray energy employed in the CT-device, and to in vivo, patient- and location-specific bone composition variables, such as voxel-specific mass density, as well as collagen and mineral contents. The latter feed an experimentally validated multiscale elastoplastic model, based on the hierarchical organization of bone. Corresponding elasticity maps across the organ enter a Finite Element simulation of a typical load case, and the resulting stress states are increased in a proportional fashion, so as to check the safety against ultimate material failure. In the young patient investigated, even normal physiological loading is probable to already imply plastic events associated with the hydrated mineral crystals in the bone ultrastructure, while the safety factor against failure is still as high

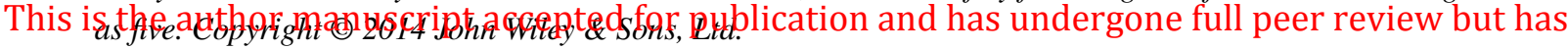
not been through the copyediting, typesetting, pagination and proofreading process, which may lead to differences between this version and the Version of Record. Please cite this article as doi:

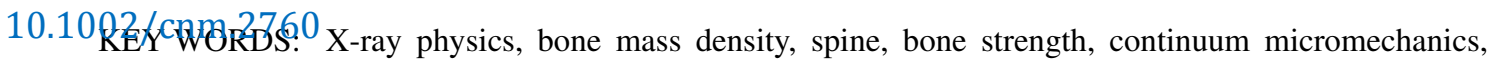
elastoplasticity

Copyright @ 2014 John Wiley \& Sons, Ltd.

Prepared using cnmauth.cls [Version: 2010/03/27 v2.00]

This article is protected by copyright. All rights reserved. 


\section{INTRODUCTION}

1 The broad scattering of ultimate forces bearable by human vertebrae [1-4] has motivated the quest

2 for indicators of the actual, i.e. patient-specific, strength exhibited by a particular vertebral body

3 of interest; and the most accepted indicator in this context remains the "bone mineral density -

4 BMD" [5, 6]. However, it is much less clear how and to which extent BMD (alone) would govern

5 bone fracture risk, and there is an ongoing discussion on additional or alternative risk indicators

6 [7-12], based on quite comprehensive statistical analyses. At the same time, it is clearly felt that

7 an engineering mechanics-based assessment of fracture risk, as it is the basis for structural design

8 in civil and mechanical engineering, should hold the capacity to overcome the shortcomings of the

9 purely statistics-based, population-related approaches referred to above. Accordingly, Computed

10 Tomography- and Finite Element-based failure risk assessment of bony structures remains one of

11 the central desires in bone biomechanics. This topic has been dealt with extensively, but broad

12 clinical application has not been achieved yet. The reason for this could be that the physical origins

13 of bone strength may need to be considered more deeply and rigorously than it has been attempted

14 so far. In fact, when screening the comprehensive literature on the topic, it becomes obvious that

15 even the most famous contributions on the topic rely on purely elastic analyses. Typically, linear

16 regression parameters between linear elastic FE analyses and strength tests performed on the same

17 piece of bone are established, which are typically superior to regressions between strength and

18 some direct radiological measures $[3,13,14]$. In other studies, stress states derived from linear

19 Finite Element analyses are averaged over suitably chosen "regions of interest", and corresponding

20 average stress levels are thought to be relevant for fracture risk assessment [15]. Still, one might argue that the choice of such regions of interest may be quite arbitrary, but at the same time very influential on the corresponding simulation results. This would call for a deeper theoretical involvement into the material mechanics of bone and a particularly notable approach was realized

for human femura $[16,17]$, where a certain consensus has been gained in the community as regards CT-to-mechanics calibration schemes [18-20]. Namely, elastic properties derived from CT- and mass density-based calibration schemes [21-24], are mapped onto Finite Element meshes, and for a variety of load cases, strains as obtained from an elastic simulation are assessed with respect to a

failure criterion based on a constant maximum principal strain. The aforementioned consensus (or

\footnotetext{
${ }^{*}$ Correspondence to: Institute for Mechanics of Materials and Structures, Karlsplatz 16, 1040 Vienna, Austria. E-mail: christian.hellmich@tuwien.ac.at 
even enough data for potentially reaching it) is hard to find for other types of bone where only very few studies exist [25]; so that again deeper theoretical understanding is necessary, the obvious next step thereby concerning elastoplasticity. In fact, elastoplastic Finite Element simulations on bony organs have already been performed [26], and they have turned out to be useful when it comes to simulate the interaction between an implant and the neighboring bone. Still, this does not render the entire issue of bone strength assessment as being solved: There is a second challenge which needs to be overcome: The determination of relevant mechanical properties (elastic as well as elasto-plastic strength values), from clinically available CT-images. The traditional approach [15] consists of regression analyses between attenuation-related grey values and mechanical properties; however, no consensus exists on unique regression parameters; they most probably depend on various additional variables, such as CT machine settings and X-ray energies used. Still, such empirical densitystiffness relations are also used in an inverse fashion, in order to relate elastic property distributions across organs to corresponding mass densities [27]. In this case, the elastic property distributions were determined such that given physiological load cases resulted in targeted strain magnitudes as proposed in the framework of the Mechanostat theory [28]. On the other hand, a more physicsoriented approach would ask for the origin of elasticity and strength of the material found within each voxel to be found in a Computed Tomograph - this origin being the material microstructure and the mechanical properties of its elementary components, in the case of bone: hydroxyapatite, collagen, and water with some non-collageneous organics. Thanks to recent discoveries concerning universal patterns in bone tissue composition and microstructure [29-32], as well as their effects on the tissue's elasticity and strength [33-35], we are now in the position to rigorously relate tissue mass densities and porosities at different scales of observation, to corresponding elastic and strength values. Still, these mass densities need to be related to the grey values defining a CT-image, in order to obtain the desired (unique and reliable) relation between CT-numbers and mechanical properties. In this context, it proved useful to translate the chemical characteristics (and hence the mass density) of the matter found in each and every voxel making up a 3D stack of Computed Tomography images, into the corresponding X-ray attenuation coefficients, based on the publicly available NIST data base [36] and the average rule for attenuation coefficients [18,37-43]. However, 56 such a determination of density/chemistry-attenuation relations is often challenged by the fact that 57 the X-ray attenuation coefficients do not only depend on the material's chemistry (which establishes a link to mass density), but also on the X-ray energy used for the CT image; and as a rule, the latter is not documented in a clinical setting. Extending, modifying, and adapting recent results gained in the 


\section{MATERIALS AND METHOD}

\subsection{Conversion of CT grey values into energy-dependent attenuation coefficients, based on} statistical image evaluation and on soft tissue composition rules

A CT scan of a motion segment of a 15-years-old male patient, consisting of two lumbar vertebral bodies L3 and L4, was obtained from Mater Dei Hospital, Malta. The HiSpeed Dual medical CT scanner from General Electrics was employed in helical mode, with the following parameters: source voltage: $140 \mathrm{kV}$, source current: $110 \mu \mathrm{A}$, exposure time: $1000 \mathrm{~ms}$, image pixel size: $0.324 \mathrm{~mm}$, and slice spacing: $1.25 \mathrm{~mm}$. In the respective CT images, which capture not only the bone 
structure of a vertebral body, but also the surrounding soft tissue, the X-ray attenuation information 90 is stored in terms of 8-bit grey values, increasing with intensifying attenuation. In order to separate 91 soft and hard tissues, all the grey values found in the 3D image are evaluated first in terms of a 92 (normalized) histogram, representing a probability density function for the grey value of one voxel 93 which is randomly chosen from the 3D image. More precisely, in such histogram, we identify two 94 peaks related to the most frequently occurring grey values containing (i) adipose tissues $\left(G V_{f a t}\right) \quad 95$ and (ii) inner organs $\left(G V_{\text {soft }}\right)$, with $G V_{f a t}<G V_{\text {soft }}$. In order to separate bone tissue voxels from 96 their surroundings, we consider the first minimum value of the probability density function, which 97 appears right of $G V_{\text {soft }}$, i.e. for $G V>G V_{\text {soft }}$. We denote this minimum value as segmentation 98 threshold $G V_{t h r}$.

In order to back-translate the user-selected grey scale values into the underlying X-ray attenuation 100 values, we consider the linear relation between grey values and X-ray energy-dependent attenuation 101 coefficients, involving three unknowns: two proportionality factors $a$ and $b$, and the X-ray energy $\mathcal{E}: \quad 102$

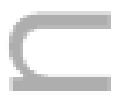

$$
\mu(\mathcal{E})=a(\mathcal{E}) \times G V+b(\mathcal{E})
$$

Eqn.(1) expresses that the X-ray attenuation coefficient is no classical material property; namely, it depends not only on the matter contained in a specific voxel, but also on the energy used for X-ray penetration of the investigated object. In order to identify the energy-dependent slope and intercept functions, $a(\mathcal{E})$ and $b(\mathcal{E})$, we specify (1) for the aforementioned two landmark values concerning fat and soft tissues:

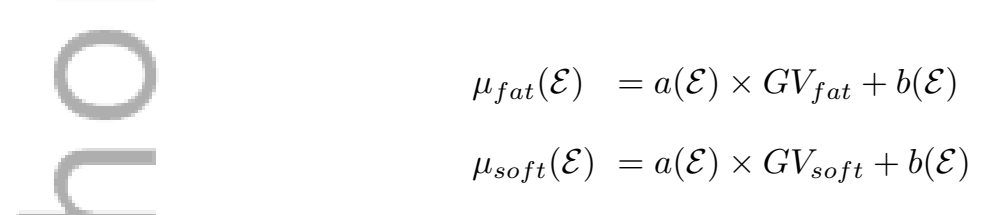

In order to determine the functions at the left-hand side of Eqn.(2) and (3), we consider two fundamental relations:
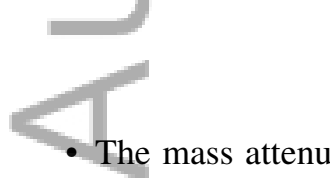

The mass attenuation coefficient of a chemical substance $i$ with mass density $\rho_{i},(\mu / \rho)_{i}$, is a function of its chemical composition, as is openly accessible from the National Institute 107 of Standards and Technology (NIST) [36]; in particular, the mass attenuation coefficient of 108 fat is directly given, so that the mass density of fat $\rho_{f a t}=0.95 \mathrm{~g} / \mathrm{cm}^{3}$ [45] gives access to the 109 attenuation coefficient of fat, as depicted by the black line in Figure 1. 
- The X-ray attenuation coefficient of a composite material located inside one voxel is identical to the volume average of the X-ray attenuation coefficients of the material's single constituents [37-39]

$$
\mu(\mathcal{E})=\sum_{i=1}^{N_{C}} \mu_{i}(\mathcal{E}) \times f_{i}
$$

with $\mu_{i}, i=1, \ldots, N_{C}$, as the X-ray attenuation coefficient of constituent $i, N_{C}$ as the total $=$ number of constituents, and with $f_{i}$ as the volume fraction of constituent $i$ within the considered voxel.
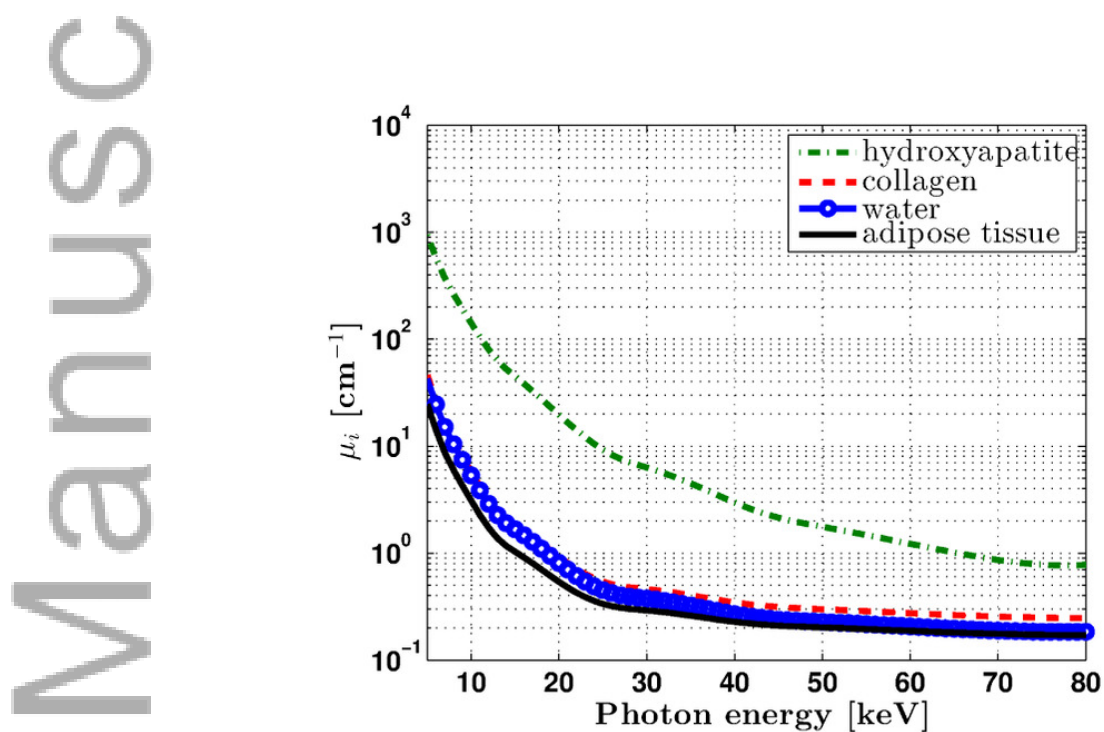

Figure 1. X-ray attenuation coefficients of the elementary constituents of bone tissue, and of adipose tissue; as functions of the photon energy (Data reproduced from [36], in combination with the mass densities of पlins

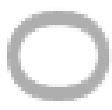

$$
\text { adipose tissue [45], of collagen [46], and of hydroxyapatite [35]) }
$$

Applying Eqn.(4) to the soft tissue, i.e. inner organs and muscles localized around the spine, yields

$$
\mu_{\text {soft }}(\mathcal{E})=\mu_{\mathrm{H}_{2} \mathrm{O}}(\mathcal{E}) \times f_{\mathrm{H}_{2} \mathrm{O}}+\mu_{\text {org }}(\mathcal{E}) \times\left(1-f_{\mathrm{H}_{2} \mathrm{O}}\right)
$$

where the attenuation coefficient of water follows from its chemical formula $\mathrm{H}_{2} \mathrm{O}$, see secondlowest line in Fig.1, and that of organic material is approximated by the smallest amino acid, glycine (making up a high percentage of collagen, and being similar in structure to the remaining portion of collagen [47]), with chemical formula $\mathrm{C}_{2} \mathrm{H}_{5} \mathrm{NO}_{2}$, see dotted line in Fig.1. The volume fraction of water, $f_{\mathrm{H}_{2} \mathrm{O}}$, is accessed through the average rule for the soft tissue mass density,

$$
\rho_{\text {soft }}=f_{\mathrm{H}_{2} \mathrm{O}} \times \rho_{\mathrm{H}_{2} \mathrm{O}}+\left(1-f_{\mathrm{H}_{2} \mathrm{O}}\right) \times \rho_{\mathrm{col}}
$$


namely through

$$
f_{H_{2} O}=\frac{\rho_{s o f t}-\rho_{c o l}}{\rho_{H_{2} O}-\rho_{c o l}}
$$

with the soft tissue mass density of tissues around the spine being documented as $\rho_{\text {soft }}=1.052 \mathrm{~g} / \mathrm{cm}^{3} \quad 124$ [45] and $\rho_{c o l}=1.42 \mathrm{~g} / \mathrm{cm}^{3}[46]$.

Conclusively, we solve Eqn.(2) and (3), while considering Eqn.(4)-(7), for $a(\mathcal{E})$ and $b(\mathcal{E})$.

2.2. Identification of $X$-ray photon energy and of extracellular bone tissue mass density, based on general bone tissue composition rules

As supplementary voxels of interest, we consider the densest voxel in the corpus vertebrae, $G V_{\max }$, 129 which hosts part of the "cortical shell" of the vertebra. However, as seen from the microCT image 130 of Figure 2, this shell is very thin, with a typical thickness of only 230 microns [48-50], so that 131 the densest voxel (with a voxel size $l_{\text {voxel }}=324$ microns) does not only contain cortical bone, but 132 also adjacent vascular porosity or soft tissue around. Hence, we consider one additional voxel, 133 namely the densest neighbor of the voxel exhibiting $G V_{\max }$, also containing both extravascular 134 tissue resembling "cortical bone", as well as vascular porosity or soft tissue, with $G V_{\text {soft }}$, see Figure

3. The grey values related to the aforementioned two voxels are used for identification of the grey
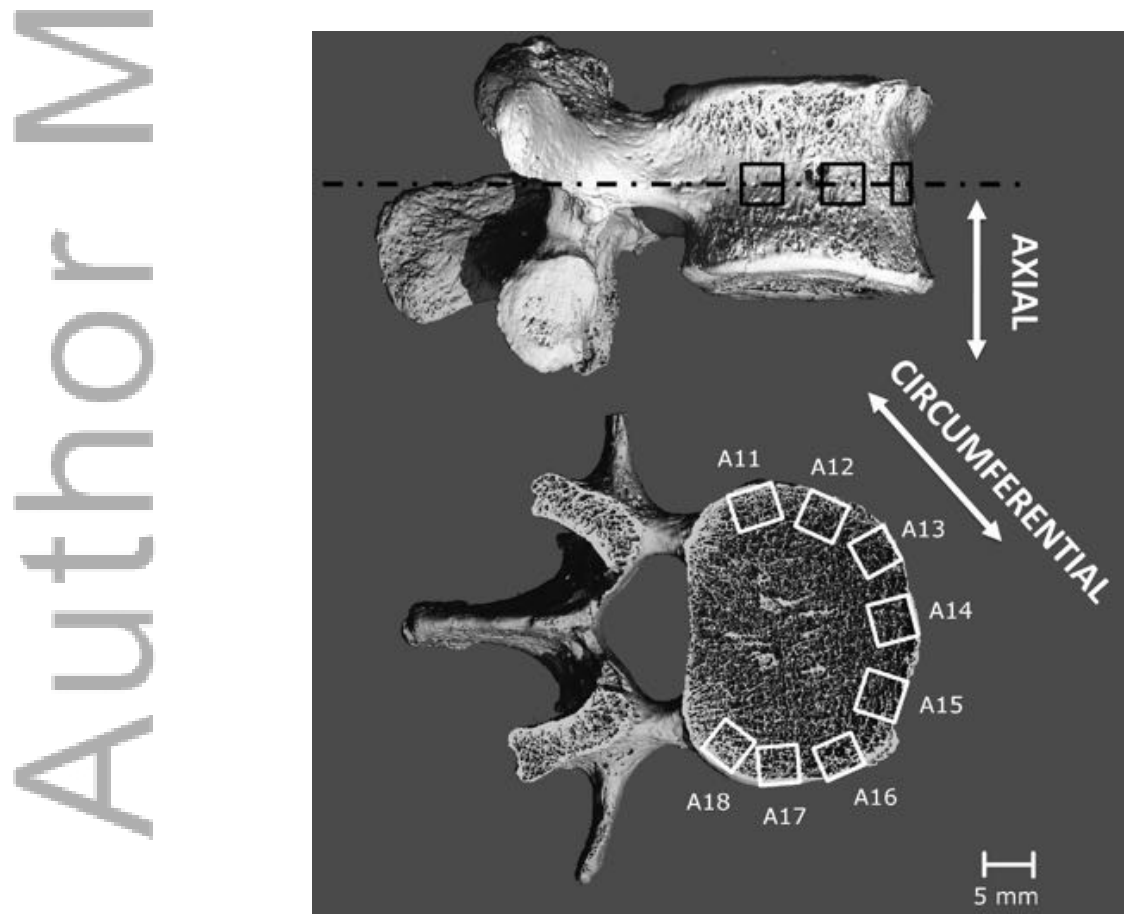

Figure 2. MicroCT image of vertebra, adapted from Malandrino et al (2012) [51]; showing very thin "cortical shell", as well as original position and orientation of cubic samples cut from the investigated mid-height vertebra. 


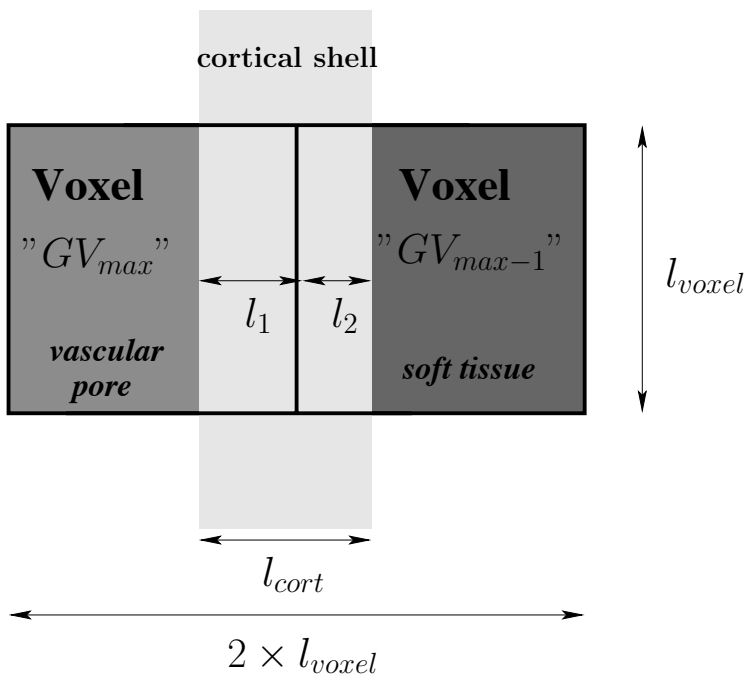

Figure 3. Partition of cortical shell (with thickness $l_{\text {cort }}$ ) between two neighboring voxels (with edge length

$$
\left.l_{\text {voxel }}\right)
$$

$$
G V=\sum_{i=1}^{N_{C}} G V_{i} \times f_{i}
$$




$$
\begin{aligned}
& \frac{l_{1}}{l_{\text {voxel }}} \times G V_{\text {ev }}+\left(1-\frac{l_{1}}{l_{\text {voxel }}}\right) \times G V_{\text {soft }}=G V_{\text {max }} \\
& \frac{l_{2}}{l_{\text {voxel }}} \times G V_{e v}+\left(1-\frac{l_{2}}{l_{\text {voxel }}}\right) \times G V_{\text {soft }}=G V_{\text {max }-1} \\
& l_{1}+l_{2}=l_{\text {cort }}
\end{aligned}
$$

= Solving these three equations for the unknowns $G V_{e v}, l_{1}$, and $l_{2}$, yields in particular the sought 151 value for $G V_{e v}$ as function of all the already identified grey values and length dimensions,

$$
G V_{e v}=\frac{l_{\text {voxel }}}{l_{\text {cort }}} \times\left(G V_{\text {max }}+G V_{\text {max-1 }}-2 G V_{\text {soft }}\right)+G V_{\text {soft }}
$$

In order to identify the $\mathrm{X}$-ray energy $\mathcal{E}$, which then will allow for a unique scaling relation between grey values and attenuation coefficients, as given through Eqn.(1), we consider two independent 154 ways to access the attenuation coefficient of the extravascular bone material, $\mu_{e v}$. These two ways 155 need to deliver one single, unique result:

The first access to $\mu_{e v}$ is provided through

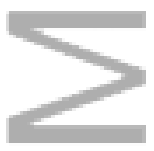

$$
\mu_{e v}(\mathcal{E})=a(\mathcal{E}) \times G V_{e v}+b(\mathcal{E})
$$

fed with the energy-dependent proportionality constants derived from Eqn.(1)-(7);

- The second access is provided through repeated use of Eqn.(4) for upscaling attenuation 159 coefficients from the level of the elementary constituents of bone tissue, up to the level of 160 the extravascular bone material.

As regards the latter item, the NIST-data base allows for retrieval of the attenuation coefficients 162 of the (mechanically relevant) elementary constituents of extracellular bone tissue: hydroxyapatite, 163 organic material, and water. The two latter ones have been already introduced in Section 2.1, and 164 the chemical formula $\mathrm{Ca}_{10}\left(\mathrm{PO}_{4}\right)_{6}(\mathrm{OH})_{2}$ allows for obtaining the hydroxyapatite-related attenuation $\quad 165$ curve, as depicted in Fig.1. Use of these functions in Eqn.(4), i.e. upscaling from the elementary to 166 the extracellular level, yields

$$
\begin{aligned}
\mu_{\text {ec }}^{u p}(\mathcal{E})= & \mu_{H A}(\mathcal{E}) \times f_{H A}^{e c}+\mu_{\text {org }}(\mathcal{E}) \times f_{\text {org }}^{e c}+\mu_{H_{2} O}(\mathcal{E}) \times f_{H_{2} O}^{e c} \\
& \text { with } \quad f_{H_{2} O}^{e c}+f_{\text {org }}^{e c}+f_{H A}^{e c}=1
\end{aligned}
$$


=

$$
\mu_{e v}^{u p}\left(\mathcal{E}, \rho_{e c}\right)=\phi_{l a c} \times \mu_{H_{2} O}(\mathcal{E})+\left(1-\phi_{l a c}\right) \times \mu_{e c}^{u p}(\mathcal{E})
$$

with as the lacunar porosity, $\phi_{l a c}=0.10[35,63]$. Expressions (13) and (15) need to deliver the same
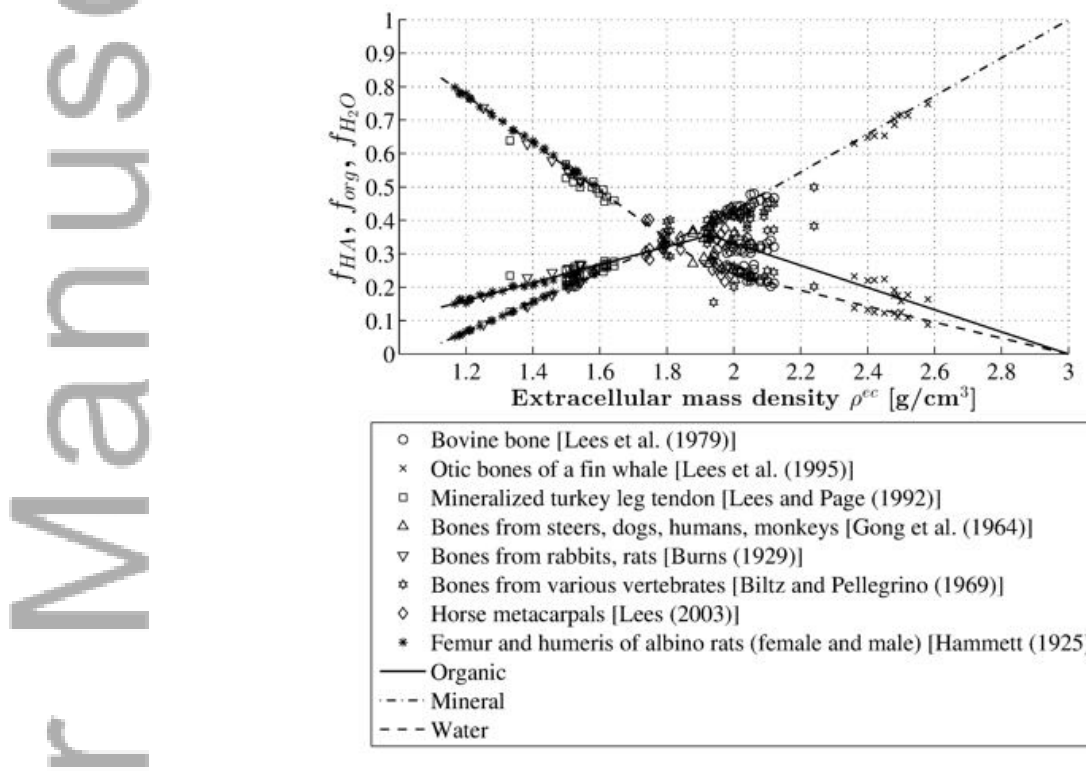

\begin{tabular}{rl|}
\hline & Bovine bone [Lees et al. (1979)] \\
$\times$ & Otic bones of a fin whale [Lees et al. (1995)] \\
$\square$ & Mineralized turkey leg tendon [Lees and Page (1992)] \\
$\triangle$ & Bones from steers, dogs, humans, monkeys [Gong et al. (1964)] \\
$\nabla$ & Bones from rabbits, rats [Burns (1929)] \\
$\star$ & Bones from various vertebrates [Biltz and Pellegrino (1969)] \\
$\diamond$ Horse metacarpals [Lees (2003)] \\
$*$ Femur and humeris of albino rats (female and male) [Hammett (1925)] \\
\hline- Organic \\
-- Mineral \\
\hline- - Water
\end{tabular}

Figure 4. Universal composition rules in bone tissue [30]: bilinear relations between constituent volume fractions and tissue mass density

Int. J. Numer. Meth. Biomed. Engng. (2014) 
In order to check the relevance of the value for the tissue mass density retrieved by means of the strategy outlined in Section 2.2, an independent experimental route towards $\rho_{e c}$ is pursued, through the following protocol: From the mid-height portion of an elderly human vertebral body provided by the Medical University of Vienna, a slice was cut out by means of a band saw under continuous 185 water irrigation (300Cp, Exakt GmbH, Germany). Out of this slice, eight cubes with 5-6 mm edge 186 length were extracted by means of a wheel saw (Isomet, Buehler, USA). All the specimens had a 187 face containing the external vertebral cortex, as can be seen in Fig.2. Two exactly parallel opposite 188 surfaces orthogonal to the cortex layer were cut, whereby attention was paid on maintaining the 189 cortex undamaged. Then, the specimens were immersed in an ultrasonic bath with $0.9 \%$ saline 190 solution and standard soap, for 3 minutes at $40^{\circ} \mathrm{C}$, in order to allow for mixing of the solution 191 with the soap. Afterwards, the specimens were left during 24 hours at the same temperature for 192 lipid dissolution. They were then washed with $0.9 \%$ saline solution for 10 minutes at $40^{\circ} \mathrm{C}$ under 193 ultrasonic bath, and finally under flushing water at room temperature, in order to further clean 194 the pores. The extracellular tissue density was measured by means of Archimedes' principle: The 195 weight $W_{s}$ of each specimen completely submerged in distilled water (air bubbles were removed 196 under vacuum) was recorded by means of an analytical balance (PG403-S, Mettler-Toledo GmbH, 197 Switzerland), as was the weight in air, $W_{a}$, the latter being accessible after centrifugation at $400 \mathrm{~g} \quad 198$ for 15 minutes, in order to remove water from the vascular and lacunar pores. The mass density $\rho_{e c}$ of the extracellular bone matrix was then determined according to:

$$
\rho_{e c}=\frac{W_{a}}{W_{a}-W_{s}}
$$

\subsection{Voxel-specific tissue composition}

Once the photon energy $\mathcal{E}$ is known, it gives access to the extravascular bone matrix attenuation 202 coefficient via Eqn.(15), which can then be upscaled to the macroscopic bone material level: 203 Therefore, we specify the average rule (4) for the constituents "extravascular bone matrix" [with 204 volume fraction $\left.\left(1-\phi_{v a s}\right)\right]$ and vascular porosity (with volume fraction $\left.\phi_{v a s}\right)$, yielding

$$
\mu_{\text {macro }}=\phi_{\text {vas }} \times \mu_{H_{2} O}+\left(1-\phi_{\text {vas }}\right) \times \mu_{e v}
$$


Solving this equation for $\phi_{\text {vas }}$ gives access to voxel-specific values for the vascular porosity,

$$
\phi_{v a s}=\frac{\mu_{m a c r o}-\mu_{e v}}{\mu_{H_{2} O}-\mu_{e v}}
$$

207

$\phi_{v a \bar{s}}$ can be also used to provide voxel-specific mass densities at the macroscopic scale

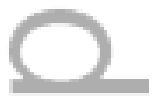

$$
\rho_{\text {macro }}=\phi_{\text {vas }} \times \rho_{H_{2} \mathrm{O}}+\left(1-\phi_{\text {vas }}\right) \times \rho_{\text {ev }}
$$

$=$

based on mass densities at the extravascular scale

$$
\rho_{e v}=\phi_{l a c} \times \rho_{H_{2} O}+\left(1-\phi_{l a c}\right) \times \rho_{e c}
$$

Moreover, we are also interested in the apparent mass densities of mineral and collagen, i.e.

the "bone mineral and collagen mass densities", the former one being sometimes referred to as

\section{vBMD [64].}

Therefore, we convert constituent volume fractions into apparent mass densities of hydroxyapatite, collagen, and water and non collageneous proteins,

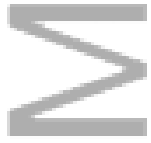

$$
\begin{aligned}
\rho_{H A}^{*, e c} & =f_{H A}^{e c} \times \rho_{H A} \\
\rho_{c o l}^{*, e c} & =0.9 \times f_{o r g}^{e c} \times \rho_{c o l} \\
\rho_{H_{2} O+n c p}^{*, e c} & =\rho_{e c}-\rho_{H A}^{*, e c}-\rho_{c o l}^{*, e c}
\end{aligned}
$$

$$
\begin{aligned}
& \rho_{H A}^{*}=\rho_{H A}^{*, e c} \times\left(1-\phi_{\text {lac }}\right) \times\left(1-\phi_{\text {vas }}\right) \\
& \rho_{\text {col }}^{*}=\rho_{\text {col }}^{*, e c} \times\left(1-\phi_{\text {lac }}\right) \times\left(1-\phi_{\text {vas }}\right) \\
& \rho_{H_{2} O+n c p}^{*}=\rho_{\text {macro }}-\rho_{c o l}^{*}-\rho_{H A}^{*}
\end{aligned}
$$

\subsection{Intravoxel tissue elasticity}

The ultrastructural mass density and the spatial distribution of vascular porosities determined from a CT scan of a patient by means of a series of X-ray physics considerations, as described in Section 
2.4 (see in particular Figure 11), are now converted into voxel-specific elastic properties, on the 220 basis of the multiscale homogenization scheme depicted in Figure 5.
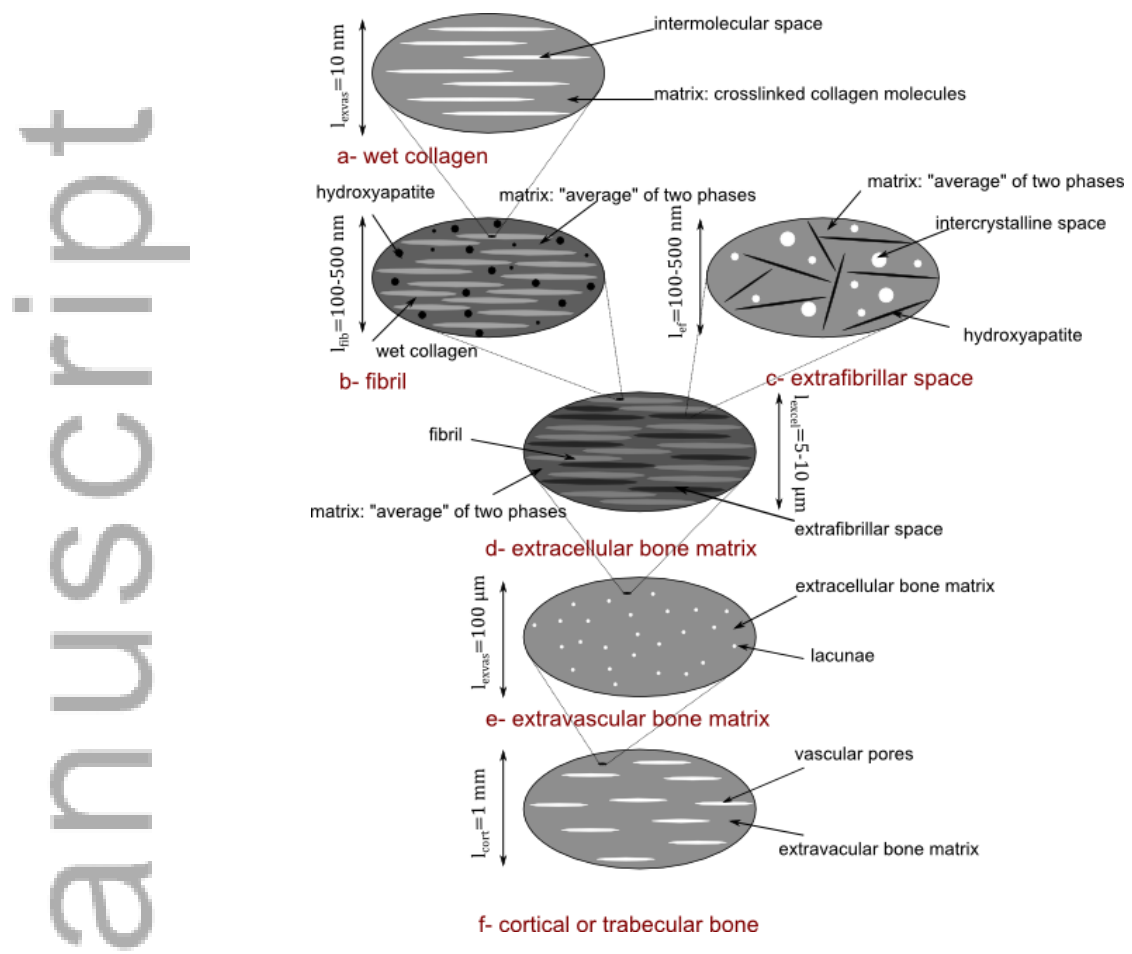

Figure 5. Multiscale micromechanical representation of bone material, according to Morin and Hellmich [35]

This scheme, described in great detail in $[29,33,35,66]$, quantifies how the elementary mechanical 222 constituents of bone, namely hydroxyapatite, collagen, and water with some non-collageneous 223 organics, as well as their dosages within the extracellular bone matrix, determine the elastic 224 properties of bone at different length scales. It has been extensively validated experimentally, 225 through an ultrasound data base stemming from a wealth of bone sources - equine cortical bone 226 [67], bovine tibia [52], drug-treated rabbit bone [68], whale malleus, incus, stapes, periotic and t. 227 bulla [53], fin whale t. bulla [69], dugong rib, elephant radius, human femur, deer antler [54] - in 228 combination with "universal" composition and mineralization rules for bone tissues $[30-32,70] .229$ The latter were derived from a wealth of biophysical, biochemical, and biomechanical experimental 230 sources $[52,55,57-60,71-79]$. In this context, bone is represented by a series of representative 231 volume elements, the size of which is significantly larger than that of the inhomogeneities 232 found within such a volume [see e.g. Figure 5(f) with the vascular pores' diameters being 233 scale-separated from the millimeter-size of the cortical or trabecular RVE]. Also, representation 234 of the microstructure within the RVE is reduced to the bare minimum needed for elasticity 235 
homogenization: the domain within the RVE is subdivided into the minimum number of material 236

Int. J. Numer. Meth. Biomed. Engng. (2014)

Copyright (C) 2014 John Wiley \& Sons, Ltd.

with $\phi_{\text {vas }}$ as the vascular porosity, $\mathbb{C}_{e v}$ and $\mathbb{C}_{H_{2} O}$ as the elastic stiffness of the extravascular bone matrix and water, $\mathbb{I}$ as the fourth-order identity tensor with components $I_{i j k l}=\frac{1}{2}\left(\delta_{i k} \delta_{j l}+\delta_{i l} \delta_{j k}\right)$, with the Kronecker delta $\delta_{i j}$ being equal to 1 for $i=j$ and zero otherwise; and $\mathbb{P}_{c y l}$ as the fourthorder Hill tensor accounting for the cylindrical shape of the inclusions embedded into a transversely isotropic matrix [66].

Within the investigated vertebral body, the vascular porosity is varying from voxel to voxel, as depicted in Figure 11; all other quantities in Eqn.(26) are constant. Particularly, the extravascular stiffness follows from feeding the homogenization scheme of Figure 5 with an ultrastructural mass density resulting from Eq. (16) (and corresponding ultrastructural volume fractions of mineral, collagen, and water as given in Figure 12) and with a lacunar porosity of $10 \%[35,63]$.

The stiffness tensor of water reads as $\mathbb{C}_{H_{2} 0}=3 \mathbb{I}_{\text {vol }} k_{H_{2} 0}$, with the bulk modulus of water amounting to $k_{H_{2} O}=2.3 \mathrm{GPa}$ [80], and with $\mathbb{I}_{\text {vol }}$ as the volumetric part of the fourth-order identity tensor, with components $I_{v o l, i j k l}=\frac{1}{3} \delta_{i j} \delta_{k l}$.

1.6.

2.6. Linear Finite Element simulations

The used Finite Element model is based on earlier work published in [81], see Figure 6: It consists of 125253 solid elements accounting for the trabecular bone tissue, and 17185 shell elements accounting for the cortical bone tissue. For the present study, we realized a cortical shell thickness of $l_{\text {cort }}=0.23 \mathrm{~mm}$ [48-50]; while the caudal and cranial (bony) endplates were assigned thicknesses of $l_{\text {end }}=1 \mathrm{~mm}[82,83]$. In order to investigate the effect of heterogeneity at the finite element level (i.e. with gradients measured along a few millimeters), we considered two ways of assigning material properties to the Finite Element model of Figure 6: 

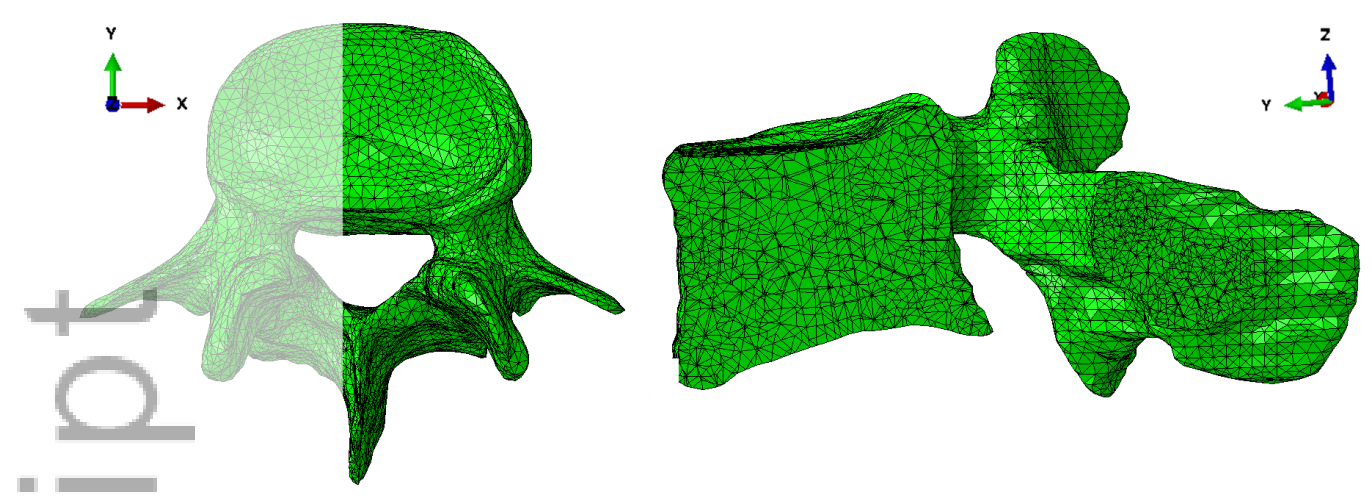

Figure 6. Finite Element mesh of the patient-specific vertebral body

- For the so-called "homogeneous model", the entire trabecular bone compartment is assigned 264 the same elastic stiffness tensor, namely that related to the average vascular porosity found 265 in that compartment, $\phi_{v a s}^{\text {trab }}=0.86$. More precisely, given the "short-beam"-type nature of our 266 structure, we assign the longitudinal Young's modulus $\quad 267$

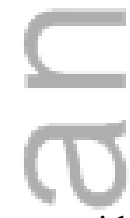

$$
E_{\text {macro }, 3}=\frac{1}{C_{\text {macro }, 3333}^{-1}}=1322 \mathrm{MPa}
$$

with $C_{\text {macro }, 3333}^{-1}$ as the longitudinal normal component of the compliance tensor $\mathbb{C}_{\text {macro }}^{-1}$ and 268 the longitudinal Poisson's ratio

$$
\nu_{31}=-C_{\text {macro }, 1133}^{-1} \times E_{\text {macro }, 3}=0.19
$$

2

as "formally isotropic" material properties to the FE model, as is normally considered as an appropriate approximation in bone organ mechanics [43, 84, 85]. As regards the very thin 271 cortical shell around the organ, whose thickness of 230 microns does not quite allow for 272 accommodation of Haversian systems (and hence of the vascular porosity), we adopt the 273 "macroscopic" stiffness tensor $\mathbb{C}_{\text {macro }}$ related to zero-porosity, i.e. that of the extravascular 274 bone matrix according to Eqn.(48). More precisely, as before, we assign as formally isotropic 275 properties, a Young's modulus and a Poisson's ratio of $9406 \mathrm{MPa}$ and of 0.28, respectively, to 276 the shell finite elements. $\quad 277$

- For the "heterogeneous model", the cortical shell treatment does not differ, while the element- 278 specific stiffness tensors are computed from the vascular porosity values assigned to the 279 centroids of the finite elements. The interpolation between the CT data and the Finite Elements 280 is made by finding the three CT pixels closest to the finite element centroid, and by assigning 281 


$$
\bar{\psi}_{\text {organ }}=\frac{1}{V_{\text {organ }}} \sum_{n=1}^{N_{n}} \psi_{n} \times V_{n}
$$

with $N_{n}$ as the number of finite elements, with $V_{n}$ as the volume of the n-th finite element and $V_{\text {organ }}$ as the volume of the entire organ. The results of the linear elastic Finite Element simulations are then used for safety assessment of the investigated structure. More precisely, we check by which proportionality factor the determined element-specific macroscopic stresses needed to be increased, so as to reach ultimate macroscopic bone material failure. This stress increase, however, is subjected to macroscopic bone RVEs in an incremental fashion, allowing for elastoplastic deformation states prior to the ultimate material failure (which obviously depends on these elastoplastic deformations). In order to quantify them, we extend the hierarchical scheme depicted in Figure 5 to the realm of elastoplasticity, extending earlier work published in [34]. There, the liquid crystal-type water interfaces between the mineral crystals and/or crystal clusters in the extrafibrillar space [see Figure 5(c)], have been identified as the major nanoscopic origin of bone elastoplasticity, both from the high interaction energies between water and hydroxyapatite as evidenced by several molecular dynamics and nuclear magnetic resonance studies [86-90], and more importantly, by successfully predicting, based on experimentally obtained upscaling mineral and collagen strengths [91-93], the macroscopic strengths of different types of bone [94-111]. Such successful representations of 
bone microstructure for mechanical property predictions, which do not resolve the material up to 311 the highest resolution ever possible, but rather focus on reliable consideration of the mechanically 312 most important micromorphological features, have not only been developed in the framework of 313 continuum micromechanics or random homogenization theory, but also in alternative theoretical 314 frames, such as that of lattice models [112].

Thereby, the fluid-induced, mutual sliding of crystals is associated to elastoplastic hydroxyapatite 316 mineral phases, which are oriented uniformly in space directions given through Eulerian angles $\phi \quad 317$ and $\theta$ related to spherical coordinates. These phases obey the following constitutive equations: The 318 needle-shaped mineral phase oriented in space direction $(\phi, \theta)$ follows an elasto-plastic stress-strain 319 relation,

$$
\boldsymbol{\sigma}_{H A, \phi \theta}=\mathbb{C}_{H A}:\left(\varepsilon_{H A, \phi \theta}-\varepsilon_{H A, \phi \theta}^{p}\right)
$$

with $\mathbb{C}_{H A}=3 k_{H A} \mathbb{I}_{v o l}+2 G_{H A} \mathbb{I}_{d e v}$ as the isotropic elasticity of hydroxyapatite, $k_{H A}=82.6 \mathrm{GPa} \quad 321$ and $G_{H A}=44.9 \mathrm{GPa}[113], \mathbb{I}_{\text {dev }}=\mathbb{I}-\mathbb{I}_{\text {vol }}$ as the deviatoric component of the fourth-order identity 322 tensor, $\varepsilon_{H A, \phi \theta}$ and $\varepsilon_{H A, \phi \theta}^{p}$ as the (average) total and plastic strains in the $(\phi \theta)$-oriented needle- 323 shaped phase, and $\boldsymbol{\sigma}_{H A, \phi \theta}$ as the corresponding average stress. Plastic events are quantified by 324 means of a Mohr-Coulomb criterion,

$$
\mathcal{F}_{H A, \phi \theta}=\mathcal{F}\left(\boldsymbol{\sigma}_{H A, \phi \theta}\right)=\beta \sigma_{H A, \phi \theta}^{I}-\sigma_{H A, \phi \theta}^{I I I}-\sigma_{H A}^{y} \leqslant 0
$$

with $\beta$ as the ratio between the compressive and the tensile yield stresses $(\beta=12), \sigma_{H A}^{y}$ as 326 the compressive yield stress $\left(\sigma_{H A}^{y}=570 \mathrm{MPa}\right)$, and $\sigma_{H A, \phi \theta}^{I} \geqslant \sigma_{H A, \phi \theta}^{I I} \geqslant \sigma_{H A, \phi \theta}^{I I I}$ as the (sorted) 327 principal stresses in the $(\phi \theta)$-oriented mineral phase. The strength parameters follow from tests 328 on porous hydroxyapatite polycrystals [114-122], mimicking those occurring in the extrafibrillar 329 space of Figure 5(c). Potential occurence of plastic events follows the Kuhn-Tucker conditions [123] 330 (actually proposed already in 1938 by Melan [124])

$$
\dot{\lambda}_{H A, \phi \theta} \geqslant 0, \quad \mathcal{F}_{H A, \phi \theta} \leqslant 0 \text { and } \dot{\lambda}_{H A, \phi \theta} \times \mathcal{F}_{H A, \phi \theta}=0
$$

in conjunction with the following, non-associative, isochoric flow rule:

$$
\dot{\varepsilon}_{H A, \phi \theta}^{p}=\dot{\lambda}_{H A} \frac{\partial \mathcal{G}}{\partial \boldsymbol{\sigma}_{H A, \phi \theta}} \quad \text { with } \quad \mathcal{G}\left(\boldsymbol{\sigma}_{H A, \phi \theta}\right)=\sigma_{H A, \phi \theta}^{I}-\sigma_{H A, \phi \theta}^{I I I}
$$


whereby the dot denotes the time derivative, $\mathcal{G}$ denotes the flow potential, the derivative of which accounts for the plastic flow direction, and $\dot{\lambda}_{H A, \phi \theta}$ denotes the plastic multiplier quantifying the amount of plastic strain.

Such plastic events imply more and more micro-stresses to be transferred to the molecular collagen of Figure 5(a), which finally fails in a brittle manner, according to a Rankine-type criterion,

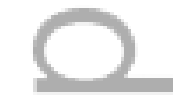

$=$

$$
\mathcal{F}_{\text {col }}=\max _{i \in\{I, I I, I I I\}}\left|\sigma_{\text {col }}^{i}\right|-\sigma_{\text {col }}^{\text {ult }} \leqslant 0
$$

with $\sigma_{c o l}^{i}, i=I \ldots I I I$, as the eigenstresses in the molecular collagen assembly at the wet collagen (microfibrillar) scale, and $\sigma_{c o l}^{u l t}$ as the strength of molecular collagen. The latter quantity is derived from experiments on rat tail tendon, which, under wet conditions, exhibits a strength of 106.1 MPa [93]. We consider close packing of collagen, so as to get access to the properties of molecular collagen. It is known from neutron diffraction studies $[46,75]$ that diffractional spacing (a measure for the lateral distance of collagen molecules) reduces from $1.52 \mathrm{~nm}$ (for wet collagen) to $1.09 \mathrm{~nm}$ [for maximally packed (dry) collagen]. Accordingly, the cross sectional area of a tensile specimen would reduce by the ratio $(1.52 / 1.09)^{2}$, so that the strength of molecular collagen follows to be $(1.52 / 1.09)^{2}$ times higher than that of wet collagen, i.e. $206 \mathrm{MPa}$.

These elastoplastic and failure laws need to be homogenized over the RVEs depicted in Figure 5 , so as to determine the elastoplastic behavior of a piece of cortical/tabecular bone illustrated in Figure 5(f). This is achieved in the framework of continuum micromechanics [125] by means of stress and strain averaging rules [126,127] and concentration-influence relations [128]; applied to each of the RVEs depicted in Figure 5. As regards the extrafibrillar RVE, homogeneous strains $\mathbf{E}_{e f}$ are prescribed in terms of displacements

$$
\boldsymbol{\xi}(\mathbf{x})=\mathbf{E}_{e f} \cdot \mathbf{x}
$$

at the boundary of the RVE - $\mathrm{x}$ is the "microscopic" location vector with a resolution much smaller than the RVE. This boundary condition implies that kinematically compatible microstrains $\varepsilon(\mathbf{x})$

$$
\varepsilon(\mathbf{x})=\nabla^{s} \boldsymbol{\xi}(\mathbf{x})
$$




$$
\mathbf{E}_{e f}=f_{H A}^{e f} \int_{\phi=0}^{2 \pi} \int_{\theta=0}^{\pi} \varepsilon_{H A, \phi \theta} \frac{\sin \theta}{4 \pi} d \phi d \theta+\left(1-f_{H A}^{e f}\right) \varepsilon_{i c}
$$

with $f_{H A}^{e f}$ as the volume fraction of hydroxyapatite within the extrafibrillar RVE, and $\varepsilon_{i c}$ as the 357 (average) strains in the inter-crystalline space. Moreover, when applying the principle of virtual 358 powers to this RVE, resulting in the so-called Hill's lemma [125], one arrives at an additional stress 359 average rule for macroscopic stresses acting on the extrafibrillar RVE,

$$
\boldsymbol{\Sigma}_{e f}=f_{H A}^{e f} \int_{\phi} \int_{\theta} \boldsymbol{\sigma}_{H A, \phi \theta} \frac{\sin \theta}{4 \pi} d \phi d \theta+\left(1-f_{H A}^{e f}\right) \boldsymbol{\sigma}_{i c}
$$

with the microstresses $\boldsymbol{\sigma}(\mathbf{x})$ fulfilling the equilibrium condition

Linearity of Eqn.(40), (37), (36), and (31) implies the strains in the $(\phi \theta)$-oriented mineral phase 362 to depend multi-linearly on the homogeneous strains $\mathbf{E}_{e f}$ and on the plastic (micro-)strains $\varepsilon_{H A, \phi \theta}^{p} \quad 363$ found in all mineral phases,

$$
\varepsilon_{H A, \phi \theta}=\mathbb{A}_{H A, \phi \theta}: \mathbf{E}_{e f}+\int_{\Phi} \int_{\Theta} \mathbb{D}_{\phi \theta \Phi \Theta}: \varepsilon_{H A, \Phi \Theta}^{p} \frac{\sin \Theta}{4 \pi} d \Phi d \Theta
$$

Similarly, the microstrains $\varepsilon_{i c}$ found in the inter-crystalline pores read as

$$
\varepsilon_{i c}=\mathbb{A}_{i c}: \mathbf{E}_{e f}+\int_{\Phi} \int_{\Theta} \mathbb{D}_{i c, \Phi \Theta}: \varepsilon_{H A, \Phi \Theta}^{p} \frac{\sin \Theta}{4 \pi} d \Phi d \Theta
$$

with $\mathbb{A}_{H A, \phi \theta}$ and $\mathbb{A}_{i c}$ as the concentration tensors of the hydroxyapatite phase oriented in direction 366 $(\phi \theta)$ and of the inter-crystalline phase respectively, and $\mathbb{D}_{\phi \theta \Phi \Theta}$ and $\mathbb{D}_{i c, \Phi \Theta}$ accounting for the 367 influence of plastic strains occurring in the $(\Phi \Theta)$-oriented phase, on the total strains occurring in 368 the mineral phase oriented in $(\phi \theta)$-direction and in the inter-crystalline phase, respectively. These 369 concentration and influence tensors are derived from extended "eigenstressed" Eshelby problems 370 [125]; as given in more detail in [129,130]. Finally, repeated use of Hill's lemma yields the upscaled 371 "macroscopic" elastoplastic constitutive equation as

$$
\Sigma_{e f}=\mathbb{C}_{e f}:\left(\mathbf{E}_{e f}-\mathbf{E}_{e f}^{p}\right)
$$


where $\mathbb{C}_{e f}$ is the homogenized stiffness tensor of the extrafibrillar space, reading as

$$
\mathbb{C}_{e f}=f_{H A}^{e f} \mathbb{C}_{H A}: \int_{\theta} \int_{\phi} \mathbb{A}_{H A, \phi \theta} \frac{\sin \theta}{4 \pi} d \phi d \theta+\left(1-f_{H A}^{e f}\right) \mathbb{C}_{H_{2} O}: \mathbb{A}_{i c}
$$

and the extrafibrillar plastic strains $\mathbf{E}_{e f}^{p}$ fulfill

$$
\mathbf{E}_{e f}^{p}=\mathbb{C}_{e f}^{-1}: f_{H A}^{e f} \int_{\phi} \int_{\theta}{ }^{t} \mathbb{A}_{H A, \phi \theta}: \mathbb{C}_{H A}: \varepsilon_{H A, \phi \theta}^{p} \frac{\sin \theta}{4 \pi} d \phi d \theta
$$

whereby the superscript $t$ denotes the transpose of the concentration tensor $\left({ }^{t} A_{i j k l}=A_{k l i j}\right)$. Equations (31-45) allow one to determine the plastic events in the crystal phases caused by extrafibrillar loading - once Eqn.(38), (39), (41), (42), (44), (45) are discretized in space, here by means of the numerical scheme proposed in [131], and Eqn.(33) and (34) are discretized in (chronological) time, here by means of the return mapping algorithm [123, 132]. In particular, the multisurface plasticity concept is realized for Mohr-Coulomb plasticity [133]. This is done for all RVEs depicted in Figure 5, so as to relate macroscopic loading at the level of cortical/trabecular bone, to plastic strains in the crystalline, extrafibrillar, extracellular, and extravascular phases in Figure 5, until the molecular collagen stresses fulfill failure criterion (35).

Within this theoretical framework, two types of "safety factors", "loading degrees", or "distances to failure" are determined:

- The macroscopic, trabecular bone-related stresses $\boldsymbol{\Sigma}_{\text {macro }}$ determined in each finite element are first multiplied with a factor $\chi_{y}$ related to just reaching the yield limit defined by equality in Eqn.(32);

$$
\boldsymbol{\Sigma}_{\text {macro }, y}=\chi_{y} \boldsymbol{\Sigma}_{\text {macro }}
$$

This factor is called the yield safety factor; it is larger than one for elastic deformation states, and reduces to one once yielding starts. Its inverse is the "yield loading degree" or "distance to yielding”, being smaller than one for elastic deformation states, and increasing towards one when approaching yielding states.

- Secondly, the aforementioned element-specific macroscopic stresses are multiplied with a factor $\chi_{u l t}$ related to reaching the ultimate load defined by equality in Eqn.(35);

$$
\boldsymbol{\Sigma}_{\text {macro, ult }}=\chi_{\text {ult }} \boldsymbol{\Sigma}_{\text {macro }}
$$


This factor is called the (local, material-based) ultimate safety factor; it is larger than one 395 for deformation states which the macroscopic bone material can still withstand, and reduces 396 to one once the material fails (through collagen tearing). Its inverse is the "ultimate loading 397 degree" or "distance to failure", being smaller than one for bearable deformation states, and 398 increasing towards one when approaching material failure.

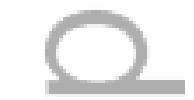

=

\section{RESULTS}

Evaluation of all grey values found in the investigated clinical CT image in form of the normalized 400 histogram or probability density function depicted in Figure 7 allows for identification of the 401 anatomical landmark values related to adipose tissue, as $G V_{f a t}=72$, to soft tissues from inner 402 organs, as $G V_{\text {soft }}=84$, and to bone tissue, as $G V_{\text {bone }}=101$, see Figure 7.

In addition, the histogram provides the segmentation threshold as $G V_{t h r}=93$. From the landmark
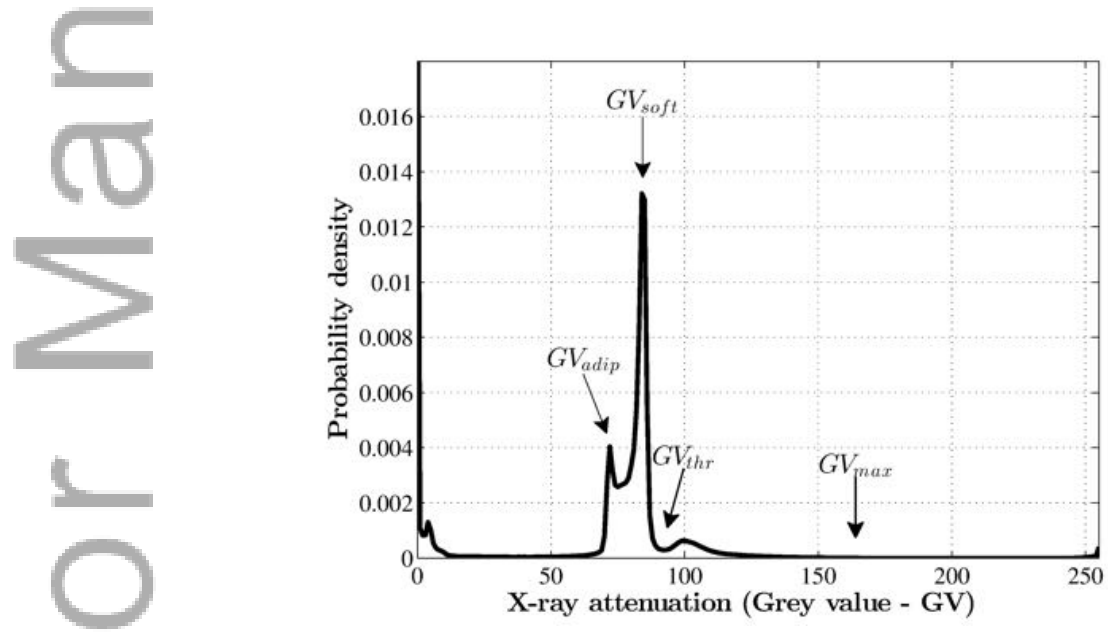

Figure 7. Frequency distribution plot of the attenuation information in terms of grey values of the vertebral body L3

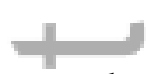

body L3

grey values for the fat and soft tissues, Eq. (1) to (7) allow for identification of the energy-dependent

slope and intercept parameters $a$ and $b$, see Figure 8. They allow for (still X-ray energy-dependent) 406 conversion of grey values to the actual physical quantities they represent.

As illustrated in Figure 9, the maximum grey value occurring in the corpus vertebrae amounts 408 to $G V_{\max }=164$, and its densest neighbor exhibits a grey value of $G V_{\max -1}=156$. According to 409 Eqn.(12), this allows for identification of the grey value related to extravascular bone as $G V_{e v}=298 . \quad 410$ A unique relation between grey values and $X$-ray attenuation coefficients can be only obtained for an 411 extracellular mass density of $1.67 \mathrm{~g} / \mathrm{cm}^{3}$, being assigned to an X-ray energy of $24 \mathrm{keV}$, as is evident 412 


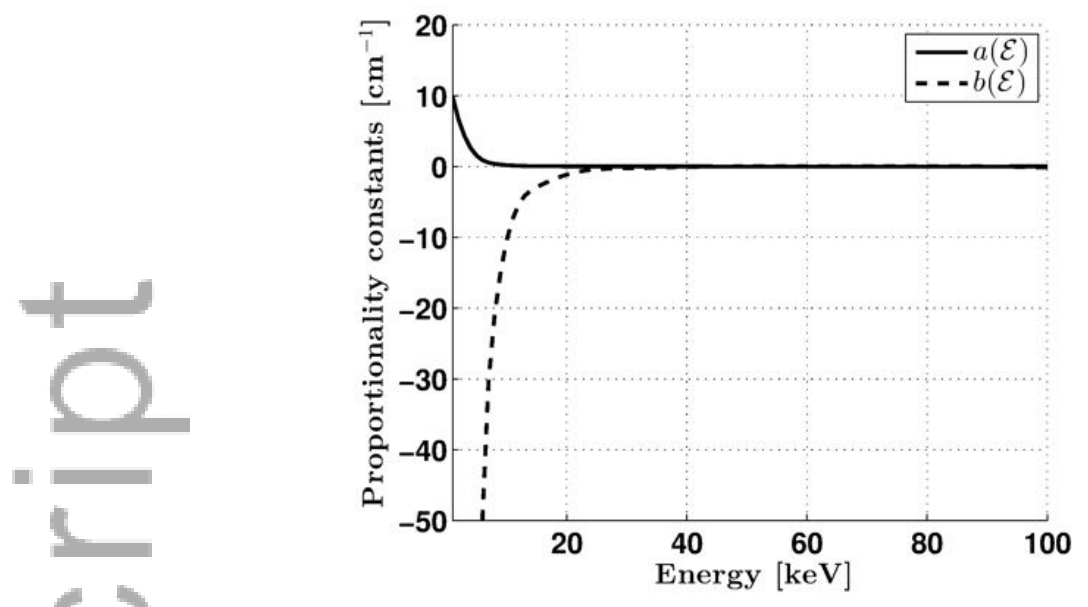

Figure 8. Slope and intercept parameters $a$ and $b$, as functions of the photon energy $\mathcal{E}$
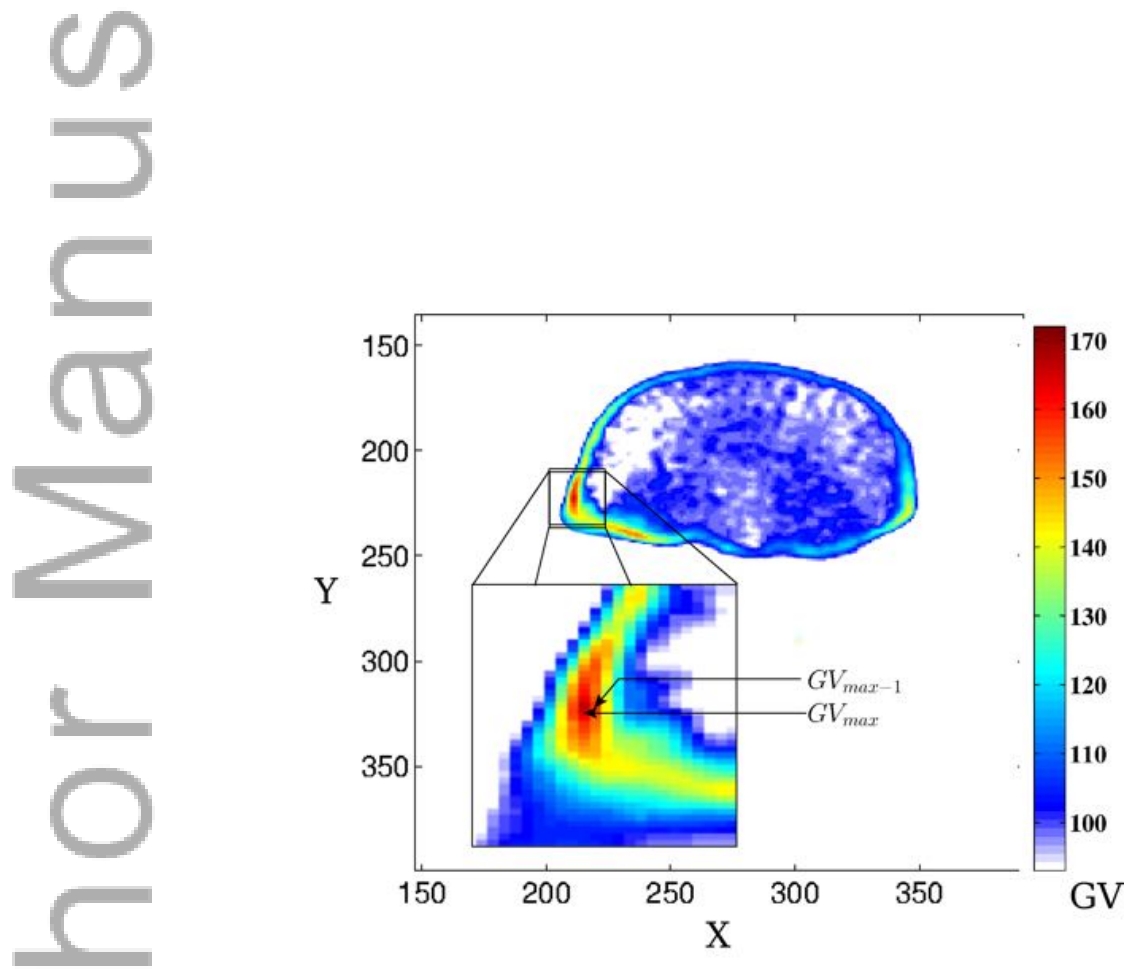

Figure 9. Grey value distribution throughout vertebral cross section where the densest voxel (with $G V_{\max }$ )

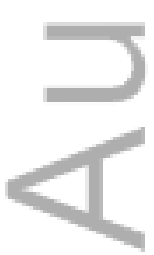

$$
\text { and its neighbor (with } G V_{\max -1} \text { ) occur }
$$

from Fig. 10, drawn on the basis of Eqn. (13) to (16). This mass density agrees very well with the one measured by Archimedes' principle as determined in Section 2.3; the latter amounting to $1.71 \pm 0.11 \mathrm{~g} / \mathrm{cm}^{3}$ (mean value \pm standard deviation). Use of $\rho_{e c}=1.67 \mathrm{~g} / \mathrm{cm}^{3}$, and of corresponding 
ultrastructural volume fractions of hydroxyapatite $f_{H A}=0.27$, organic matter $f_{\text {org }}=0.29$, and water 416 $f_{\mathrm{H}_{2} \mathrm{O}}=0.44$ in the homogenization scheme of Figure 5 yields to the extravascular stiffness tensor $\quad 417$

$\mathbb{C}_{e v}=\left(\begin{array}{ccccccc}C_{1111} & C_{1122} & C_{1133} & 0 & 0 & 0 \\ C_{1122} & C_{2222} & C_{2233} & 0 & 0 & 0 \\ C_{1133} & C_{2233} & C_{3333} & 0 & 0 & 0 \\ 0 & 0 & 0 & 2 C_{2323} & 0 & 0 \\ 0 & 0 & 0 & 0 & 2 C_{1313} & 0 \\ 0 & 0 & 0 & 0 & 0 & 2 C_{1212}\end{array}\right)=$
$=\left(\begin{array}{ccccccc}10.56 & 4.82 & 5.30 & 0 & 0 & 0 \\ 4.82 & 10.56 & 5.30 & 0 & 0 & 0 \\ 5.30 & 5.30 & 13.06 & 0 & 0 & 0 \\ 0 & 0 & 0 & 5.99 & 0 & 0 \\ 0 & 0 & 0 & 0 & 5.99 & 0 \\ 0 & 0 & 0 & 0 & 0 & 5.75\end{array}\right)$ in GPa
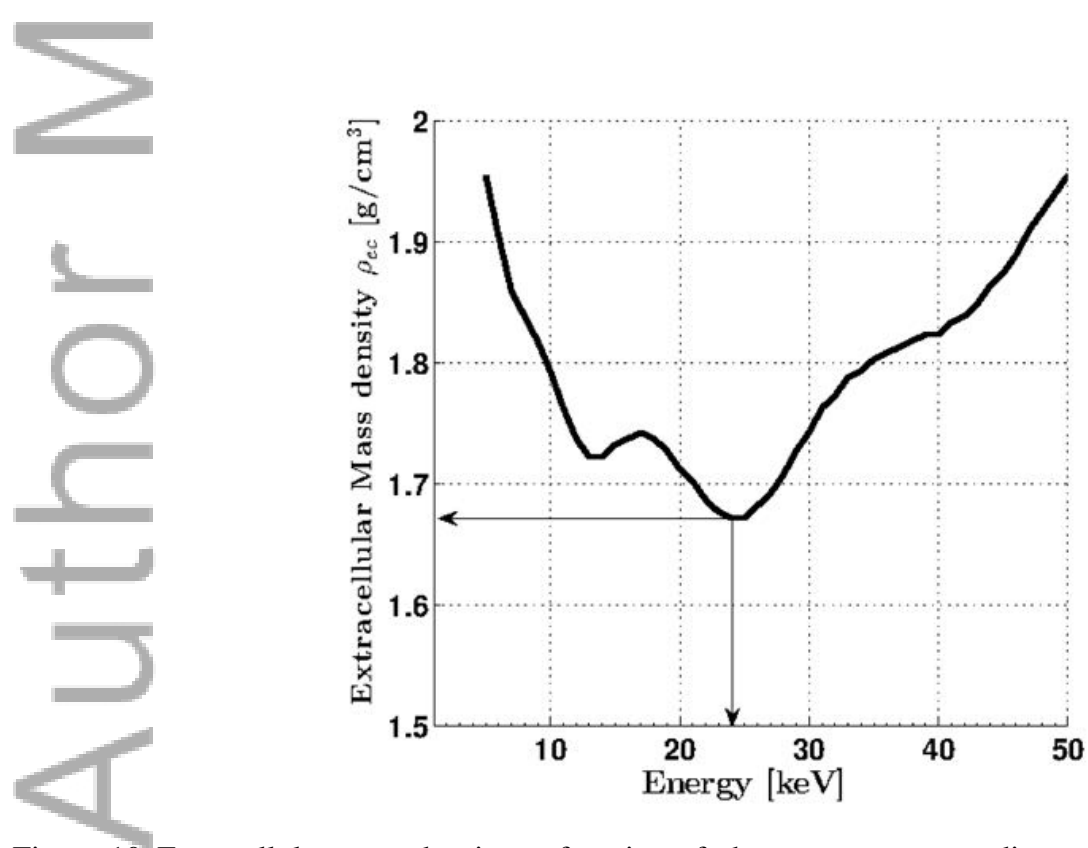

Figure 10. Extracellular mass density as function of photon energy, according to Eqn. (1)-(20), with $a(\mathcal{E})$ and $b(\mathcal{E})$ as depicted in Figure 8

Evaluation of the energy-dependent functions of Fig. 8 for the photon energy as $24 \mathrm{keV}$ yields 418 the grey value-to-attenuation conversion factors $a$ and $b$ as $a=0.0107 \mathrm{~cm}^{-1}$ and $b=-0.4154 \mathrm{~cm}^{-1} . \quad 419$ 

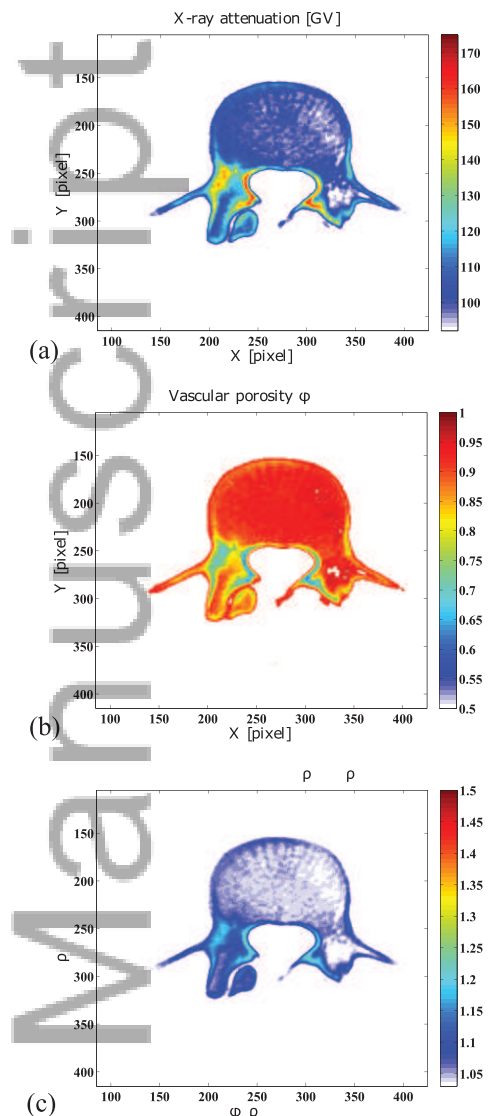

(c)

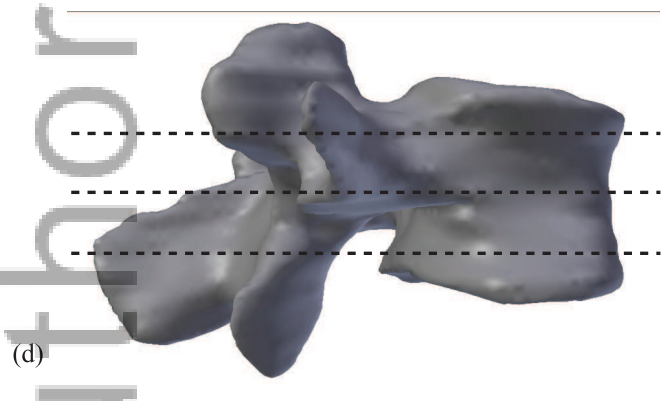

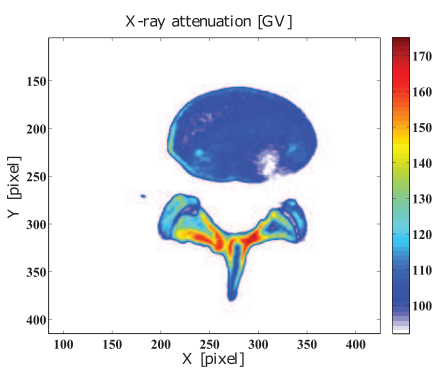
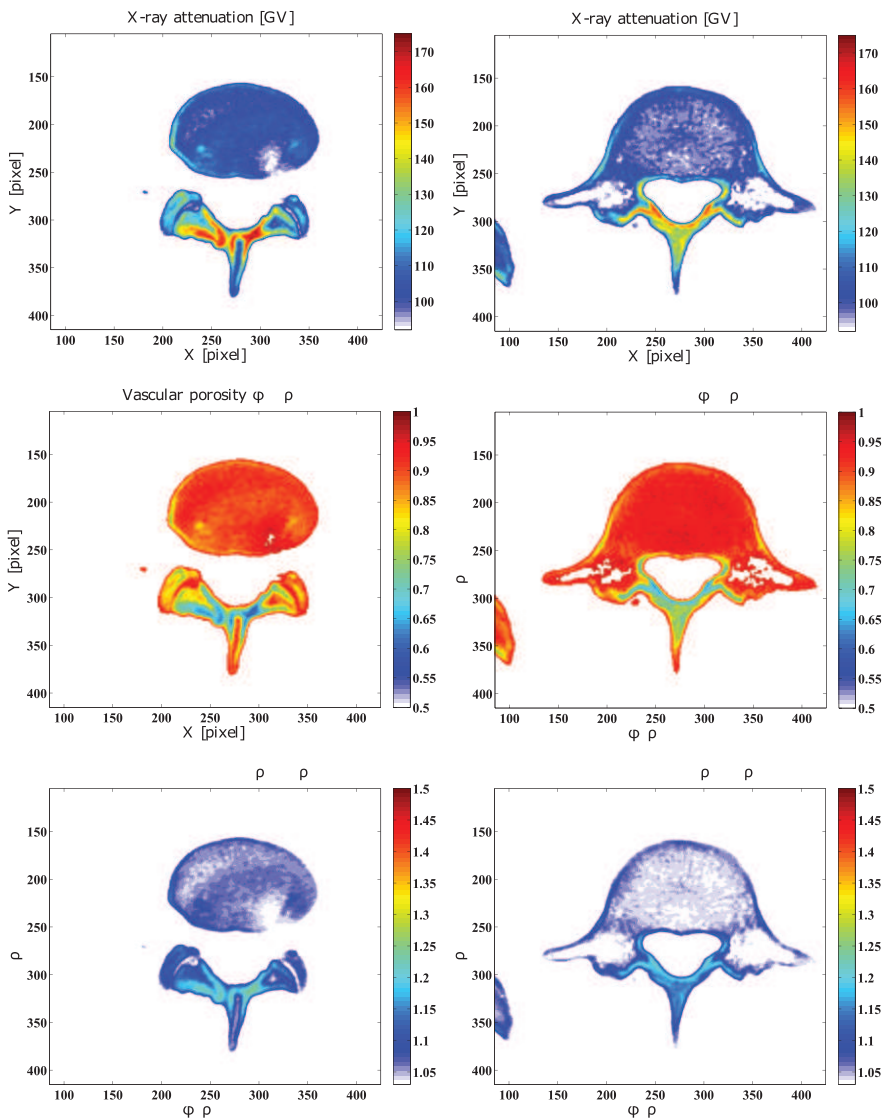

Figure 11. Property maps in CT slices in the transverse plane: (a) X-ray attenuation coefficient in terms of grey value, (b) vascular porosity, (c) macroscopic mass density; (d) locations of the mapped cross sections;

(e) mean values of the previous quantities

\begin{tabular}{|l|c|} 
quantity & mean value \\
\hline grey value [GV] & 109 \\
vascular porosity [-] & 0.88 \\
macroscopic mass density $\left[\mathrm{g} / \mathrm{cm}^{3}\right]$ & 1.07
\end{tabular}

(e)

expected (i.e. most frequently occurring) values for macroscopic mass density, mineral and collagen content amount to $\rho_{\text {macro }}^{E V}=1.04 \mathrm{~g} / \mathrm{cm}^{3}, \rho_{H A}^{*, E V}=54.1 \mathrm{mg} / \mathrm{cm}^{3}$, and $\rho_{\text {col }}^{* E V}=39.1 \mathrm{mg} / \mathrm{cm}^{3}$, while their averages over the entire vertebral body amount to $\overline{\rho_{\text {macro }}}=1.07 \mathrm{~g} / \mathrm{cm}^{3}, \overline{\rho_{H A}^{*}}=87.8 \mathrm{mg} / \mathrm{cm}^{3}$, and $\overline{\rho_{\text {col }}^{*}}=39.2 \mathrm{mg} / \mathrm{cm}^{3}$. 

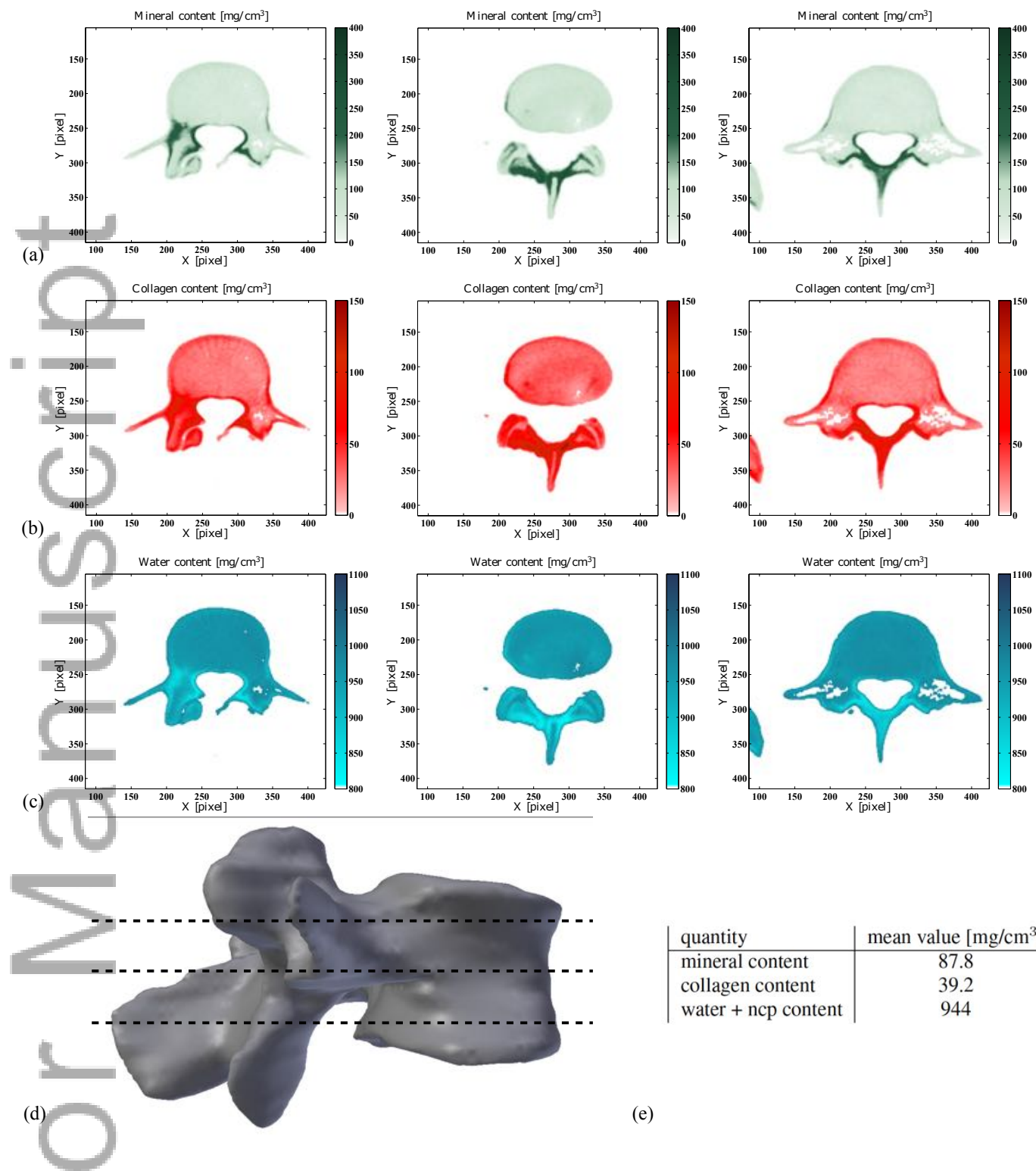

Figure 12. Property maps in CT slice in the transverse plane: (a) Mineral content, (b) collagen content, (c) water and non-collageneous proteins (ncp) content; (d) locations of the mapped cross sections; (e) mean values of the previous quantities

The micromechanics-based porosity-stiffness relations based on the hierarchical representation 427 depicted in Figure 5, see also Eqn.(26) and (48), in combination with the X-ray physics-based grey 428 value-to-porosity conversion scheme described in Section 2.4, yields organ-specific grey value-to- 429 stiffness relations as depicted in Figure 14.

Combination of the latter with the porosity maps illustrated in Figure 11, allows for assembly of 431 mechanical property maps as depicted in Figure 15 . The latter evidences the very inhomogeneous 432 nature of the organ: The left side of the vertebra organ is less porous, and hence, denser and stiffer 

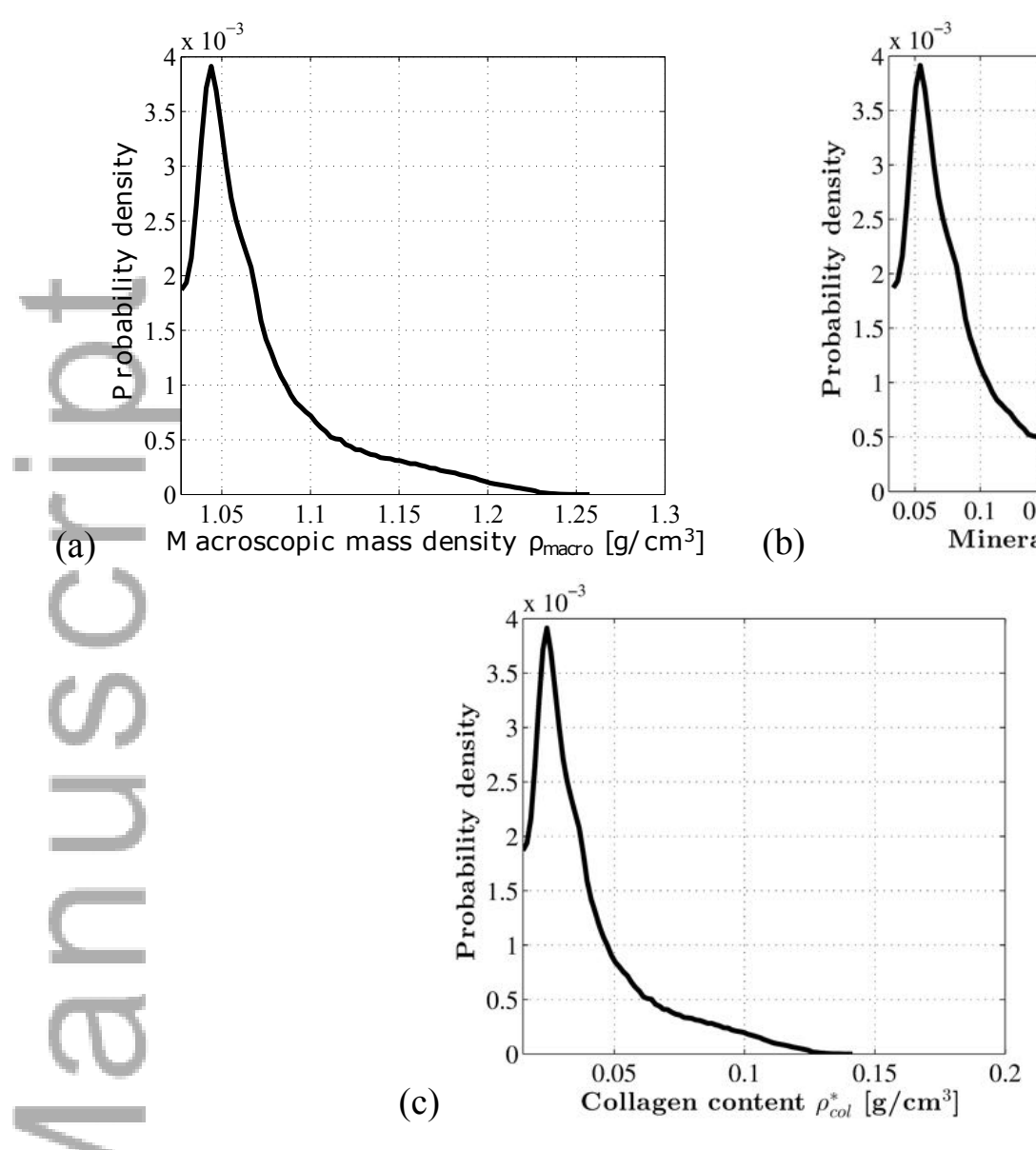

Figure 13. Probability density plots of (a) the macroscopic mass density, (b) the mineral content, and (c) the collagen content.

than its right-hand side. Feeding these properties into the differently fine Finite Element models described in Section 2.6 and Figure 6, yields very similar results in terms of the strain energy density (see Figure 16), which underlines the sufficient accuracy of the employed Finite Element meshes. This implies at the same time that the algorithm for using the minimum of three CTbased porosity values for characterizing one finite element (see Section 2.6) delivers satisfactorily accurate results. However, there are truly significant differences between the homogeneous and heterogeneous simulations. Given the employed traction boundary conditions, this indicates that the homogeneous simulations by far overestimate the stiffness of the investigated organ. Stress levels obtained, under axial "dead load", in both homogeneous and heterogeneous simulations reach the level of material yielding (see Figure 18), more pronouncedly so in the heterogeneous simulations [compare Figure 18(a-c) to Figure 18(d-e)]; while this load level is characterized by a "safety factor" of about 10 (for homogeneous simulations) and 5 (for heterogeneous simulations) from material failure [compare Figure 19(a,c,e) to 19(b,d,f)]. Corresponding element-wise increase of the linear 


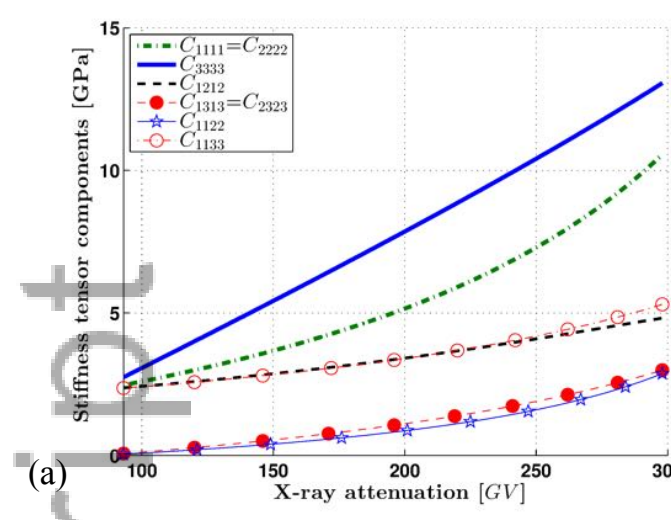

(b)
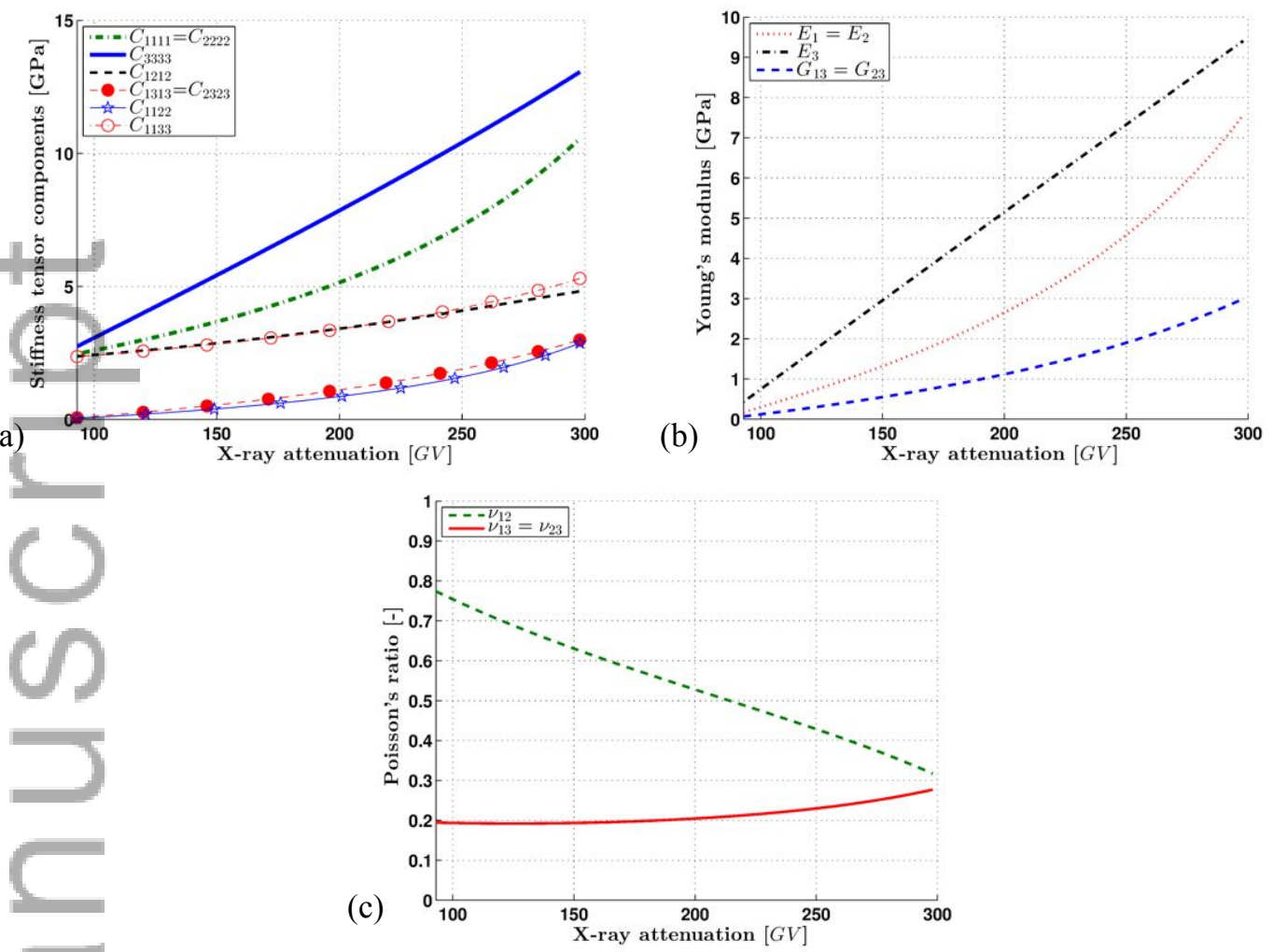

Figure 14. Translation of X-ray attenuation information into tissue elasticity: (a) stiffness tensor components, (b) Young's and shear moduli, and (c) Poisson's ratios; $1,2 \ldots$ transverse direction, $3 \ldots$ axial direction

elastically determined stress tensors up to the level of material failure is evoking remarkably non- 447 linear strain evolutions, as is seen in Figure 17.

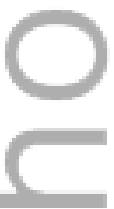

\section{DISCUSSION}

Combining latest continuum micromechanics models with "universal" composition and 449 mineralization rules for bone, which both were successfully validated against a multitude of 450 physically and statistically independent experimental data, and with X-ray physics and Finite 451 Element modeling, allowed for patient-specific fracture-risk assessment of lumbar vertebrae. In 452 this context, it should be emphasized that we here extended the patient specificity beyond purely 453 geometric aspects, which are somehow defining the current state-of-the-art in computational patient- 454 specific analysis [134-138]; in fact, we here explicitly consider the patient-specific grey value 455 distribution quantifying the spatial X-ray attenuation behavior the scanned organs, and convert the 456 latter into patient-specific microstructural information. The latter then provides, via micromechanics 457 

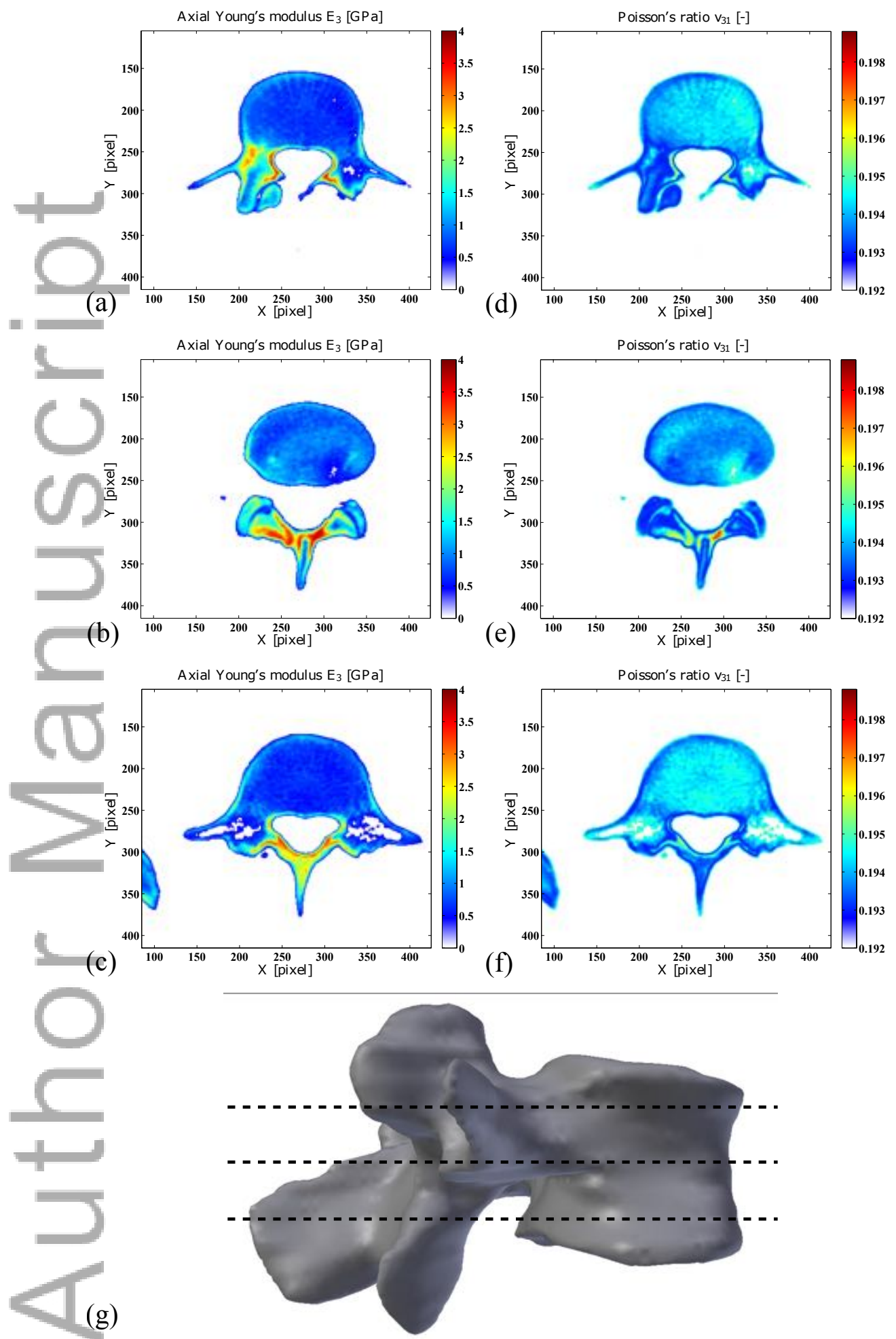

Figure 15. Property maps in CT slices in the transverse plane:(a-c) axial Young's modulus, and (d-f) axial Poisson's ratio; (g) locations of the mapped cross sections 

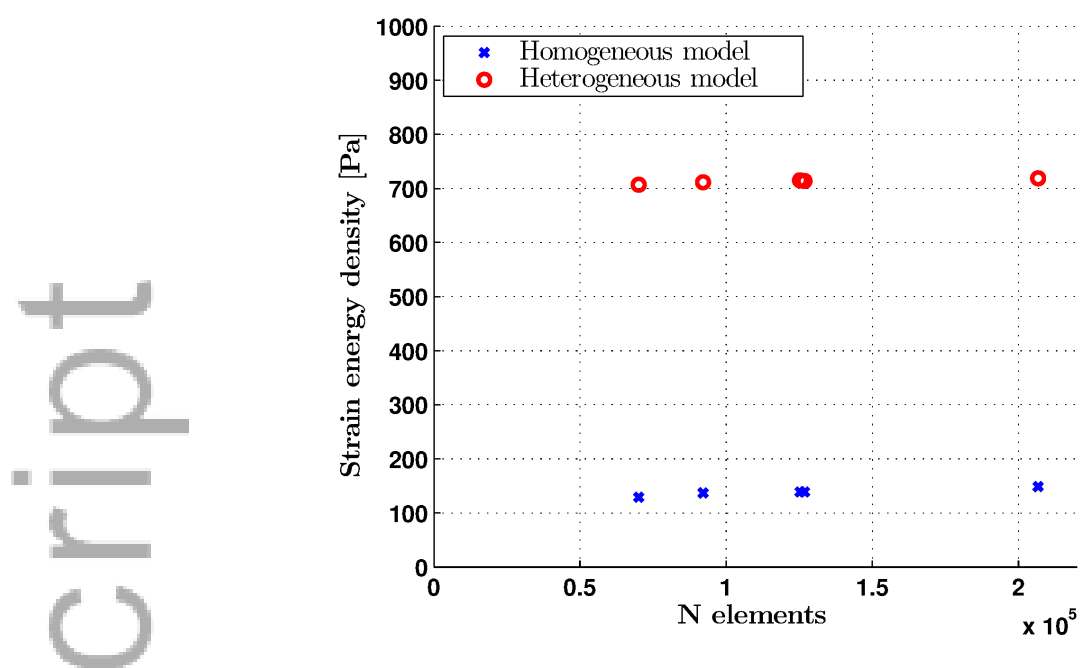

Figure 16. Convergence study: strain energy density averaged over all finite elements of the investigated FE mesh.

analysis, patient-specific elasticity and strength distributions, which are finally mapped onto the 458 patient-specific geometrical data that we started off with.

Secondly, it is very interesting and instructive to compare the results of our novel method which 460 is solely based on clinical CT data, to results from well established, say "conventional", methods 461 published in the open literature. These methods comprise Archimedes' principle, ultrasound, micro 462 Computed Tomography, macromechanical testing, nanoindentation, and microFE-based tissue 463 elasticity determination.

To begin with, two different techniques, namely Archimedes' principle and evaluation of clinical 465 CT images based on energy-dependent, intravoxel attenuation averaging in conjunction with 466 "universal" compositional rules for soft and hard tissues, delivered the same extracellular bone mass 467 density, when applied to two differently old human vertebrae characterized at two different hospitals. 468 This strongly underlines the organ-specificity, but location- and age-independence of extracellular 469 tissue properties (when averaged over one-to-several-millimeter-sized domains). This remarkable 470 extracellular tissue characteristic is also evident from age-independent nanoindentation moduli on 471 human proximal femora [139-141], as well as from age- and location-independent mineral contents, 472 as obtained from computerized quantitative contact radiography of whole human iliac bone [142], 473 as observed by means of quantitative backscattered electron imaging of iliac and vertebral trabecular 474 samples [143], as seen under Raman microscopy of femoral cortices [144], or as investigated 475 through a Micro Computer Tomograph of an entire human radius [145]. 476

It may also be noteworthy that mass densities obtained ex vivo, from samples being stored in a 477 frozen state with temperature and humidity conditions varying quite strongly from those in vivo, 478 

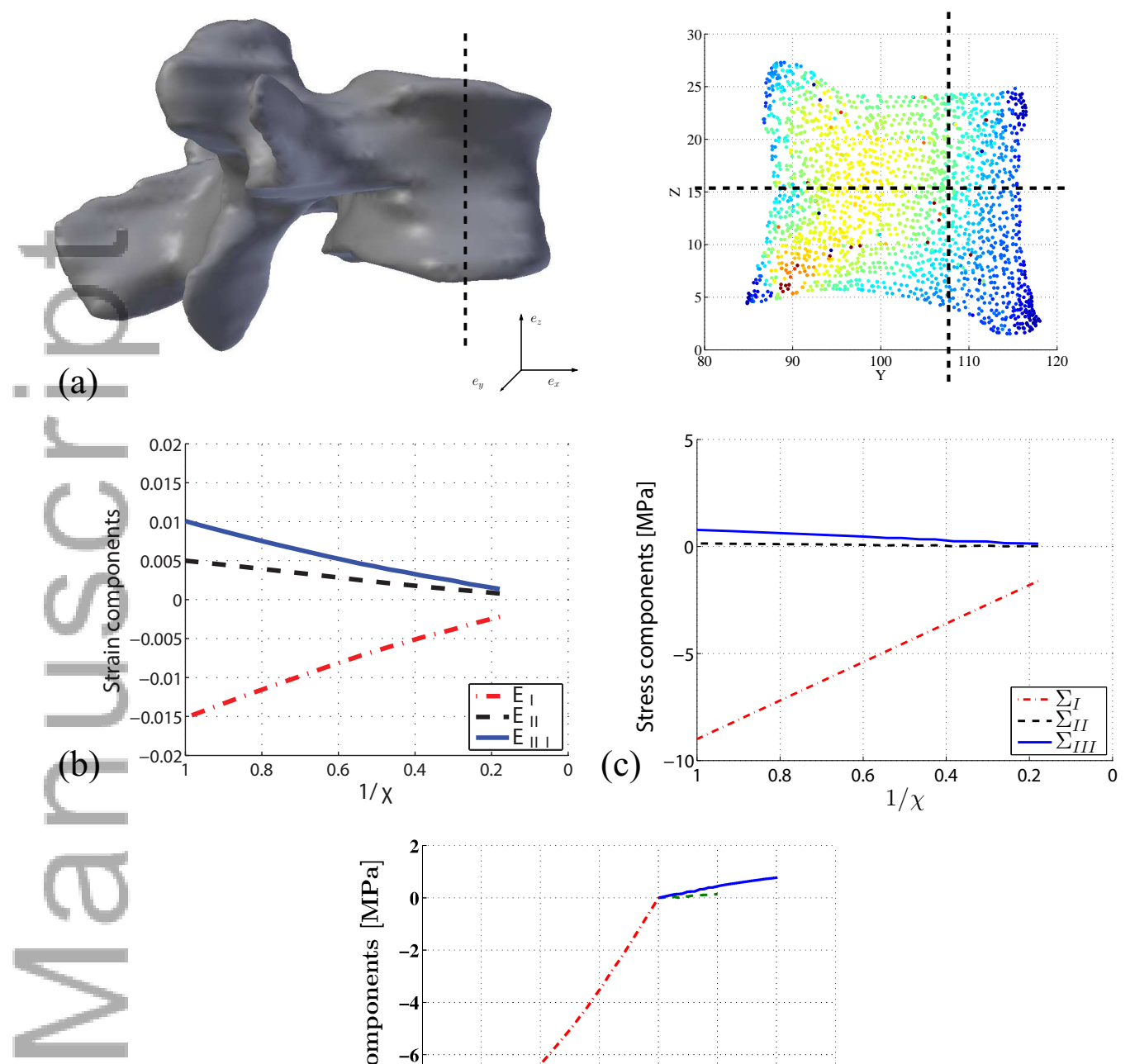

(d)

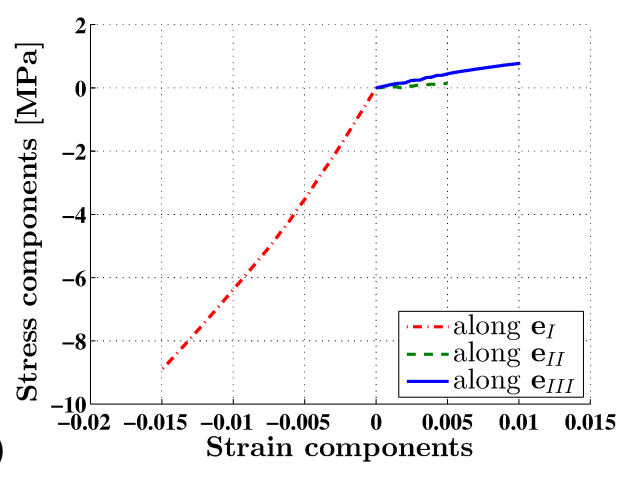

Figure 17. Proportional stress loading in chosen finite element [see (a)]; (b) principal stress components and (c) principal strain components as function of the loading degree; (d) stress-strain relation along principal directions agrees very well with evidence put forward by a number of studies [146-149] that the mechanical properties of bone tissue are preserved through storage, also when bones are frozen. Since the mechanical properties of bone tissue depend on the tissue's composition and microstructure $[30,150]$ it appears as very natural that also the composition-related quantities, such as the tissue mass density, would not be more than negligibly affected by the storage and testing procedure. As a side result, this allowed us to do without human biopsies when validating our in vivo method. In fact, a biopsy from a young young healthy patient was never considered for ethical reasons, thus ruling out intrusive 


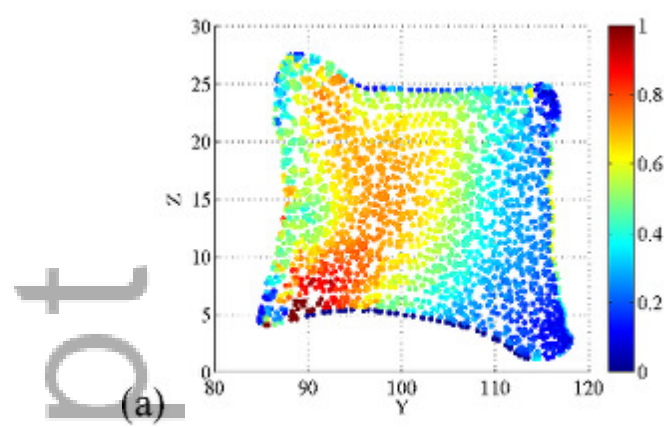

(b)
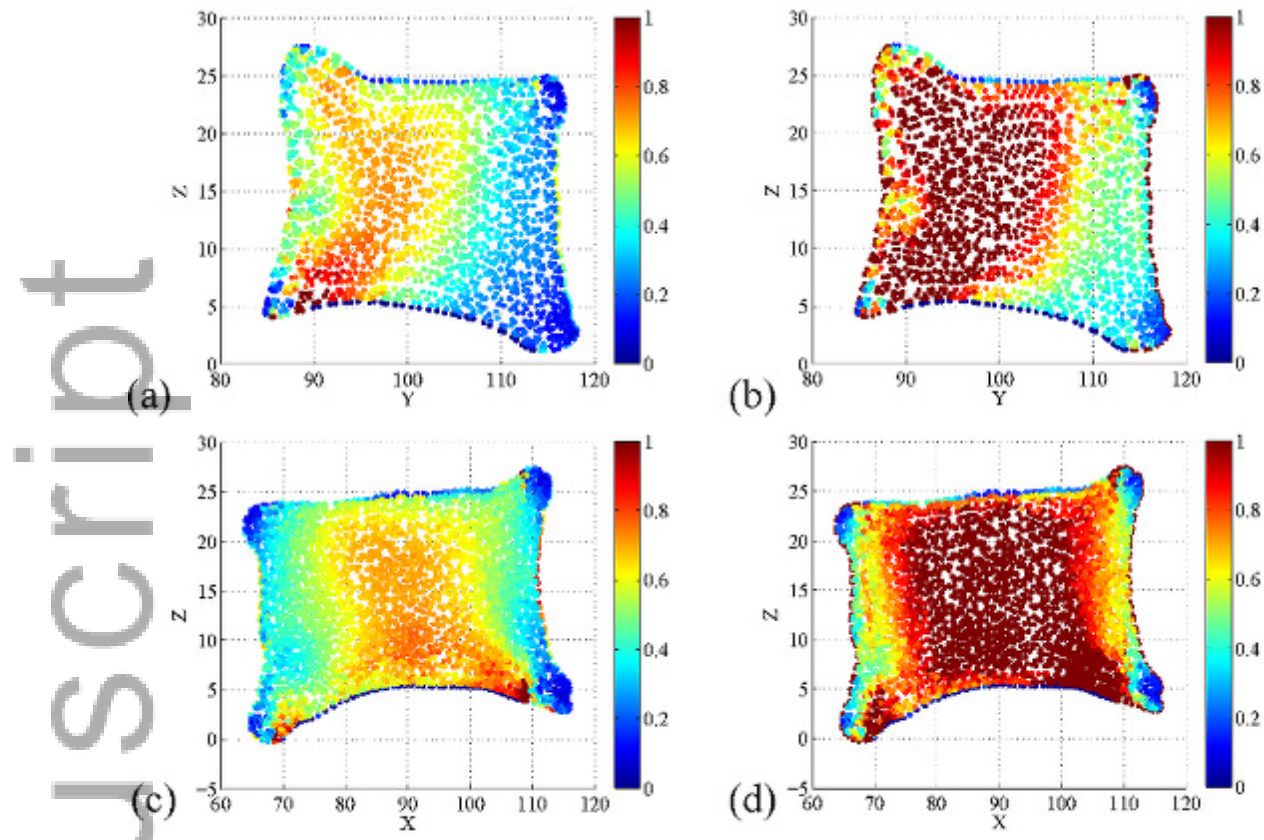

(d)
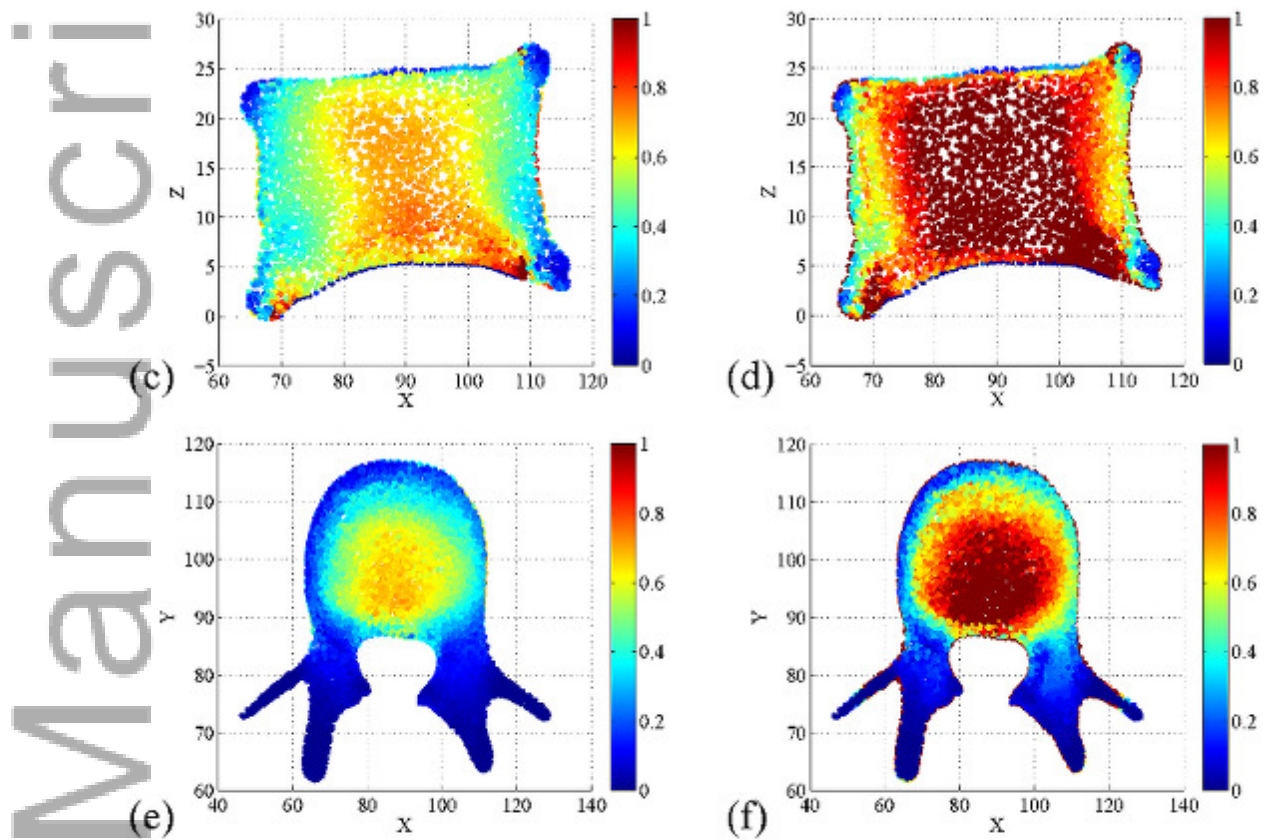

(f)
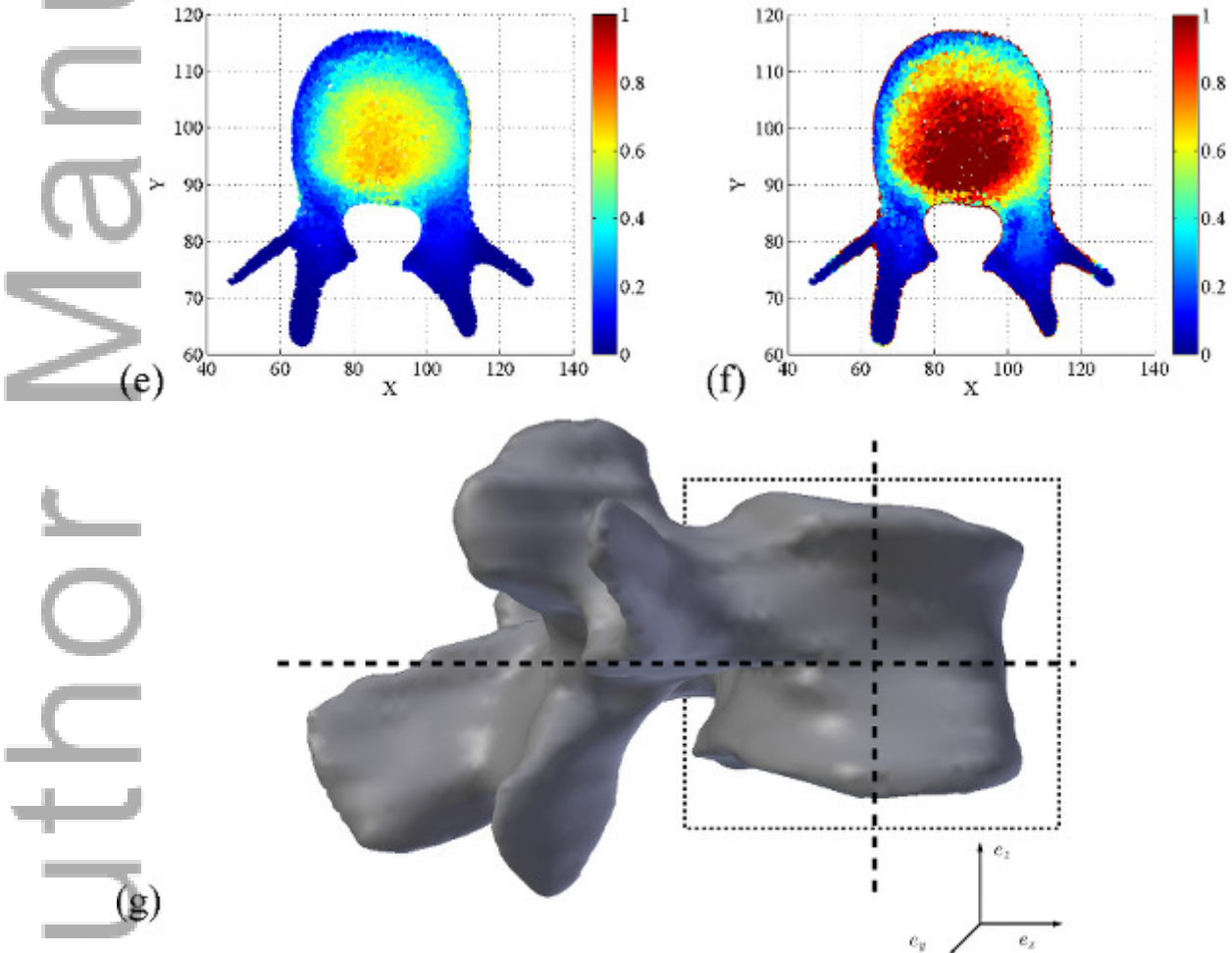

Figure 18. Maps of the "yield loading degree" $1 / \chi_{y}$, related to $1 \mathrm{MPa}$ pressure loading; across the sagittal plane through the vertebral body, for (a) homogeneous, and (b) heterogeneous Finite Element model, across the coronal plane, for (c) homogeneous, and (d) heterogeneous FEM; across the transverse plane, for (e) homogeneous, and (f) heterogeneous FEM. (g) 3D representation of the organ and position of the slices. Cross-sectional dimensions are in millimeters

measurement of the patient-specific bone mineral density. This is a normal situation for any analysis 


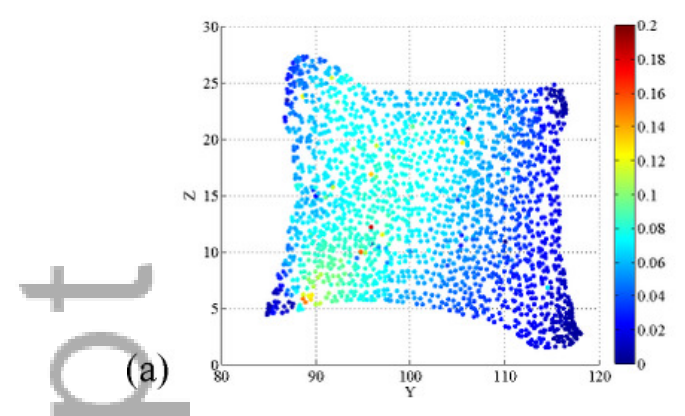

(b)
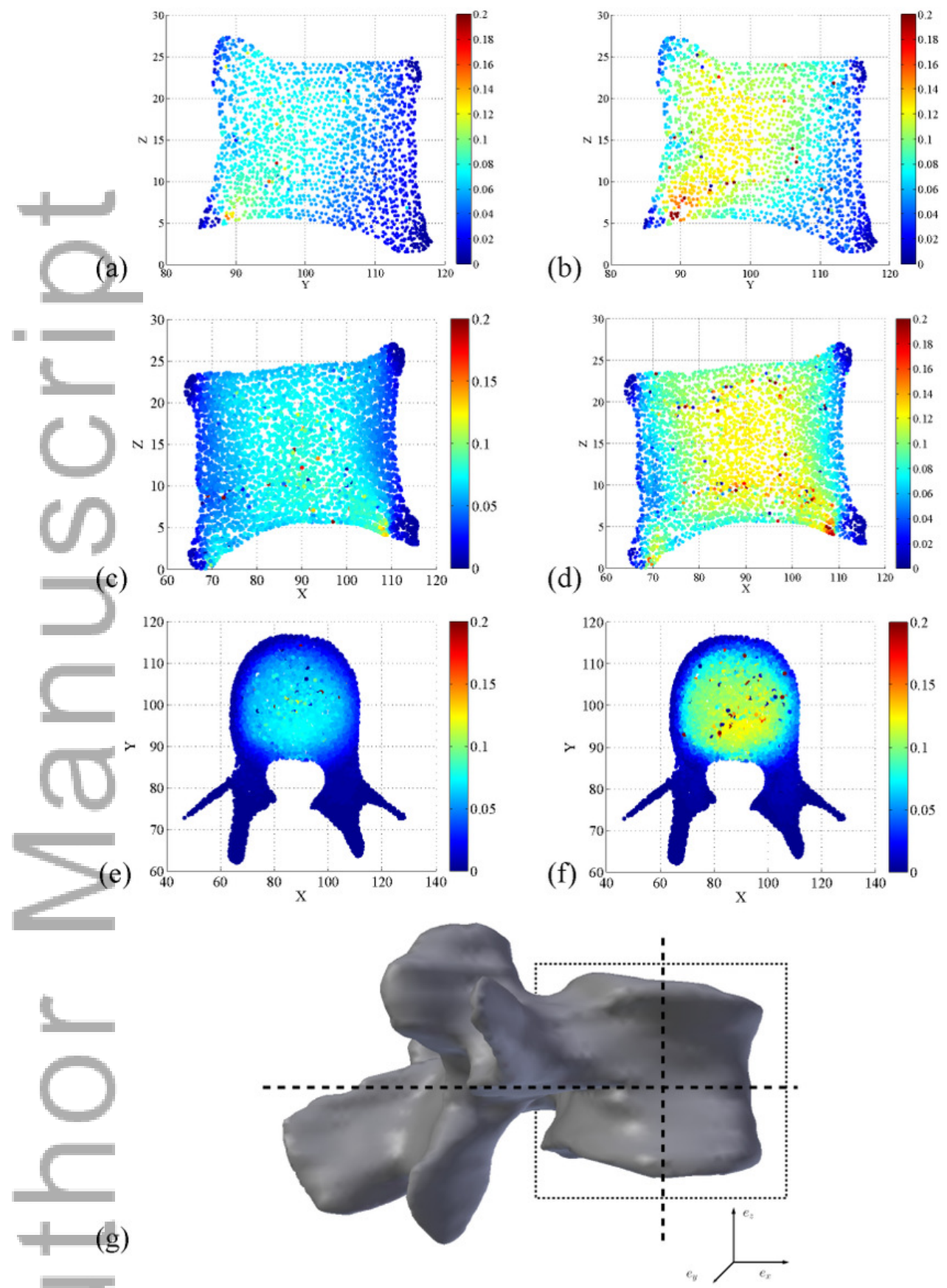

Figure 19. Maps of the "ultimate loading degree" $1 / \chi_{u l t}$, related to 1 MPa pressure loading; across the sagittal plane through the vertebral body, for (a) homogeneous, and (b) heterogeneous Finite Element model; across the coronal plane, for (c) homogeneous, and (d) heterogeneous FEM; across the transverse plane, for (e) homogeneous, and (f) heterogeneous FEM. (g) 3D representation of the organ and position of the slices. Cross-sectional dimensions are in millimeters

Agreement of our tissue mass density result with all these prior investigations nurtures the confidence in our new method, which delivers fully patient- and site-specific data on bone tissue composition, resolved down to the single voxel level. At this stage, it already drives forward the 
highly desired knowledge on local bone composition characteristics, as it was achieved by HR- 492 pQCT acquisition schemes on radial bones [64, 152, 153], delivering, as a result, bone mineral 493 densities as averages over cortical or trabecular compartments, with values lying well within the 494 ranges illustrated in Figure 9. Our method, however, while not being dependent on HR-pQCT 495 (which is only applicable to extremities), but just based on standard clinical CTs, gives not 496 only compartment averages, but bone composition gradients resolved down to a voxel size of 497 $0.324 \times 0.324 \times 1.25 \mathrm{~mm}^{3}$. The identifed mass density of $1.67 \mathrm{~g} / \mathrm{cm}^{3}$ underlines that vertebral tissue 498 is remarkably less dense than femoral or tibial tissue, with reported extracellullar mass densities 499 lying between 1.9 and $2.0 \mathrm{~g} / \mathrm{cm}^{3}$ [30,54,57]. This is consistent with ultrasonic waves traveling 500 slower through vertebral as compared to femoral tissues [51]. 501

Moreover, our mineral contents derived from in vivo CT data without the need of any type of 502 phantom, agree remarkably well with ex vivo QCT studies as well as ashing studies on vertebral 503 autopsies [154]: for an age slightly below 20 years, the latter reference reports bone mineral contents 504 relating to a similarly aged patient between 70 and $200 \mathrm{mg} / \mathrm{cm}^{3}$, a range which well frames the 505 mean value in Figure 12(e). Hence, we provided a new in vivo access to values for the so-called 506 "volumetric Bone Mineral Density - vBMD". The latter are very valuable indicators for clinical 507 decisions, as they have been shown to significantly correlate to the occurrence of bone fracture [155], 508 i.e. they are valuable indicators for bone fracture risk. However, such correlations [156-158] do not 509 consider the wealth of knowledge on how materials break, as it has been gained in the fields of 510 material physics and mechanics over centuries. 511

To the best knowledge of the authors, we here provided the first calibration-free, X-ray physics- 512 and multiscale mechanics-based fracture risk analysis tool applied to human vertebra, based on 513 multiscale elastoplasticity. In this context, it is first interesting to compare the results of the 514 multiscale model as depicted on Figure 5, to corresponding independent experimental results found 515 in the open literature. Namely, the (average) axial normal stiffness component of extracellular bone 516 matrix, amounting to $15.4 \mathrm{GPa}$, agrees virtually perfectly with the nanoindentation-derived value 517 reported by Wolfram et al. [141], amounting also to $15.4 \mathrm{GPa}$. At the same time, we observe that the 518 nanoindentation measurements may reveal, when using respective protocols [159], strictly speaking 519 orthotropic material properties, while the micromechanical model employed herein is based on 520 hexagonal symmetry, and hence provides transversely isotropic properties. The question arises how 521 our approximation of orthotropy through transverse isotropy may influence the results of the type 522 of analysis as reported herein. This question can be answered in two independent ways, leading 523 
to virtually the same answer. The first answer builds on computing the axial Young's modulus of a piece of orthotropic bone matrix from both the orthotropic stiffness tensor, and from the transversely isotropic approximation of this stiffness tensor, as obtained from rotation around the axial material direction [160]. In the latter reference, it was shown the corresponding difference in axial Youngs moduli computed for the orthotropic data of Ashman et al. [161] amounts to less than 1\%; and the same is true for the analogous computations based on the data of [159]. Since only this (axial) Young's modulus enters our Finite Element analyses, we regard the latters' results to be almost entirely independent of the choice of transversely isotropic as compared to orthotropic material properties. The second answer relates to the reliability of formally isotropic analysis as described in Section 2.6: use of such formally isotropic properties as retrieved from the aforementioned nanoindentation campaign indeed delivered Microfinite Element results which agreed particularly well with direct test results of entire vertebrae in both compression and torsion [162]. This further increases the confidence into our method.

As regards the plastic load regime, our results for a human lumbar vertebra aged 15 years indicate plastic deformations to even occur under normal physiological loading, agree well with the growing evidence of low-level plasticity in bone tissue, demonstrated by means of mechanical experiments and Finite Element simulations of trabecular bone [163,164]. The safety factor against ultimate fracture is found to be around five, corresponding to an ultimate load amounting to $4614 \mathrm{~N}$, which lies well within the broad range of values determined experimentally on different human vertebrae [1-4]. Our ultimate load particularly well agrees with the values of ultimate load measured on vertebrae of similar mean BMD $[1,3,11]$, and for a bone of similar mean porosity $[2,10]$. It is very interesting that our failure also agrees very well with those determined for femurs, both experimentally [16] and by means of FE strength computations [17]. This indicates larger domains of the skeleton to be designed for bearing the same level of loading. Thereby, the critical load may well be attained in extreme sport activities, as compressive forces of $8676 \mathrm{~N}$ in the block action of an American football player, $7500 \mathrm{~N}$ during a golf swing, or $7756 \mathrm{~N}$ during torso weight lifting [165]. The question may arise whether the large regions close to yielding under kind of a "light loading" makes sense from an evolutionary biology standpoint. The answer may actually be affirmative, given the evolution of the spine as a lightweight shock absorbing organ system. In fact, dissipative mechanical behavior of vertebral bone even under light loads seems very much consistent with spine's function as kind of a "shock absorber". Accordingly, even at low loading, the mechanical work put into the system would not be entirely recoverable upon unloading, but 
be partially dissipated into heat. Identification of related yielding phenomena critically relies on 556 the advanced multiscale formulation used herein, in order to describe the elastoplastic behavior of 557 bone, in particular at the scale of the extracellular bone matrix. The plastic behavior of bone at low 558 load levels at this small scale has been very recently shown also by a direct experimental method 559 where single micron-sized samples glued onto a rigid substrate have been loaded and unloaded in 560 the compressive regime [166]. A particular feature of our new method is the consistent consideration 561 of heterogeneous elasticity and strength properties throughout the organ - it is remarkable that 562 our bottom-up approach value for the Young's modulus of the extravascular space [see Figure 563 14(a) and Eqn.(27)] compares well to data stemming from top-down back-computations reported 564 in the literature [167]; and the importance of heterogeneity for fracture loads has been repeatedly 565 stated [168]. In our case, the heterogeneity results from the bone remodeling induced by the natural 566 asymmetry of the human body, with the right part of the middle section of the vertebra being less 567 porous, and therefore stiffer than the left-hand part, see Figure 6(a). Resulting stress concentrations 568 govern the organ's compliance and safety margin against fracture: stiffness and strength properties 569 based on an averaged homogeneous vascular porosity would overestimate the strain energy density 570 by a factor of 5 , and the safety factor by a factor of 2 . This key role of tissue heterogeneity in the 571 mechanics of the investigated biological system is fully consistent with similar earlier findings on a 572 variety of other tissues, such as human and murine femoral bone $[43,169,170]$, primate skull [171], 573 human patellar cartilage [172], or human arterial wall tissue [173]. 574

Our method critically depended on a successful micromechanial representations of bone 575 microstructure for mechanical property predictions, which does not resolve the material up to the 576 highest resolution ever possible, but rather focus on reliable consideration of the mechanically most 577 important micromorphological features. While in the present case, the micromechanics model was 578 set within the framework of continuum micromechanics or random homogenization theory, the 579 same philosophy can also be followed within alternative theoretical frames, such as that of lattice 580 models [112]. At the same time, our method impressively confirms the increasing expectations of 581 the clinical environments with regards to advanced numerical methods, especially those based on 582 the Finite Element method [174].

It is also appropriate to discuss potential limitations of the new method presented here. The 584 phantom-free CT data evaluation critically relies on the existence of two distinguishable peaks 585 in the histogram of grey values as depicted in Figure 7, these peaks being related to the adipose 586 and the soft tissue, respectively. Certain pathological conditions or poor resolution images may 587 
Copyright $@ 2014$ John Wiley \& Sons, Ltd.

Prepared using cnmauth.cls 
yet computationally and commercially less expensive advanced beam model solutions. In fact, 620 preliminary work in our research group (which is obviously beyond the scope of the present paper) 621 indicates that advanced "sandwich beam"-type theories turn out as theoretically challenging, but 622 highly effective alternatives to Finite Element models. They are particularly effective when it comes 623 to tackling load cases which go beyond the basic situation of a constant pressure acting on the upper 624 boundary of the investigated vertebra as described in this paper. This can be already sketched here, 625 in order to give a first-order approximation of how the safety factors would roughly change when 626 a typical bending moment of some $40 \mathrm{Nm}$ [178], in addition to the constant pressure of $1 \mathrm{MPa}$ as 627 discussed earlier, would be applied to the studied vertebra. Approximating the vertebral cross section 628 as shown in Figure 12 as a homogeneous ellipse with some $50 \mathrm{~mm}$ width and $33 \mathrm{~mm}$ height results in 629 a minimal area moment of inertia of $I=33^{3} \times 50 \times \frac{\pi}{4}=1.4 \times 10^{6} \mathrm{~mm}^{4}$, so that the normal stresses due 630 to bending can be roughly estimated as $\sigma=40 /\left(1.4 \times 10^{-6}\right) \times 16.5 \times 10^{-3} \approx 500 \times 10^{3} \mathrm{~Pa}=0.5 \mathrm{MPa} . \quad 631$ Hence, a typical bending mode on top of the compressive loading studied throughout this paper 632 leads to an increase of the pseudo-uniaxial stress state of Figure 17 by around 30\%; i.e. the overall 633 safety would be expected to be around four in combined axial-bending load.

\section{CONCLUSION}

Based on consistent integration of micromechanics, Finite Element analysis, and X-ray physics, 635 conventional clinical CT data alone allow for reliable determination of tissue mass density and 636 mineralization degree, as well as engineering mechanics-based fracture risk analysis considerung 637 both patient-specific loading and microstructurally governed conditions of mechanical integrity. $\quad 638$

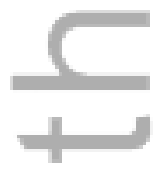

\section{CONFLICT OF INTEREST STATEMENT}

The authors Romane Blanchard, Claire Morin, Andrea Malandrino, Alain Vella, Zdenka Sant, and 639 Christian Hellmich hereby declare that they have no conflict of interest.

\section{ACKNOWLEDGMENTS}

The grey value-to-composition conversion scheme development was financially supported through 641 project MySPINE, grant number 269909 of EC call FP7-ICT-2009-6. Collaboration with the 642 
University of Malta and Mater Dei Hospital, Malta, was supported through grant NAMABIO, MPNS Action COST MP1005. Completion of the strength model became possible through project MICROBONE, Grant number 257023, granted by the European Research Council (ERC). Moreover, the authors gratefully acknowledge the support of Manfred Tschabitscher from the Center of Anatomy and Cell Biology at the Medical University of Vienna, providing a vertebra for the mass density tests. The latter were performed as part of a 2010 internship of Andrea Malandrino from the Institute of Bioengineering of Catalonia (IBEC), Biomechanics and Mechanobiology Group (headed by Damien Lacroix until 2012, and by Jerome Noailly since 2012), at Vienna University of Technology, which was made possible through the bilateral Austro-Spanish scientific exchange grant ES06/2010 AT2009-0029. CT scanning of the aforementioned vertebra was provided by Heinz Redl from the Ludwig Boltzmann Institute for Clinical and Experimental Traumatology, in the framework of the Austrian Cluster for Tissue Regeneration.

References

1. Cheng X, Nicholson P, Boonen S, Lowet G, Brys P, Aerssens J, van der Perre G, Dequeker J. Prediction of

vertebral strength in vitro by spinal bone densitometry and calcaneal ultrasound. Journal of Bone and Mineral Research. 1997;12(10):1721-1728.

2. Perilli E, Briggs A, Kantor S, Codrington J, Wark J, Parkinson I, Fazzalari N. Failure strength of human vertebrae:Prediction using bone mineral density measured by DXA and bone volume by micro-CT. Bone. 2012; 50(6):1416-1425.

3. Crawford R, Rosenberg W, Keaveny T. Quantitative computed tomography-based Finite Element models of the human lumbar vertebral body: effect of element size on stiffness, damage, and fracture strength predictions. Journal of Biomechanical Engineering. 2003;125:434 - 438.

4. McBroom RJ, Hayes WC, Edwards WT, Goldberg RP, White AA. Prediction of vertebral body compressive fracture using quantitative computed tomography. The Journal of Bone and Joint Surgery American volume. 1985;67:1206-1214.

5. Melton III L, Atkinson E, O'Fallon W, Wahner H, Riggs B. Long-term fracture prediction by bone mineral assessed at different skeletal sites. Journal of Bone and Mineral Research. 1993;8(10):1227-1233.

6. Black D, Steinbuch M, Palermo L, Dargent-Molina P, Lindsay R, Hoseyni M, Johnell O. An assessment tool for predicting fracture risk in postmenopausal women. Osteoporosis International. 2001;12(7):519-528.

7. Hulme P, Boyd S, Ferguson S. Regional variation in vertebral bone morphology and its contribution to vertebral fracture strength. Bone. 2007;41:946-957.

8. Singer K, Edmondston S, Day R, Breidahl P, Price R. Prediction of thoracic and lumbar vertebral body compressive strength: correlations with bone mineral density and vertebral region. Bone. 1995;17(2):167-74.

9. Hutton WC, Cyron BM, Stott JR. The compressive strength of lumbar vertebrae. Journal of Anatomy. 1979; 129(4):753-8. 
10. Jiang G, Luo J, Pollintine P, Dolan P, Adams Ma, Eastell R. Vertebral fractures in the elderly may not always be "osteoporotic". Bone. 2010;47(1):111-6.

11. Ebbesen EN, Thomsen JS, Beck-Nielsen H, Nepper-Rasmussen HJ, Mosekilde L. Lumbar vertebral body compressive strength evaluated by dual-energy X-ray absorptiometry, quantitative computed tomography, and ashing. Bone. 1999;25:713-724.

12. Rockhoff S, Sweet E, Bleustein J. The relative contribution of trabecular and cortical bone to the strength of human lumbar vertebrae. Calcified Tissue Research. 1969;3:163-175.

13. Cody D, Gorss G, Hou F, Spencer H, Goldstein S, Fyhrie D. Femoral strength is better predicted by finite element models than QCT and DXA. Journal of Biomechanics. 1999;32:1013 - 1020.

14. MacNeil JA, Boyd SK. Bone strength at the distal radius can be estimated from high-resolution peripheral quantitative computed tomography and the finite element method. Bone. 2008;42(6):1203-1213.

15. Keyak J, Rossi S, Jones K, Skinner H. Prediction of femoral fracture load using automated finite element modeling. Journal of Biomechanics. 1998;31(2):125 - 133

16. Schileo E, Taddei F, Cristofolini L, Viceconti M. Subject-specific Finite Element models implementing a maximum principal strain criterion are able to estimate failure risk and fracture location on human femurs tested in vitro. Journal of Biomechanics. 2008;41:356-367.

17. Falcinelli C, Schileo E, Balistreri L, Baruffaldi F, Bordini B, Viceconti M, Albisinni U, Ceccarelli F, Milandri L, Toni A, Taddei F. Multiple loading conditions analysis can improve the association between finite element bone strength estimates and proximal femur fractures: A preliminary study in elderly women. Bone. 2014;67:71-80.

18. Yosibash Z, Padan R, Joskowicz L, Milgrom C. A CT-based high-order Finite Element analysis of the human proximal femur compared to in-vitro experiments. Journal of Biomechanical Engineering. 2007;129(3):297-309.

19. Trabelsi N, Yosibash Z. Patient-specific finite-element analyses of the proximal femur with orthotropic material properties validated by experiments. Journal of Biomechanical Engineering. 2011;133(6).

20. Trabelsi N, Milgrom C, Yosibash Z. Patient-specific FE analyses of metatarsal bones with inhomogeneous isotropic material properties. Journal of the Mechanical Behavior of Biomedical Materials. 2014;29:177-189.

21. Morgan E, Bayraktar H, Keaveny T. Trabecular bone modulus-density relationships depend on anatomic site. Journal of Biomechanics. 2003;36(7):897-904.

22. Keyak J, Lee I, Skinner H. Correlations between orthogonal mechanical properties and density of trabecular bone: Use of different densitometric measures. Journal of Biomedical Materials Research. 1994;28(11):1329-1336.

23. Goulet R, Goldstein S, Ciarelli M, Kuhn J, Brown M, Feldkamp L. The relationship between the structural and orthogonal compressive properties of trabecular bone. Journal of Biomechanics. 1994;27(4):375 - 389.

24. Rho JY, Hobatho M, Ashman R. Relations of mechanical properties to density and CT numbers in human bone. - Medical Engineering \& Physics. 1995;17(5):347 - 355.

25. Périé D, Sales de Gauzy J, Baunin C, Hobatho MC. Tomodensitometry measurements for in vivo quantification of mechanical properties of sciolotic vertebrae. Clinical Biomechanics. 2001;16:373 - 379.

26. Natali AN, Carniel EL, Pavan PG. Investigation of bone inelastic response in interaction phenomena with dental implants. Dental Materials. 2008;24(4):561-569.

27. Geraldes D, Phillips AM. A comparative study of orthotropic and isotropic bone adaptation in the femur. International Journal for Numerical Methods in Biomedical Engineering. 2014;30:873 - 889.

28. Frost HM. Bone Mass and the Mechanostat : A Proposal. The Anatomical Record. 1987;219:1-9.

29. Hellmich C, Ulm F, Dormieux L. Can the diverse elastic properties of trabecular and cortical bone be attributed to only a few tissue-independent phase properties and their interactions? Arguments from a multiscale approach. Biomechanics and Modeling in Mechanobiology. 2004;2(4):219-238. 
30. Vuong J, Hellmich C. Bone fibrillogenesis and mineralization: Quantitative analysis and implications for tissue elasticity. Journal of Theoretical Biology. 2011;287:115-130.

31. Morin C, Hellmich C, Henits P. Fibrillar structure and elasticity of hydrating collagen: A quantitative multiscale approach. Journal of Theoretical Biology. 2013;317:384-393.

32. Morin C, Hellmich C. Mineralization-driven bone tissue evolution follows from fluid-to-solid phase

33. Fritsch A, Hellmich C. 'Universal' microstructural patterns in cortical and trabecular, extracellular and extravacular bone materials: Micromechanics-based prediction of anisotropic elasticity. Journal of Theoretical Biology. 2007;244:597 - 620 .

34. Fritsch A, Hellmich C, Dormieux L. Ductile sliding between mineral crystals followed by rupture of collagen crosslinks: experimentally supported micromechanical explanation of bone strength. Journal of Theoretical Biology. 2009;260:230 - 252.

35. Morin C, Hellmich C. A multiscale poromicromechanical approach to wave propagation and attenuation in bone. Ultrasonics. 2014;54(5):1251 - 1269.

36. Hubbell JH, Seltzer SM. Tables of X-Ray Mass Attenuation Coefficients and Mass Energy-Absorption Coefficients from $1 \mathrm{keV}$ to $20 \mathrm{MeV}$ for Elements $\mathrm{Z}=1$ to 92 and 48 Additional Substances of Dosimetric Interest. 2011. Http://www.nist.gov/pml/data/xraycoef/index.cfm/.

37. Hellmich C, Kober C, Erdmann B. Micromechanics-based conversion of CT data into anisotropic elasticity tensors, applied to FE simulations of a mandible. Annals of Biomedical Engineering. 2008;36(1):108 - 122.

38. Crawley E, Evans W, Owen GM. A theoretical analysis of the accuracy of single-energy CT bone measurements. Physics in Medicine and Biology. 1988;33(10):1113-1127.

39. Jackson DF, Hawkes DJ. X-ray attenuation coefficients of elements and mixtures. Physics Reports. 1981; 70(3):169-233.

40. Yosibash Z, Trabelsi N, Hellmich C. Subject-Specific p-FE Analysis of the Proximal Femur Utilizing

Micromechanics-Based Material Properties. International Journal for Multiscale Computational Engineering. 2008;6(5):483-498.

41. Scheiner S, Sinibaldi R, Pichler B, Komlev V, Renghini C, Vitale-Brovarone C, Rustichelli F, Hellmich C. Micromechanics of bone tissue-engineering scaffolds, based on resolution error-cleared computer tomography. Biomaterials. 2009;30:2411-2419.

42. Dejaco A, Komlev VS, Jaroszewicz J, Swieszkowski W, Hellmich C. Micro CT-based multiscale elasticity of double-porous (pre-cracked) hydroxyapatite granules for regenerative medicine. Journal of Biomechanics. 2012; 45(6): $1068-1075$.

43. Blanchard R, Dejaco A, Bongaers E, Hellmich C. Intravoxel bone micromechanics for microCT-based finite element simulations. Journal of Biomechanics. 2013;46(15):2710-2721.

44. Czenek A, Blanchard R, Dejaco A, Sigurjónsson OE, Örlygsson G, Gargiulo P, Hellmich C. Quantitative intravoxel analysis of microCT-scanned resorbing ceramic biomaterials Perspectives for computer-aided biomaterial design. Journal of Materials Research. 2014;29(23):2757-2772.

45. Mast TD. Empirical relationships between acoustic parameters in human soft tissues. Acoustics Research Letters Online. 2000;1(2):37-42.

46. Lees S. Considerations regarding the structure of the mammalian mineralized osteoid from viewpoint of the generalized packing model. Connective Tissue Research. 1987;16(4):281-303.

47. Gautieri A, Buehler M, Redaelli A. Deformation rate controls elasticity and unfolding pathways of single tropocollagen molecules. Journal of the Mechanical Behavior of Biomedical Materials. 2009;2:130-137. 
48. Silva M, Wang C, Keaveny T, Hayes W. Direct and computed tomography thickness measurements of the human, lumbar vertebral shell and endplate. Bone. 1994;15(4):409-414.

49. Whitehouse WJ, Dyson ED, Jackson CK. The scanning electron microscope in studies of trabecular bone from a human vertebral body. Journal of Anatomy. 1971;108(3):481-496.

50. Ritzel H, Amling M, Pösl M, Hahn M, Delling G. The thickness of human vertebral cortical bone and its changes in aging and osteoporosis: a histomorphic analysis of the complete spinal column from thirty-seven autopsy specimen. Journal of Bone and Mineral Research. 1997;12(1):89-95.

51. Malandrino A, Fritsch A, Lahayne O, Kropik K, Redl H, Noailly J, Lacroix D, Hellmich C. Anisotropic tissue elasticity in human lumbar vertebra, by means of a coupled ultrasound-micromechanics approach. Materials

a Letters. 2012;78:154-158.

52. Lees S, Cleary P, Heeley J, Gariepy E. Distribution of sonic plesio-velocity in a compact bone sample. Journal of the Acoustical Society of America. 1979;66(3):641-646.

53. Lees S, Hanson D, Page E. Some acoustical properties of theotic bones of a fin whale. Journal of the Acoustical Society of America. 1995;99(4):2421-2427.

54. Lees S, Ahern J, Leonard M. Parameters influencing the sonic velocity in compact calcified tissues of various species. Journal of the Acoustical Society of America. 1983;74(1):28-33.

55. Lees S. Mineralization of type I collagen. Biophysical Journal. 2003;85:204 - 207.

56. Lees S, Page E. A study of some properties of mineralized turkey leg tendon. Connective Tissue Research. 1992; 28(4):263-287.

57. Biltz R, Pellegrino E. The chemical anatomy of bone. I. A comparative study of bone composition in sixteen vertebrates. Journal of Bone and Joint Surgery - Series A. 1969;51(3):456-466.

58. Gong J, Arnold J, Cohn S. Composition of trabecular and cortical bone. The Anatomical Record. 1964;149:325 -332 .

59. Burns C. XCIV. The effect of the continued ingestion of mineral acid on growth of body and bone and on the composition of bone and of the soft tissues. Biochemical Journal. 1929;23(5):860-867.

60. Hammett F. A biochemical study of bone growth. I. Changes in the ash, organic matter and water during growth (mus norvegicus albinus). Journal of Biological Chemistry. 1925;64:409-428.

61. Hammett F. Studies of the thyroid apparatus: XIV. The growth of the humerus and femur of male and female albino rats thyro-parathyroidectomized and parathyroidectomized when 100 days of age. The Journal of Experimental Zoology. 1924;39(3):465-504.

62. Chick H, Korenchevsky V, Roscoe M. LXXXIII. The difference in chemical composition of the skeletons of young rats fed (1) on diets deprived of fat-soluble vitamins and (2) on a low phosphorus rachitic diet, compared I. with those of normally nourished animals of same age. Biochemical Journal. 1926;20(3):621-631.

63. Tai K, Pelled G, Sheyn D, Bershteyn A, Han L, Kallai I, Zilberman Y, Ortiz C, Gazit D. Nanobiomechanics of Repair Bone Regenerated by Genetically Modified Mesenchymal Stem Cells. Tissue Engineering: Part A. 2008; 14(10):1709-1720.

64. Neu C, Manz F, Rauch F, Merkel A, Schoenau E. Bone density and bone size at the distal radius in healthy children and adolescents: a study using peripheral quantitative computed tomography. Bone. 2001;28(2):227 232.

65. Urist M, DeLange R, Finerman G. Bone Cell Differentiation and Growth Factors. Science. 1983;220:680 - 686.

66. Hellmich C, Barthélémy JF, Dormieux L. Mineral-collagen interactions in elasticity of bone ultrastructure - a continuum micromechanics approach. European Journal of Mechanics A-Solids. 2004;23:783 - 810. 
67. McCarthy R, Jeffcott L, McCartney R. Ultrasound speed in equine cortical bone: effects of orientation, density, porosity and temperature. Journal of Biomechanics. 1990;23(11):1139 - 1143.

68. Lees S, Hanson D, Page E, Mook H. Comparison of dosage-dependent effects of beta-aminopropionitrile, sodium fluoride, and hydrocortisone on selected physical properties of cortical bone. Journal of Bone and Mineral Research. 1994;9(9):1377 - 1389.

69. Lees S. Ultrasonic measurements of deer antler, bovine tibia and tympanic bulla. Journal of Biomechanics. 1982; 15(11):867 - 874

70. Hellmich C, Ulm FJ. Average hydroxyapatite concentration is uniform in extracollageneous ultrastructure of mineralized tissue. Biomechanics and Modeling in Mechanobiology. 2003;2:21 - 36

71. Zylberberg L, Traub W, de Buffrenil V, Allizard F, Arad T, Weiner S. Rostrum of a toothed whale: Ultrastructural study of a very dense bone. Bone. 1998;23:241 - 247.

72. Prostak K, Lees S. Visualization of crystal-matrix structure. In situ demineralization of mineralized turkey leg tendon and bone. Calcified Tissue International. 1996;59:474 - 479.

73. Lees S. Water content in type I collagen tissues calculated from the generalized packing model. International Journal of Biological Macromolecules. 1986;8:66 - 72.

74. Bonar L, Lees S, Mook H. Neutron diffraction studies of collagen in fully mineralized bone. Journal of Molecular Biology. 1985;181:265-270.

75. Lees S, Bonar L, Mook H. A study of dense mineralized tissue by neutron diffraction. International Journal of Biological Macromolecules. 1984;6(6):321-326.

76. Hodge A, Petruska J. Recent studies with the electron microscope on ordered aggregates of the tropocollagen molecule. In: Aspects of Protein Structure - Proceedings of a Symposium held in Madras 14 - 18 January 1963 and organized by the University of Madras, India, edited by Ramachandran G. Academic Press, London and New York. 1963; pp. $289-300$

77. Meek KM, Fullwood NJ, Cooke PH, Elliott GF, Maurice DM, Quantock aJ, Wall RS, Worthington CR. Synchrotron X-ray diffraction studies of the cornea, with implications for stromal hydration. Biophysical journal. 1991;60(2):467-74.

78. Bergman I, Loxley R. Two Improved and Simplified Methods for the Spectrophotometric Determination of Hydroxyproline. Analytical Chemistry. 1963;35(12):1961-1965.

79. Rougvie M, Bear R. An X-ray diffraction investigation of swelling by collagen. Journal of the American Leather Chemists Association. 1953;48(12):735-751.

80. Grosso VAD, Mader CW. Speed of sound in pure water. Journal of the Acoustical Society of America. 1972; 52(5B):1442-1446

81. Sant Z, Cauchi M, Spiteri M. Analysis of stress-strain distribution within a spinal segment. Journal of Mechanics of Materials and Structures. 2012;7(3):255-263.

82. Wang Y, Battié M, Boyd S, Videman T. The osseous endplates in lumbar vertebrae: thickness, bone mineral density and their associations with age and disk degeneration. Bone. 2011;48(4):804-809.

83. Yoganandan N, Mykiebust J, Cusick J, Wilson C, Jr AS. Functional biomechanics of the thoracolumbar vertebral cortex. Clinical Biomechanics. 1988;3(1):11 - 18.

84. Rietbergen BV, Odgaard A, Kabel J, Huiskes R. Direct mechanics assessment of elastic symmetries and properties of trabecular bone architecture. Journal of Biomechanics. 1996;29(12):1653-1657.

85. Cowin S. Remarks on the paper entitled 'Fabric and elastic principal directions of cancellous bone are closely related'. Journal of Biomechanics. 1997;30(11/12):1191-1192. 
86. Bhowmik R, Katti K, Katti D. Mechanics of molecular collagen is influenced by hydroxyapatite in naturial bone. Journal of Materials Science. 2007;42:8824 - 8837.

87. Bhowmik R, Katti K, Katti D. Mechanisms of load-deformation behavior of molecular collagen in hydroxyapatitetropocollagen molecular system: steered molecular dynamics study. Journal of Engineering Mechanics. 2009; 135(5):413-421.

88. Wilson E, Awonusi A, Kohn M, Tecklenburg M, Beck L. Three structural roles for water in bone observed by solid-state NMR. Biophysical Journal. 2006;90:3722-3731.

89. Pan H, Tao J, Tang R. Molecular simulation of water behaviors on crystal faces of hydroxyapatite. Frontiers of Chemistry in China. 2007;2(2):156 - 163.

90. Zahn D, Hochrein O. Computational study of interfaces between hydroxyapatite and water. Physical Chemistry Chemical Physics. 2003;5:4004-4007.

91. Catanese J, Iverson E, Ng R, Keaveny T. Heterogeneity of the mechanical properties of demineralized bone. Journal of Biomechanics. 1999;32:1365 - 1369.

92. Christiansen D, Huang E, Silver F. Assembly of type I collagen: fusion of fibril subunits and the influence of fibril diameter on mechanical properties. Matrix Biology. 2000;19:409 - 420.

93. E G, Lay A, Dickerson D, Neuman E, Livesay G, Dee K. Mechanical characterization of collagen fibers and scaffolds for tissue engineering. Biomaterials. 2003;24:3805-3813.

94. Burstein AH, Currey JD, Frankel VH, Reilly DT. The ultimate properties of bone tissue: the effects of yielding. Journal of Biomechanics. 1972;5:35-44.

95. Burstein AH, Zika JM, Heiple KG, Klein L. Contribution of collagen and mineral to the elastic-plastic properties of bone. The Journal of Bone and Joint Surgery American volume. 1975;57:956-961.

96. Burstein AH, Reilly DT, Martens M. Aging of bone tissue: mechanical properties. The Journal of Bone and Joint Surgery American volume. 1976;58:82-86.

97. Cezayirlioglu H, Bahniuk E, Davy D, Heiple K. Anisotropic yield behavior of bone under combined axial force and tension. Journal of Biomechanics. 1985;18(1):61 - 69.

98. Currey J. Differences in the tensile strength of bone of different histological types. Journal of Anatomy. 1959; 93:87-95.

99. Currey JD. The effects of strain rate, reconstruction and mineral content on some mechanical properties of bovine bone. Journal of Biomechanics. 1975;8:81-86.

100. Currey JD. Physical characteristics affecting the tensile failure properties of compact bone. Journal of Biomechanics. 1990;23:837-844.

101. Currey JD. Tensile yield in compact bone is determined by strain, post-yield behaviour by mineral content. J Journal of Biomechanics. 2004;37(4):549-556.

102. Dickenson RP, Hutton WC, Stott JR. The mechanical properties of bone in osteoporosis. The Journal of Bone and Joint Surgery British volume. 1981;63-B:233-238.

103. Hellmich C, Müllner H, Kohlhauser C. Mechanical (triaxial) tests on biological materials and biomaterials. Tech. Rep. DNRT3-1.2-3, Network of excellence 'Knowledge-based Multicomponent Materials for Durable and Safe Performance-KMM-NoE', sponsored by the European Commission. 2006.

104. Kotha SP, Guzeslu N. Modeling the tensile mechanical behavior of bone along the longitudinal direction. Journal of Theoretical Biology. 2002;219:269-279.

105. Lee SC, Coan BS, Bouxsein ML. Tibial ultrasound velocity measured in situ predicts the material properties of tibial cortical bone. Bone. 1997;21:119-125. 
106. Martin R, Burr D. Structure, Function, and Adaptation of Compact Bone. New York, NY, USA: Raven Press. 1989.

107. Reilly DT, Burstein AH, Frankel VH. The elastic modulus for bone. Journal of Biomechanics. 1974;7:271-275.

108. Reilly D, Burstein A. The elastic and ultimate properties of compact bone tissue. Journal of Biomechanics. 1975; 8:393 - 405 .

109. Riggs C, Vaughan L, Evans G, Lanyon L, Boyde A. Mechanical implications of collagen fibre orientation in cortical bone of equine radius. Anatomy and Embryology. 1993;187:239 - 248.

110. Evans FG, Lebow M. The strength of human compact bone as revealed by engineering technics. American Journal of Surgery. 1952;83(3):326-31.

111. Walsh W, Guzelsu N. Ion concentration effects on bone streaming potentials and zeta potentials. Biomaterials. 1993;14(5):331 - 336.

112. Diamant I, Shahar R, Masharawi Y, Gefen A. A method for patient-specific evaluation of vertebral cancellous bone strength: In vitro validation. Clinical Biomechanics. 2007;22(3):282-291.

113. Katz J, Ukraincik K. On the anisotropic elastic properties of hydroxyapatite. Journal of Biomechanics. 1971; $4: 221-227$.

114. Fritsch A, Dormieux L, Hellmich C, Sanahuja J. Mechanical behaviour of hydroxyapatite biomaterials: An experimentally validated micromechanical model for elasticity and strength. Journal of Biomedical Materials Research. 2009;88A:149 - 161.

115. Akao M, Aoki H, Kato K. Mechanical properties of sintered hydroxyapatite for prosthetic applications. Journal of Materials Science. 1981;16:809 - 812.

116. Shareef M, Messer P, Noort R. Fabrication, characterization and fracture study of a machinable hydroxyapatite ceramic. Biomaterials. 1993;14(1):69 - 75.

117. Liu DM. Preparation and characterisation of porous hydroxyapatite bioceramic via a slip-casting route. Ceramics International. 1998;24(6):441-446.

118. Charrière E, Terrazzoni S, Pittet C, Mordasini P, Dutoit M, Lemaître J, Zysset P. Mechanical characterization of brushite and hydroxyapatite cements. Biomaterials. 2001;22:2937-2945.

119. Arita IH, Wilkinson DS, Mondragón MA, Castaño VM. Chemistry and sintering behaviour of thin hydroxyapatite ceramics with controlled porosity. Biomaterials. 1995;16:403-408.

120. Peelen J, Rejda B, de Groot K. Preparation and properties of sintered hydroxylapatite. Ceramurgia International. $1978 ; 4: 71-74$.

121. De With G, van Dijk H, Hattu N, Prijs K. Preparation, microstructure and mechanical properties of dense polycrystalline hydroxyapatite. Journal of Materials Science. 1981;16:1592-1598.

122. Martin RI, Brown PW. Mechanical properties of hydroxyapatite formed at physiological temperature. Journal of Materials Science: Materials in Medicine. 1995;6:138-143.

123. Simo JC, Hughes TJR. Computational Inelasticity, vol.7 of Interdisciplinary Applied Mathematics. SpringerVerlag, New York. 1998.

124. Melan E. Zur Plastizität des räumlichen Kontinuums. Ingenieur-Archiv. 1938;9(2):116-126.

125. Zaoui A. Continuum micromechanics: survey. Journal of Engineering Mechanics (ASCE). 2002;128(8):808-816.

126. Hill R. Elastic properties of reinfored solids: some theoretical principles. Journal of the Mechanics and Physics of Solids. 1963;11:357 - 362

127. Hashin Z. Analysis of composite materials - a survey. Journal of Applied Mechanics (ASME). 1983;50(3):481503.

128. Levin V. Thermal expansion coefficient of heterogeneous materials. Inzh Zh Mekh Tverd Tela. 1967;2(1):83-94. 
129. Pichler B, Hellmich C. Estimation of influence tensors for eigenstresses multiphase elastic media with nonaligned inclusion phases of arbitrary ellipsoidal shape. Journal of Engineering Mechanics. 2010;136(8):1043-1053.

130. Fritsch A, Hellmich C, Young P. Micromechanics-derived scaling relations for poroelasticity and strength of brittle porous polycrystals. Journal of Applied Mechanics, Transactions ASME. 2013;80(2).

131. Badel PB, Leblond JB. A note on integration schemes for the microplane model of the mechanical behaviour of concrete. Communications in Numerical Methods in Engineering. 2004;20(1):75-81.

132. Simo J, Taylor R. Consistent tangent operators for rate-independent elastoplasticity. Computer Methods in Applied Mechanics and Engineering. 1985;48(1):101-118.

133. Clausen J, Damkilde L, Andersen L. Efficient return algorithms for associated plasticity with multiple yield

$=$ planes. International Journal for Numerical Methods in Engineering. 2006;66(6):1036-1059.

134. Pant S, Fabrèges B, Gerbeau JF, Vignon-Clementel IE. A methodological paradigm for patient-specific multiscale CFD simulations: from clinical measurements to parameter estimates for individual analysis. International Journal for Numerical Methods in Biomedical Engineering. 2014;30(12):1614-48.

135. Onishi Y, Aoki K, Amaya K, Shimizu T, Isoda H, Takehara Y, Sakahara H, Kosugi T. Accurate determination of patient-specific boundary conditions in computational vascular hemodynamics using 3D cine phase-contrast MRI.

International Journal for Numerical Methods in Biomedical Engineering. 2013;29(10):1089-103.

136. Liang F, Sughimoto K, Matsuo K, Liu H, Takagi S. Patient-specific assessment of cardiovascular function by combination of clinical data and computational model with applications to patients undergoing Fontan operation. International Journal for Numerical Methods in Biomedical Engineering. 2014;30(10):1000-18.

137. Boileau E, Bevan RLT, Sazonov I, Rees MI, Nithiarasu P. Flow-induced ATP release in patient-specific arterial geometries-a comparative study of computational models. International Journal for Numerical Methods in Biomedical Engineering. 2013;29(10):1038-56.

138. Arzani A, Les AS, Dalman RL, Shadden SC. Effect of exercise on patient specific abdominal aortic aneurysm flow topology and mixing. International Journal for Numerical Methods in Biomedical Engineering. 2014;30(2):280295.

139. Hoffler CE, Moore KE, Kozloff K, Zysset PK, Goldstein SA. Age, gender, and bone lamellae elastic moduli. Journal of Orthopaedic Research. 2000;18:432-437.

140. Rho J, Zioupos P, Currey J, Pharr G. Microstructural elasticity and regional heterogeneity in human femoral bone of various ages examined by nano-indentation. Journal of Biomechanics. 2002;35:189 - 198.

141. Wolfram U, Wilke HJ, Zysset PK. Rehydration of vertebral trabecular bone: influences on its anisotropy, its stiffness and the indentation work with a view to age, gender and vertebral level. Bone. 2010;46(2):348-54.

142. Boivin G, Meunier P. The degree of mineralization of bone tissue measured by computerized quantitative contact microradiography. Calcified Tissue International. 2002;70:503 - 511.

143. Roschger P, Gupta H, Berzlanovich A, Ittner G, Dempster D, Fratzl P, Cosman F, Parisien M, Lindsay R, Nieves J, Klaushofer K. Constant mineralization density distribution in cancellous human bone. Bone. 2003;32:316323.

144. Akkus O, Polyakova-Akkus A, Adar F, Schaffler M. Aging of microstructural compartments in human compact bone. Journal of Bone and Mineral Research. 2003;18(6):1012 - 1019.

145. Bossy E, Talmant M, Peyrin F, Akrout L, Cloetens P, Laugier P. In in vitro study of the ultrasonic axial transmission technique at the radius: $1 \mathrm{MHz}$ velocity measurements are sensitive to both mineralization and introcortical porosity. Journal of Bone and Mineral Research. 2004;19(9):1548 - 1556.

146. Panjabi MM, Krag M, Summers D, Videman T. Biomechanical time-tolerance of fresh cadaveric human spine specimens. Journal of Orthopaedic Research. 1985;3(3):292-300. 
147. Linde F, Christian H, Sorensen F. The effect of different storage methods on the mechanical properties of trabecular bone. Journal of Biomechanics. 1993;26(10):1249-1252.

148. Nazarian A, Hermannsson BJ, Muller J, Zurakowski D, Snyder BD. Effects of tissue preservation on murine bone mechanical properties. Journal of Biomechanics. 2009;42(1):82-86.

149. Fölsch C, Mittelmeier W, Bilderbeek U, Timmesfeld N, Von Garrel T, Matter HP. Effect of storage temperature I on allograft bone. Transfusion Medicine and Hemotherapy. 2012;39(1):36-40.

150. Fritsch A, Hellmich C. 'Universal' microstructural patterns in cortical and trabecular, extracellular and extravacular bone materials: Micromechanics-based prediction of anisotropic elasticity. Journal of Theoretical Biology. 2007;244:597 - 620 .

151. Castro I, Humbert L, Whitmarsh T, Lazary A, Del Rio Barquero LM, Frangi AF. 3D reconstruction of intervertebral discs from T1-weighted magnetic resonance images. 2012 9th IEEE International Symposium on Biomedical Imaging (ISBI). 2012;pp. 1695-1698.

152. Hasegawa K, Hasegawa Y, Nagano A. Estimation of bone mineral density and architectural parameters of the distal radius in hemodialysis patients using peripheral quantitative computed tomography. Journal of Biomechanics. 2004;37(5):751-756.

153. Nishiyama KK, Macdonald HM, Moore Sa, Fung T, Boyd SK, McKay Ha. Cortical porosity is higher in boys compared with girls at the distal radius and distal tibia during pubertal growth: an HR-pQCT study. Journal of Bone and Mineral Research. 2012;27(2):273-82.

154. Ebbesen EN, Thomsen JS, Beck-Nielsen H, Nepper-Rasmussen HJ, Mosekilde L. Vertebral bone density evaluated by dual-energy X-ray absorptiometry and quantitative computed tomography in vitro. Bone. 1998; 23(3):283-90.

155. Lang T, Guglielmi G, van Kuijk C, De Serio A, Cammisa M, Genant H. Measurement of bone mineral density at the spine and proximal femur by volumetric quantitative computed tomography and dual-energy Xray absorptiometry in elderly women with and without vertebral fractures. Bone. 2002;30(1):247-250.

156. Wachter NJ, Augat P, Mentzel M, Sarkar MR, Krischak GD, Kinzl L, Claes LE. Predictive value of bone mineral density and morphology determined by peripheral quantitative computed tomography for cancellous bone strength of the proximal femur. Bone. 2001;28(1):133-139.

157. Yu W, Chan K, Yu F, Ng B, Lee K, Qin L, Lam T, Cheng J. Bone structural and mechanical indices in Adolescent Idiopathic Scoliosis evaluated by high-reolution peripheal quantitative computed tomography (HR-pQCT). Bone. 2014;61:109-115.

158. Melton III L, Riggs B, van Lenthe G, Achenbach S, Müller R, Bouxsein M, Amin S, Atkinson E, Khosla S. Contribution of in vivo structural measurements and load/strength ratios to the determination of forearm fracture risk in postmenopausal women. Journal of Bone and Mineral Research. 2007;22(9):1442-1448.

159. Franzoso G, Zysset PK. Elastic anisotropy of human cortical bone secondary osteons measured by nanoindentation. Journal of Biomechanical Engineering. 2009;131(2):021001.

160. Yoon YJ, Yang G, Cowin SC. Estimation of the effective transversely isotropic elastic constants of a material from known values of the material's orthotropic elastic constants. Biomechanics and Modeling in Mechanobiology. 2002;1(1):83-93.

161. Ashman RB, Cowin SC, Van Buskirk WC, Rice JC. A continuous wave technique for the measurement of the elastic properties of cortical bone. Journal of Biomechanics. 1984;17(5):349-361.

162. Wolfram U, Wilke HJ, Zysset PK. Valid micro finite element models of vertebral trabecular bone can be obtained using tissue properties measured with nanoindentation under wet conditions. Journal of Biomechanics. 2010; 43(9):1731-1737.

Copyright @ 2014 John Wiley \& Sons, Ltd.

Int. J. Numer. Meth. Biomed. Engng. (2014)

Prepared using cnmauth.cls

DOI: $10.1002 / \mathrm{cnm}$

This article is protected by copyright. All rights reserved. 
163. Kelly N, Harrison NM, McDonnell P, McGarry JP. An experimental and computational investigation of the post-yield behaviour of trabecular bone during vertebral device subsidence. Biomechanics and Modeling in Mechanobiology. 2013;12(4):685-703.

164. Schwiedrzik J, Raghavan R, Bürki A, LeNader V, Wolfram U, Michler J, Zysset P. In situ micropillar compression reveals superior strength and ductility but an absence of damage in lamellar bone. Nature materials. 2014;

(June): $1-8$.

165. Gatt C, Hosea T, Palumbo R, Zawadsky J. Impact loading of the lumbar spine during football blocking. American Journal of Sports Medicine. 1997;25(3):317-321.

166. Luczynski KW, Steiger-Thirsfeld A, Bernardi J, Eberhardsteiner J, Hellmich C. Extracellular bone matrix exhibits

$=$ hardening elastoplasticity and more than double cortical strength: Evidence from homogeneous compression of non-tapered single micron-sized pillars welded to a rigid substrate. Journal of the Mechanical Behavior of Biomedical Materials. 2015;In Press: http://dx.doi.org/10.1016/j.jmbbm.2015.03.001.

167. Bevill G, Keaveny TM. Trabecular bone strength predictions using finite element analysis of micro-scale images at limited spatial resolution. Bone. 2009;44(4):579 - 584.

168. Bürklein D, Lochmüller E, Kuhn V, Grimm J, Barkmann R, Müller R, Eckstein F. Correlation of thoracic and

lumbar vertebral failure loads with in situ vs. ex situ dual energy X-ray absorptiometry. Journal of Biomechanics. 2001;34(5):579-87.

169. Baca V, Horak Z, Mikulenka P, Dzupa V. Comparison of an inhomogeneous orthotropic and isotropic material models used for FE analyses. Medical Engineering and Physics. 2008;30:924-930.

170. Schneider R, Faust G, Hindenlang U, Helwig P. Inhomogeneous, orthotropic material model for the cortical structure of long bones modelled on the basis of clinical CT or density data. Computer Methods in Applied Mechanics and Engineering. 2009;198(27-29):2167-217.

171. Wroe S, Moreno K, Clausen P, McHenry C, Curnoe D. High-Resolution Three- Dimensional Computer Simulation of Homonid Cranial Mechanics. The Anatomical Record. 2007;290:1248-1255.

172. Pierce DM, Ricken T, Holzapfel GA. Modeling sample/patient-specific structural and diffusional responses of cartilage using DT-MRI. International Journal for Numerical Methods in Biomedical Engineering. 2013; 29(8):807-21.

173. Decorato I, Kharboutly Z, Vassallo T, Penrose J, Legallais C, Salsac AV. Numerical simulation of the fluid structure interactions in a compliant patient-specific arteriovenous fistula. International Journal for Numerical Methods in Biomedical Engineering. 2014;30(2):143-159.

174. Sievaenen H. Bone densitometry and true BMD accuracy for predicting fractures : what are the alternatives ? Review. International Journal of Clinical Rheumatology. 2010;5(3):371-385.

175. Epstein NE. Are recommended spine operations either unnecessary or too complex? Evidence from second opinions. Surgical Neurology International. 2013;4(Suppl 5):S353-8.

176. Schwier M, Chitiboi T, Hülnhagen T, Hahn HK. Automated spine and vertebrae detection in CT images using object-based image analysis. International Journal for Numerical Methods in Biomedical Engineering. 2013; 29(9):938-63.

177. Castro-Mateos I, Pozo J, Lazary A, Frangi A. 3D Vertebra Segmentation by Feature Selection Active Shape Model vol.20 of Lecture Notes in Computational Vision and Biomechanics, pp. 241-245. Springer International Publishing. 2015;

178. Adams M, Dolan P. A technique for quantifying the bending moment acting on the lumbar spine in vivo. Journal of Biomechanics. 1991;24(2):117-126. 


\section{NOMENCLATURE}

\section{Variables}

a ... slope of linear relation between grey values and X-ray attenuation coefficients

A l.... area

A ... strain concentration tensor

$b \quad$... intercept of linear relation between grey values and X-ray attenuation coefficients

$\mathbb{C}$.... stiffness tensor

$C_{i j k l} \quad \ldots$ stiffness tensor component

$C_{i j k l}^{-1} \quad . .$. compliance tensor component

$\mathbb{D}_{i c, \Phi \Theta} \ldots$ influence tensor accounting for the influence of plastic strains in the $(\Phi, \Theta)$-oriented mineral phase on the total strains in the inter-crystalline pores

$\mathbb{D}_{\phi \theta \Phi \Theta} \quad \ldots$ influence tensor accounting for the influence of plastic strains in the $(\Phi, \Theta)$-oriented mineral phase on the total strains in the $(\phi, \theta)$-oriented phase

$E$. ... Young's modulus

$\mathcal{E}$...photon energy

E ... macroscopic strain

$f_{i}^{j} \quad \ldots$ volume fraction of phase $i$ (if specified, in the RVE $j$; otherwise, in the macroscopic RVE)

$\mathcal{F}$... yield function

$\mathcal{G}$... flow potential

$G_{i} \ldots$ shear modulus of constituent $i$

$G V \quad \ldots$ X-ray attenuation-related grey value

$l$...characteristic length

II ... fourth-order identity tensor

$k_{i} \ldots$... bulk modulus of constituent $i$

$l$.... characteristic length

$N \ldots$ total number of finite elements

$N_{C} \quad \ldots$ number of constituents in the volume (voxel)

$\mathbb{P}$.... Hill tensor or morphological tensor

$R \quad$... ratio

$V_{n} \quad \ldots$ volume of the $n$-th finite element

$W \quad$... weight 
x ... (microscopic) position vector inside the RVE

$\beta \quad .$. ration between compressive and tensile yield stress of HA

$\delta_{i j} \quad \ldots$ Kronecker delta

$\varepsilon \quad$... microscopic strain tensor

$\dot{\lambda} / \ldots$ plastic multiplier

$\mu_{i} \quad \ldots$ X-ray intensity attenuation coefficient of constituent $i$

$\nu$... Poisson's ratio

$\xi \quad$... displacement

$\rho_{i} \quad .$. "real" mass density of material constituent $i$

$\rho_{i}^{*, j} \quad \ldots$ apparent mass density of material constituent $i$ per volume of space $j$

$\bar{\rho} \quad$... average mass density

$\sigma \quad \ldots$ microscopic stress

$\Sigma \ldots$ macroscopic stress

$\phi_{i} \quad$... porosity of constituent $i$

$\phi_{i}^{j} \quad$... porosity of space $i$ (if specified, in the RVE $j$; otherwise, in the macroscopic RVE)

$\chi$... risk factor

$\psi \quad$... macroscopic strain energy density

$\bar{\psi}$... strain energy density averaged over organ

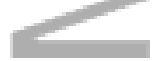

Subscripts

1 .... in radial direction

2 ... in circumferential direction

3 ... in axial direction

a ... dried in air

bone ... of bone

col .... of collagen

cort $\ldots$ of cortical shell

cyl ... of cylindrical inclusions

dev ... deviatoric part

$e c \quad$... of extracellular bone matrix

ef $\ldots$ of the extrafibrillar space

end ... of the bony endplate 


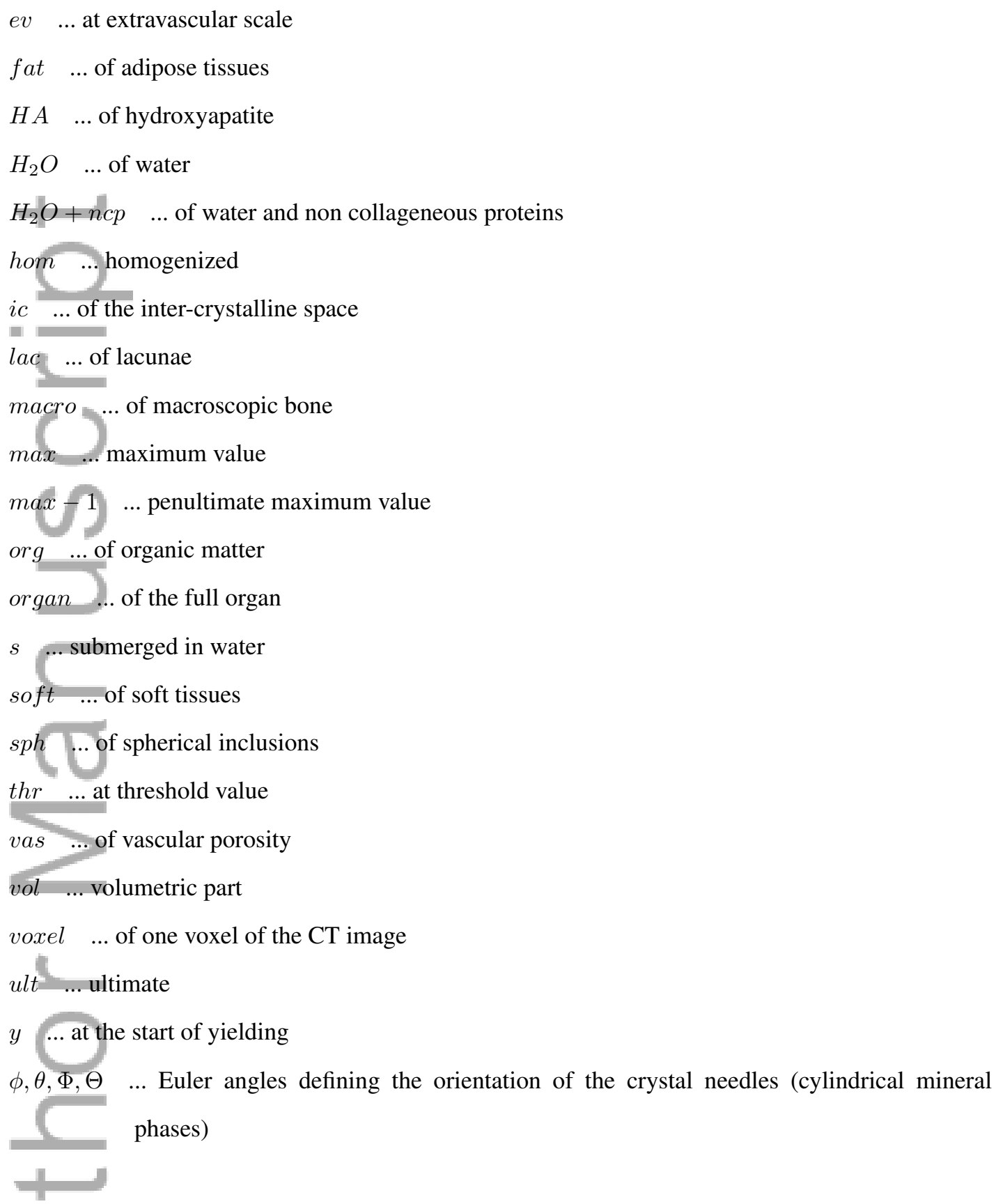




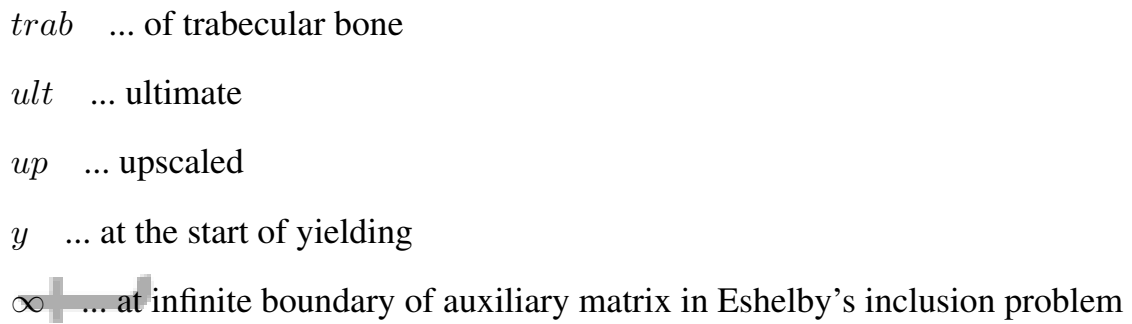

Mathematical symbols

$\nabla_{s} \ldots$ symmetrized nabla operator

: ... second-order tensor contraction
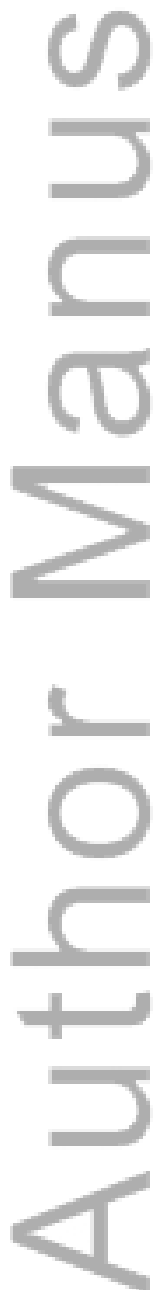


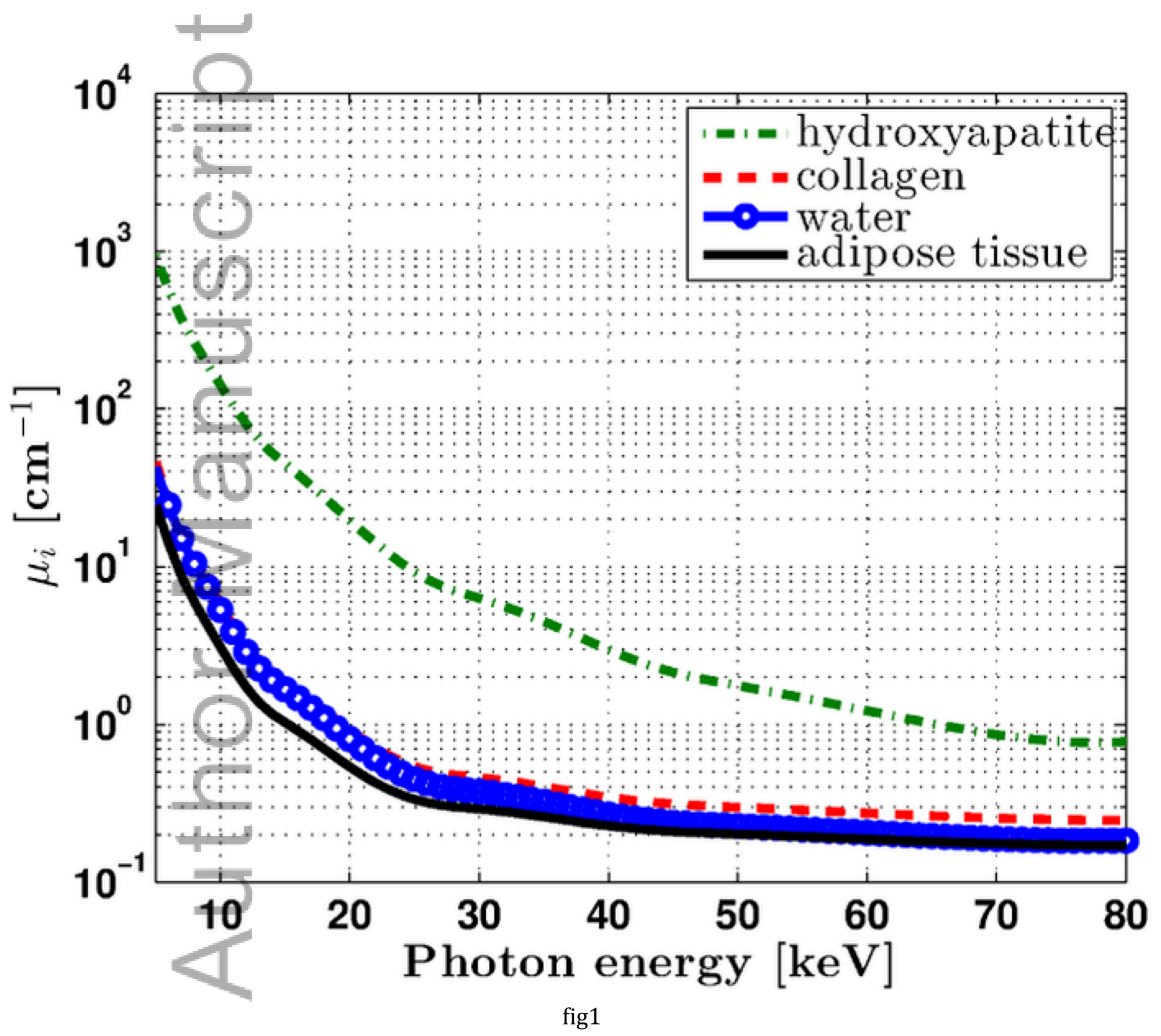




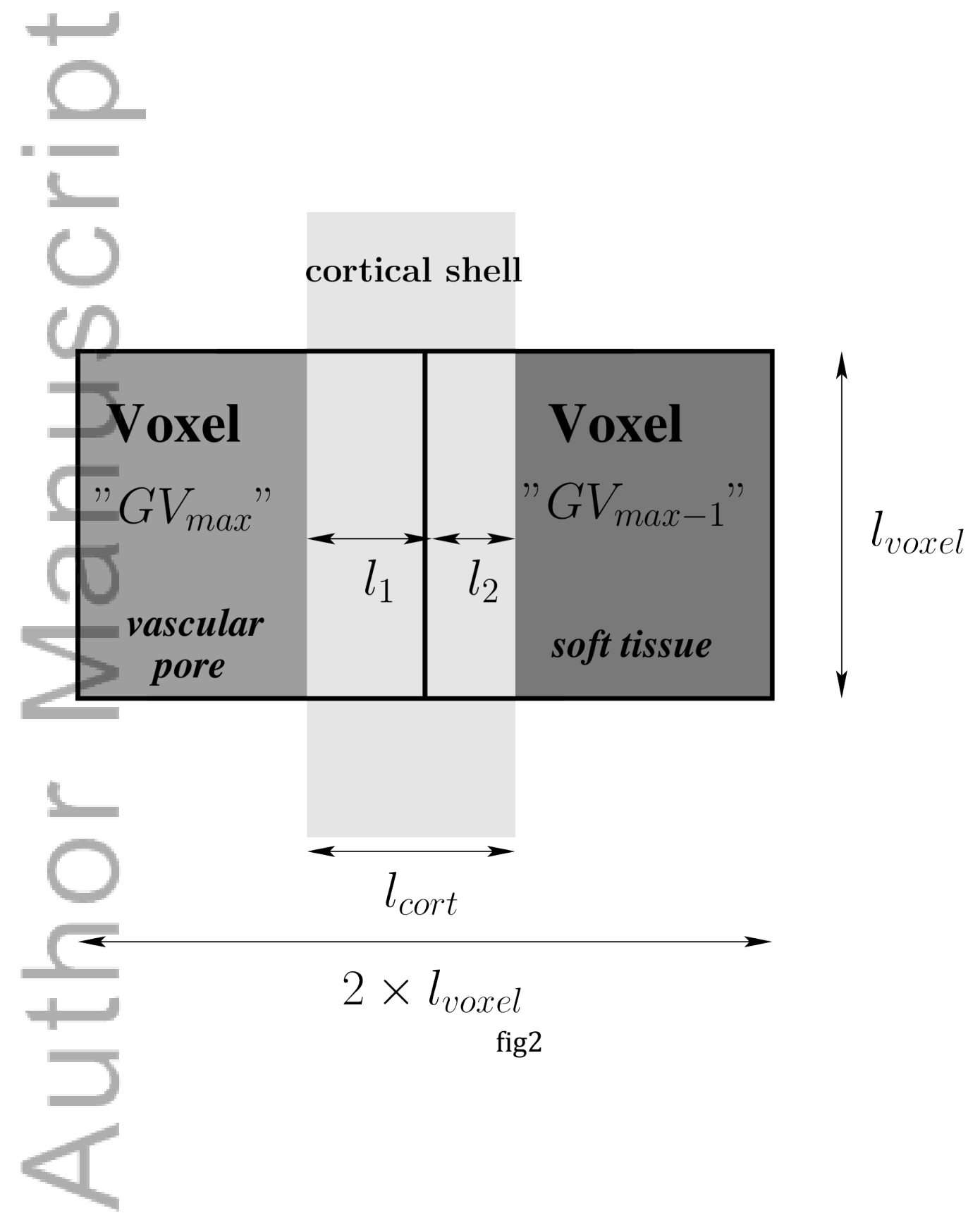

This article is protected by copyright. All rights reserved. 


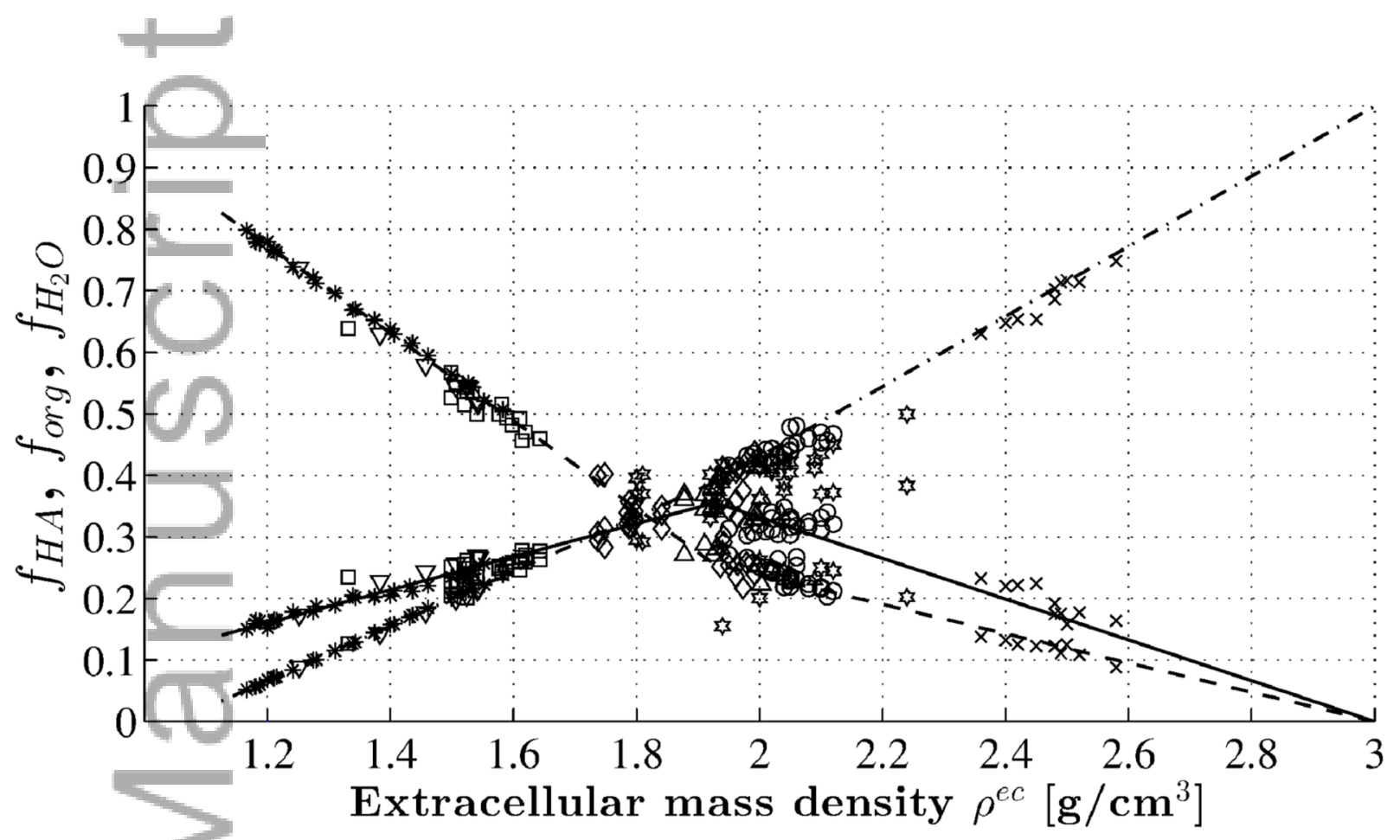

o Bovine bone [Lees et al. (1979)]

$\times$ Otic bones of a fin whale [Lees et al. (1995)]

a Mineralized turkey leg tendon [Lees and Page (1992)]

$\triangle$ Bones from steers, dogs, humans, monkeys [Gong et al. (1964)]

$\nabla$ Bones from rabbits, rats [Burns (1929)]

* Bones from various vertebrates [Biltz and Pellegrino (1969)]

$\diamond$ Horse metacarpals [Lees (2003)]

* Femur and humeris of albino rats (female and male) [Hammett (1925)]

- Organic

- Mineral

- - Water

fig3 


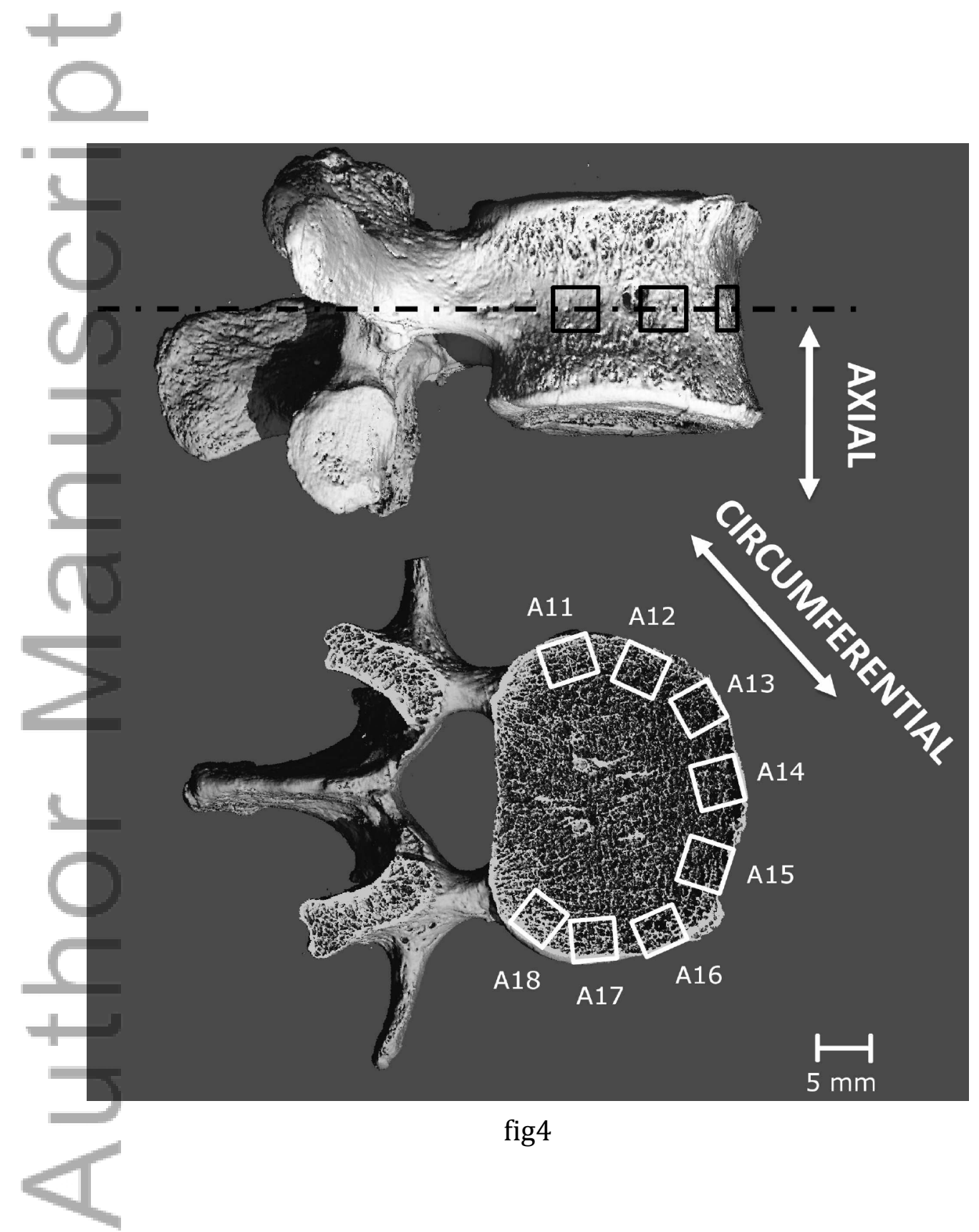

This article is protected by copyright. All rights reserved. 

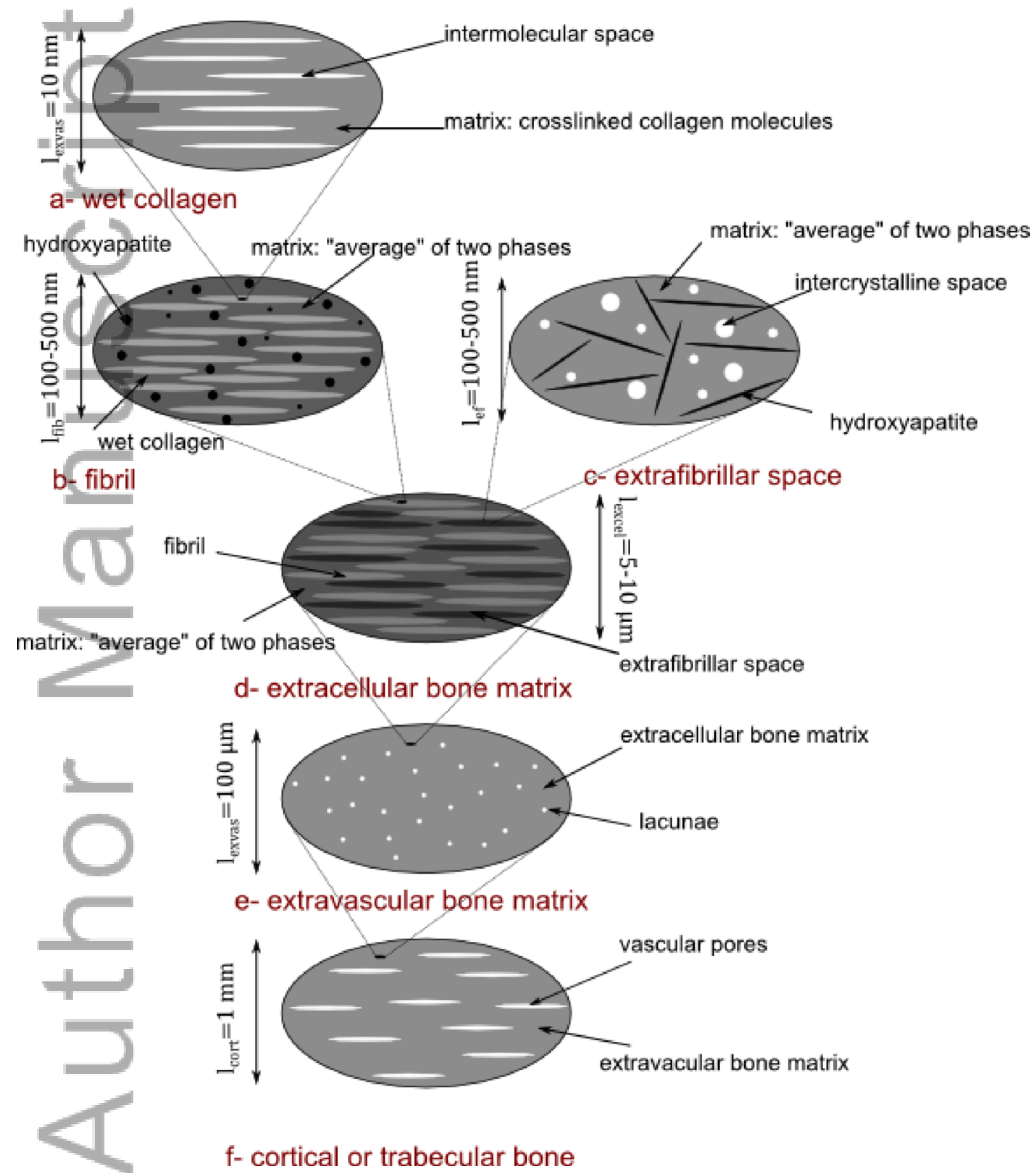

f- cortical or trabecular bone

fig5

This article is protected by copyright. All rights reserved. 


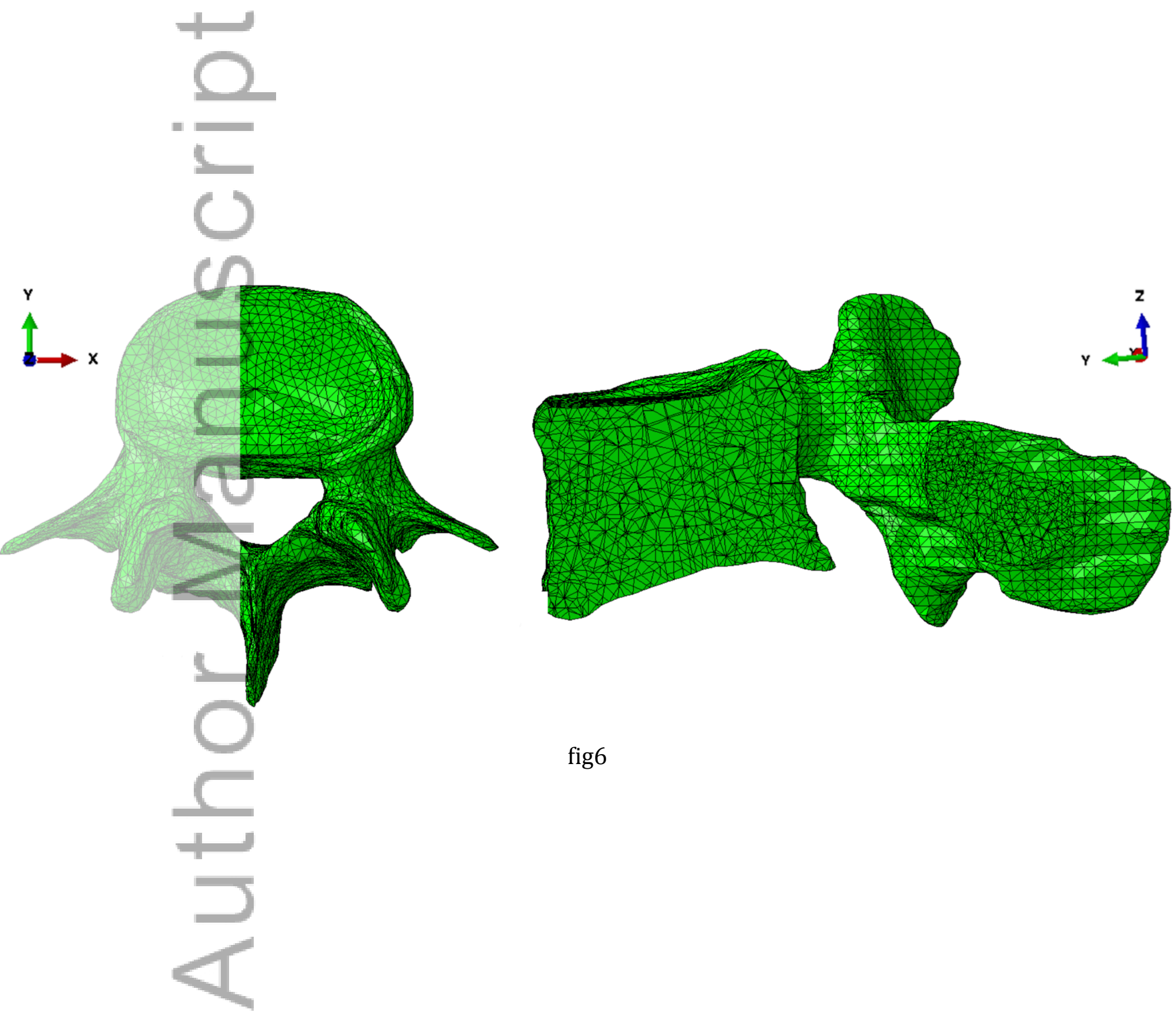

This article is protected by copyright. All rights reserved. 


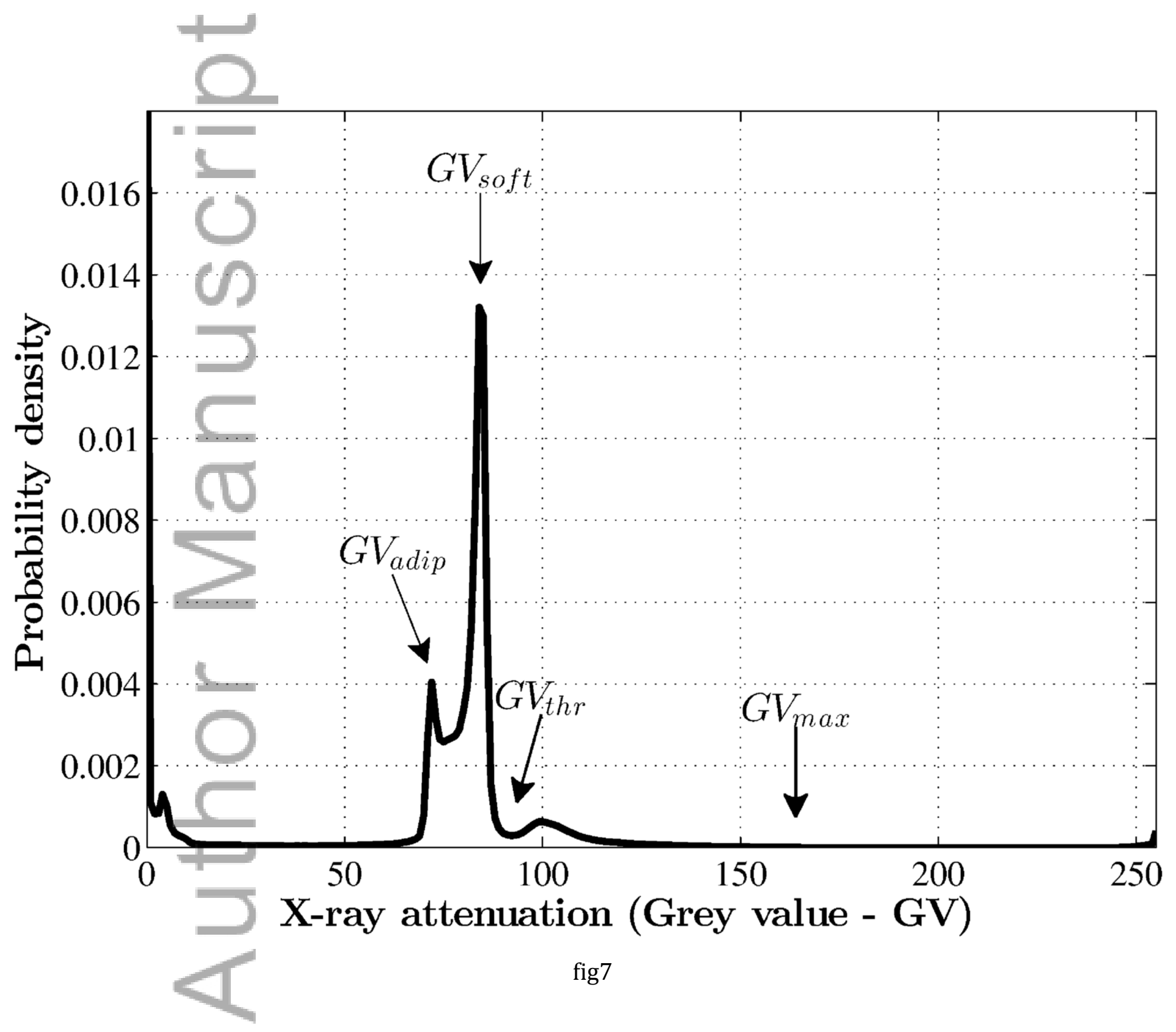




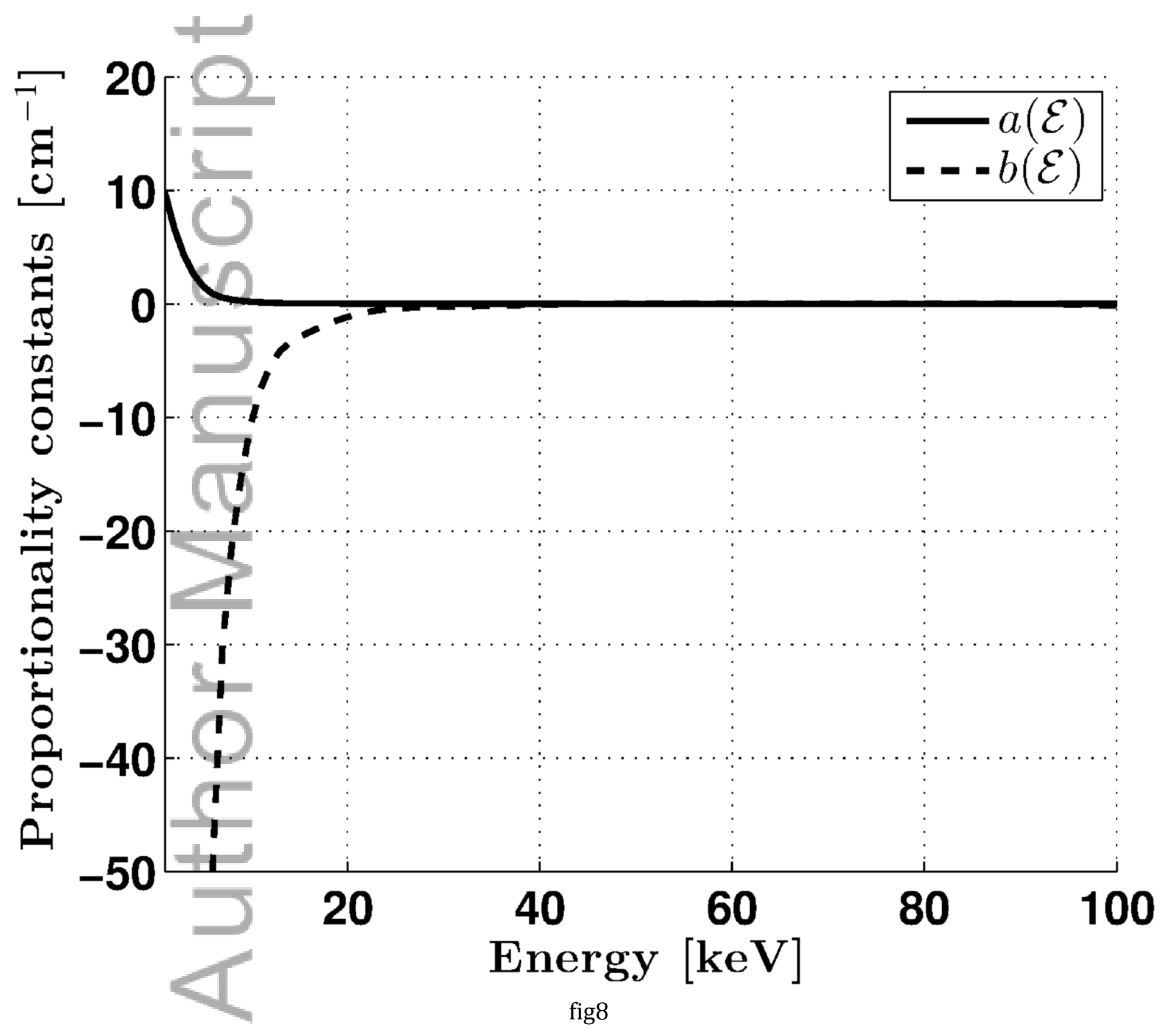




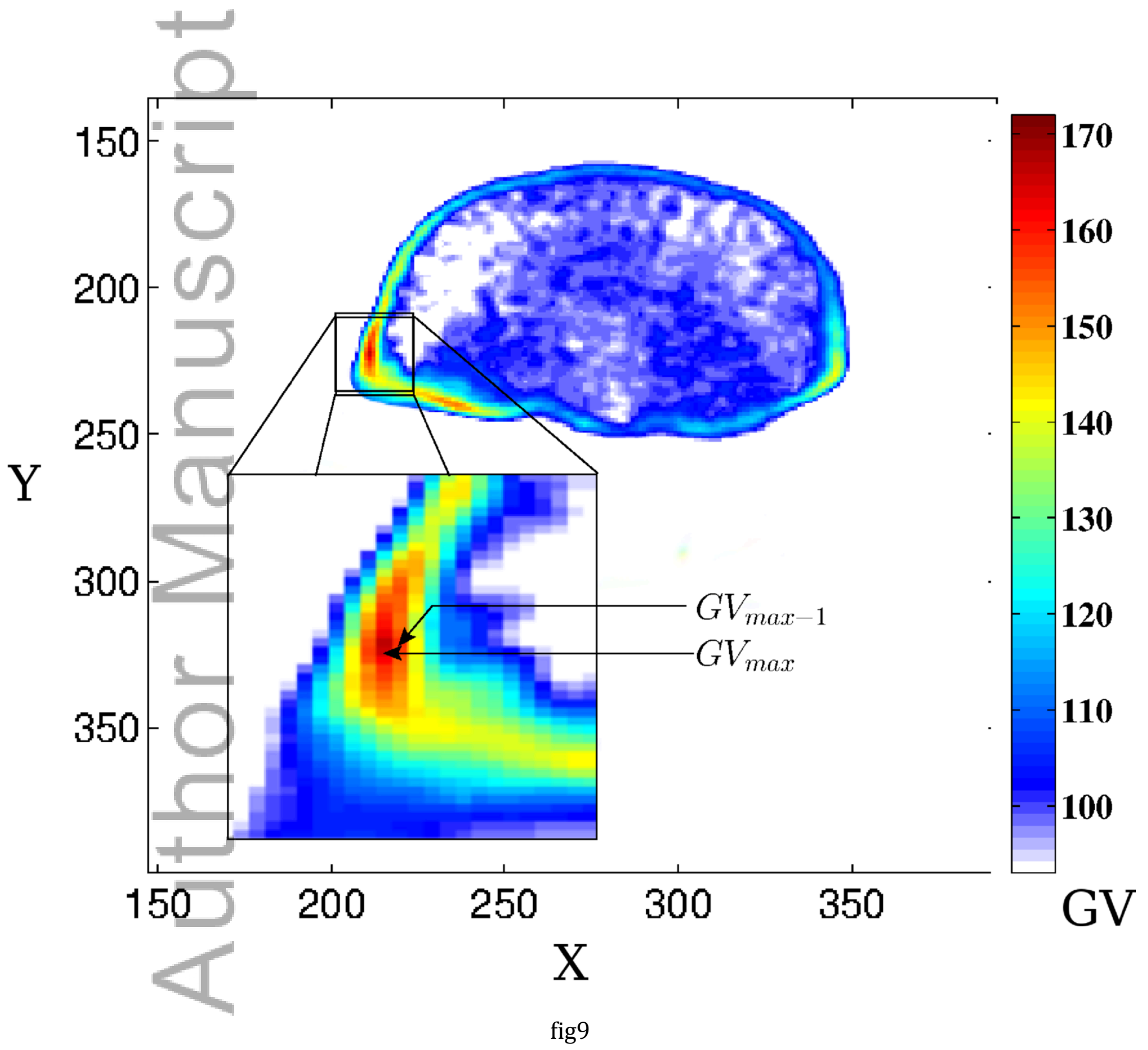

This article is protected by copyright. All rights reserved. 


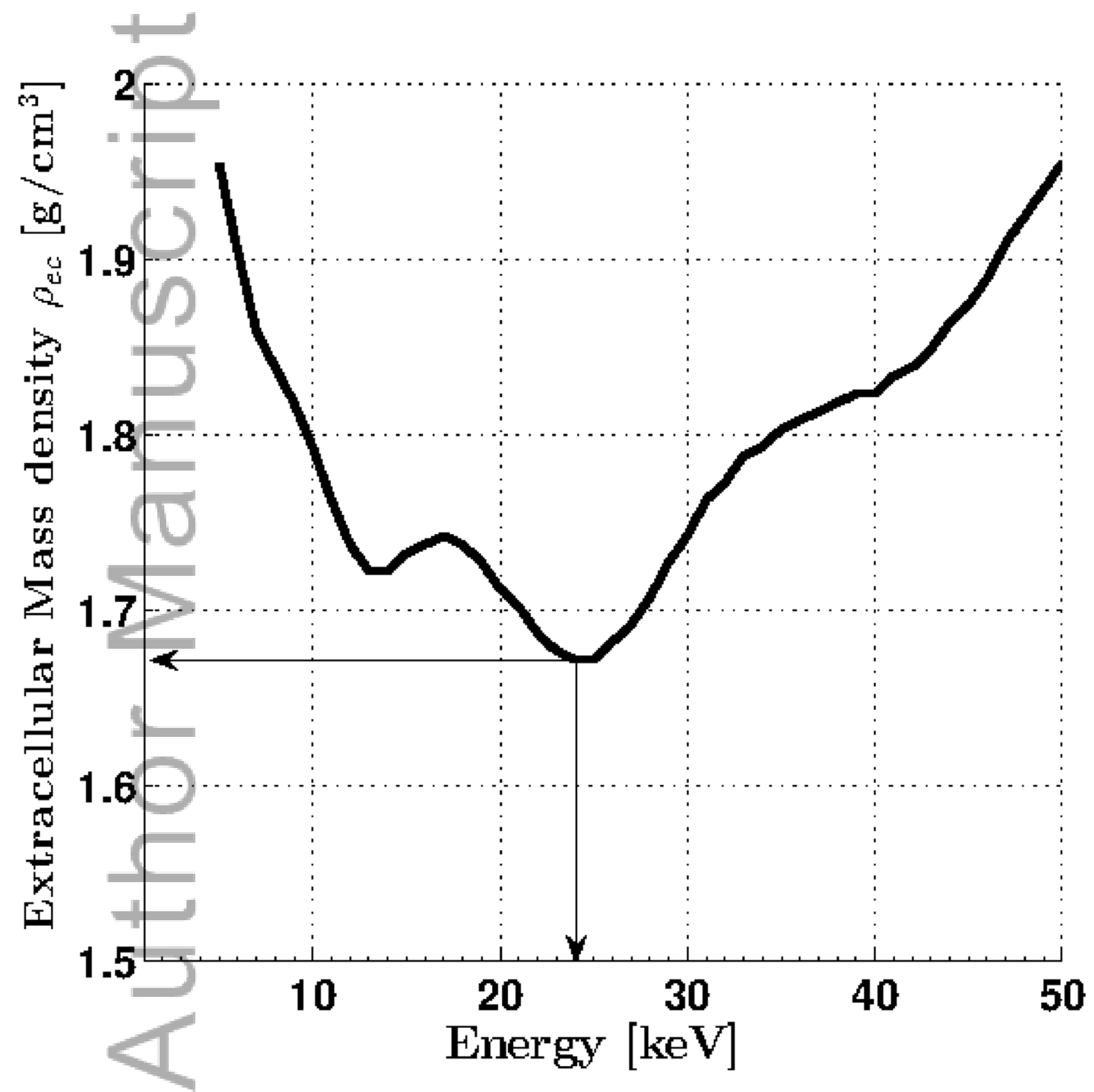

fig10 


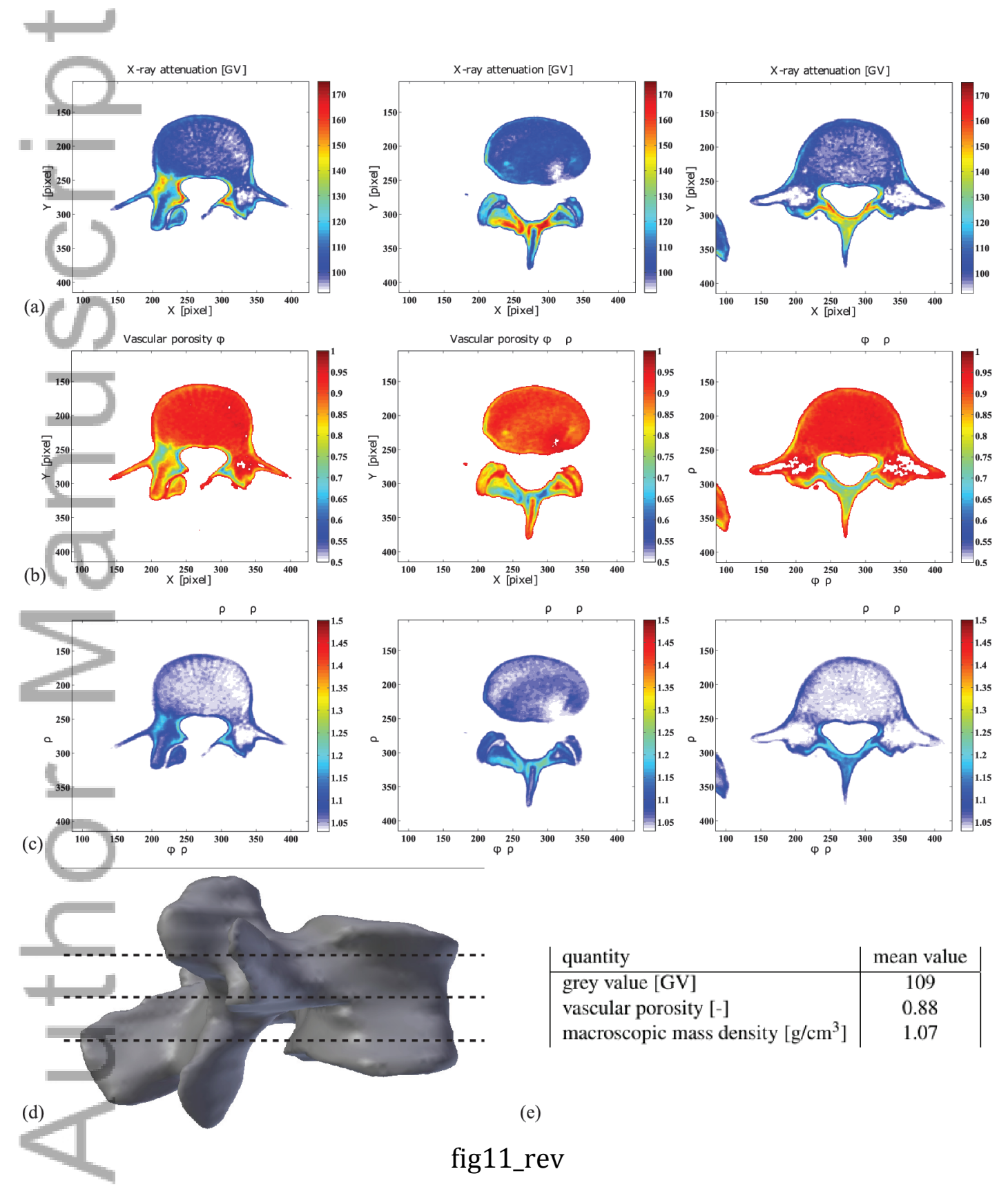

This article is protected by copyright. All rights reserved. 


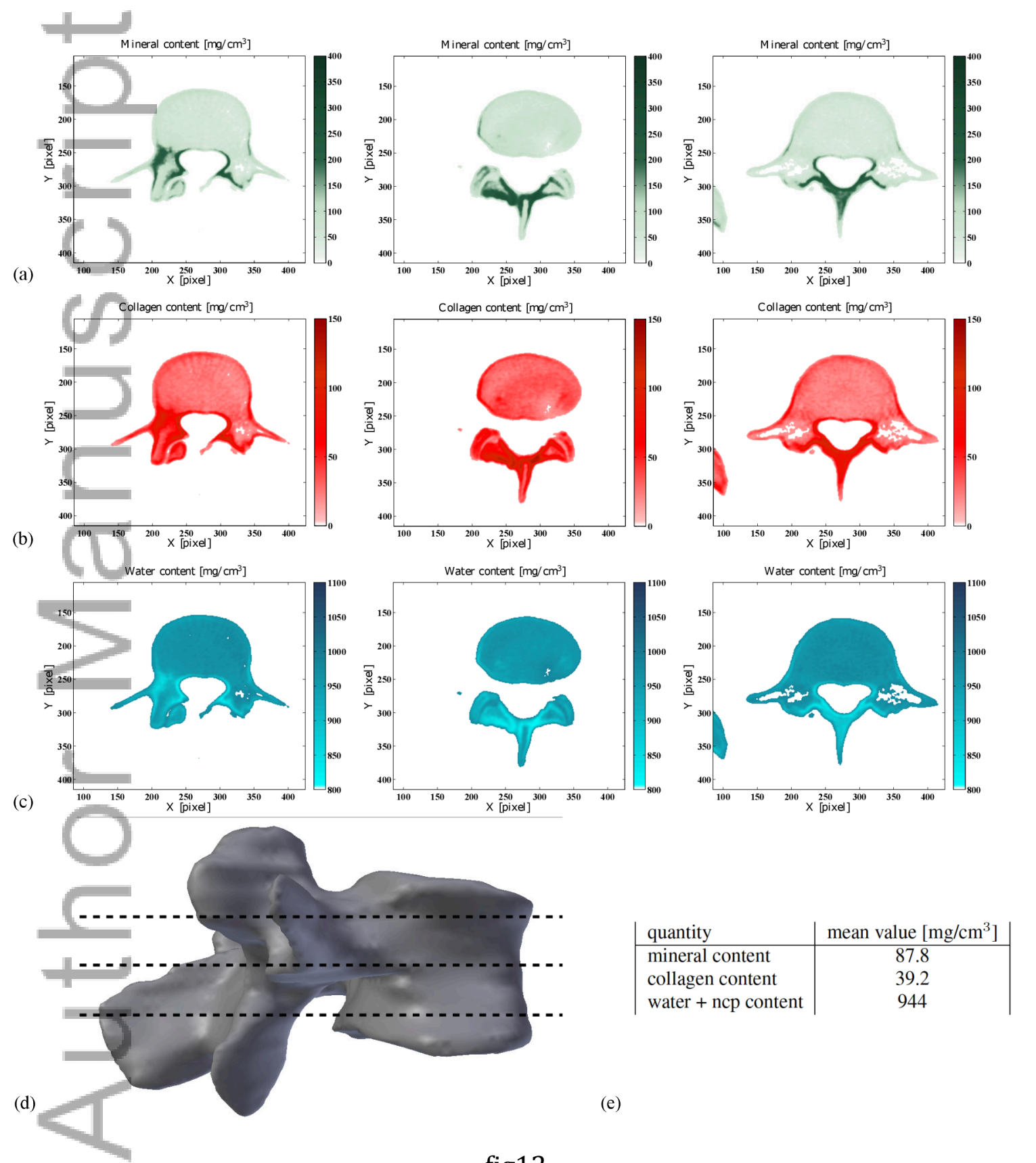

fig12

This article is protected by copyright. All rights reserved. 

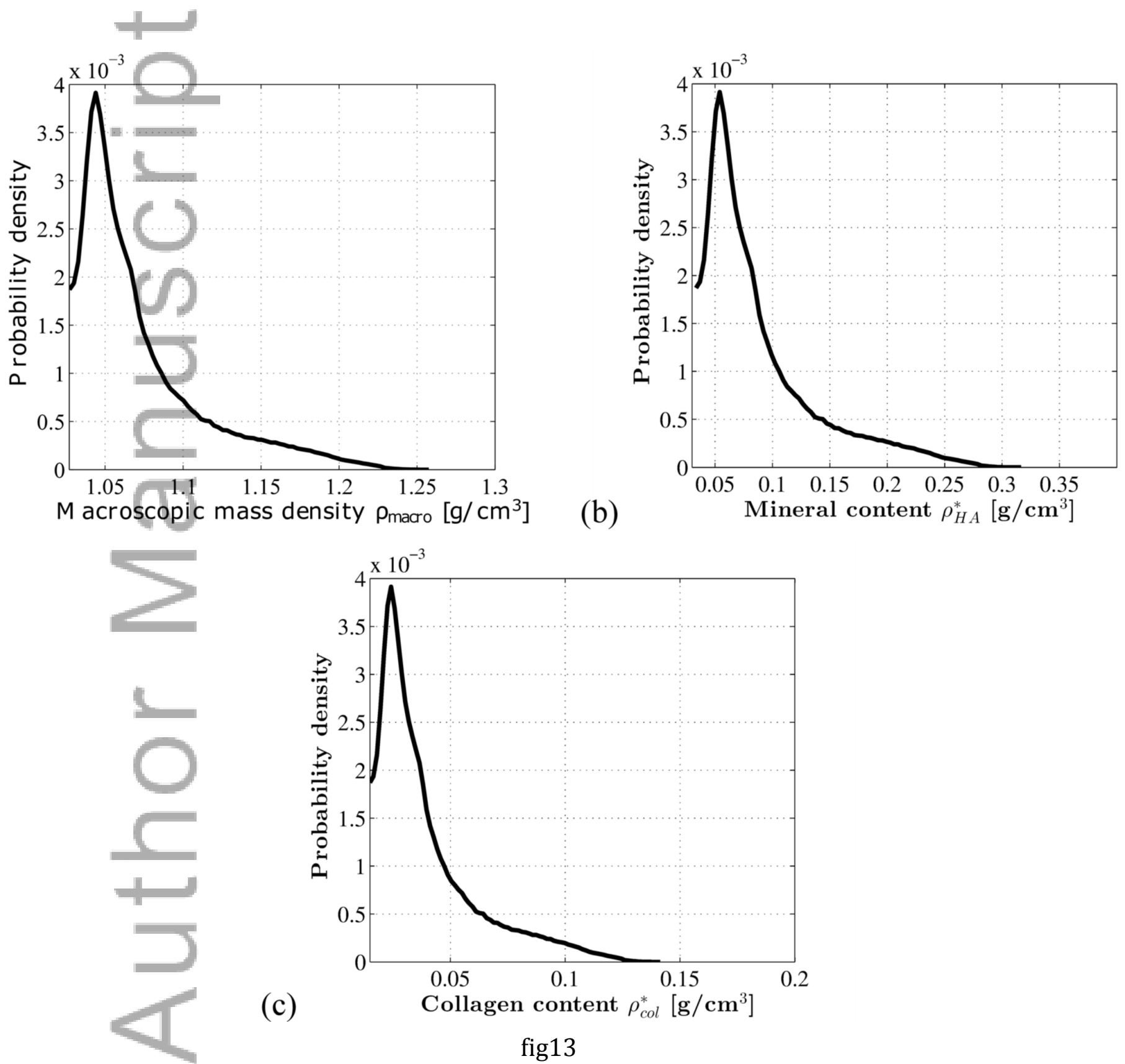

(b)

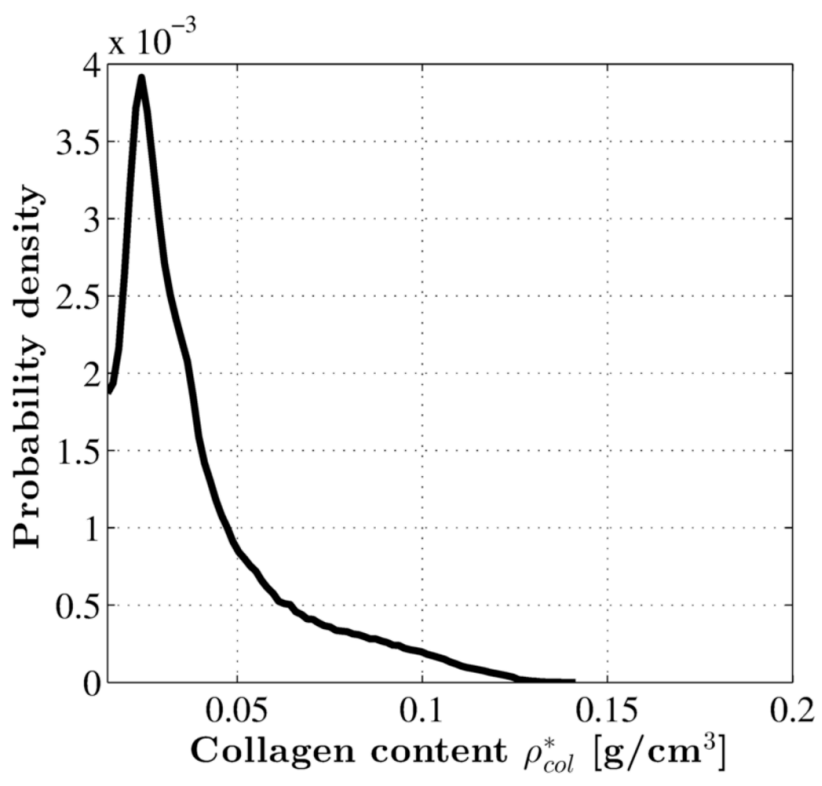

fig13

This article is protected by copyright. All rights reserved. 


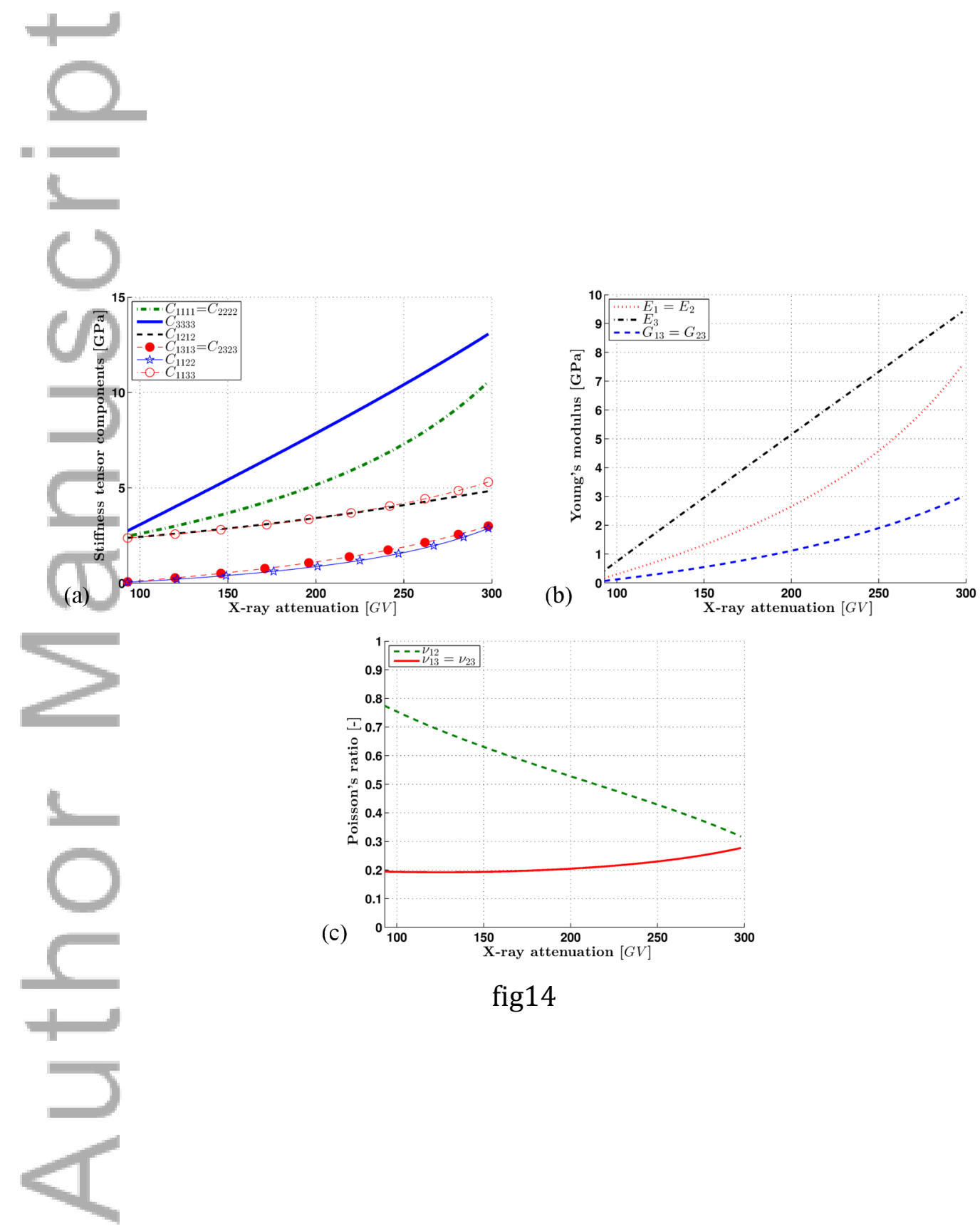

This article is protected by copyright. All rights reserved. 

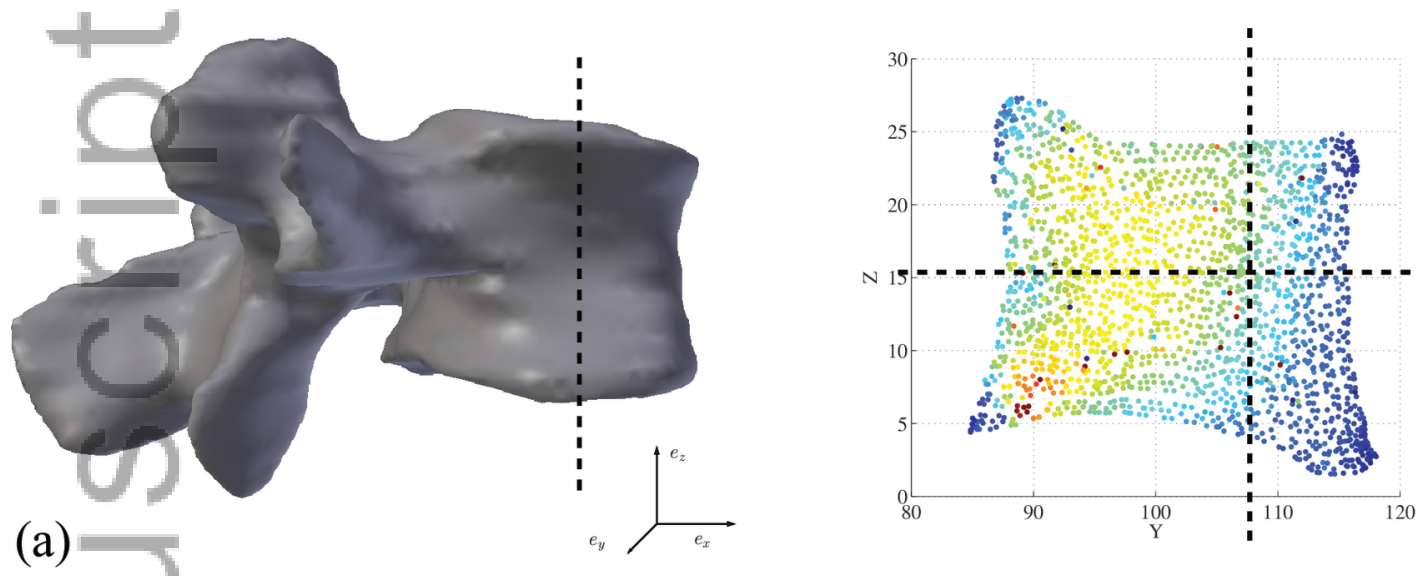

(a)

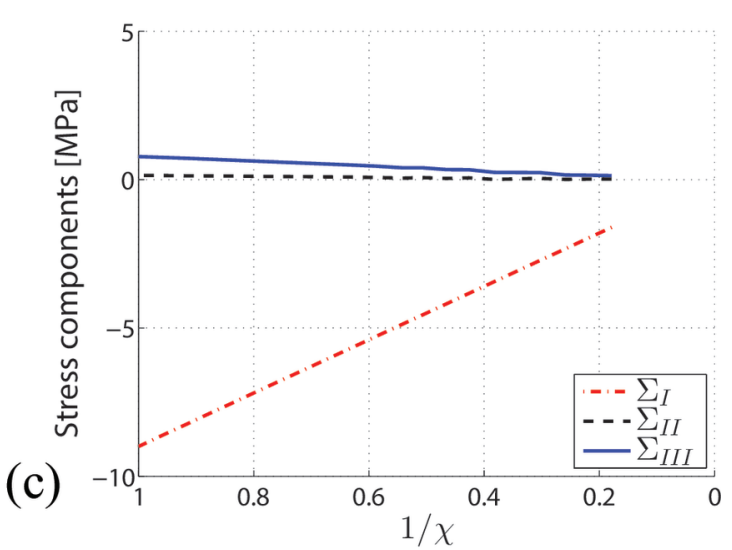

(b)

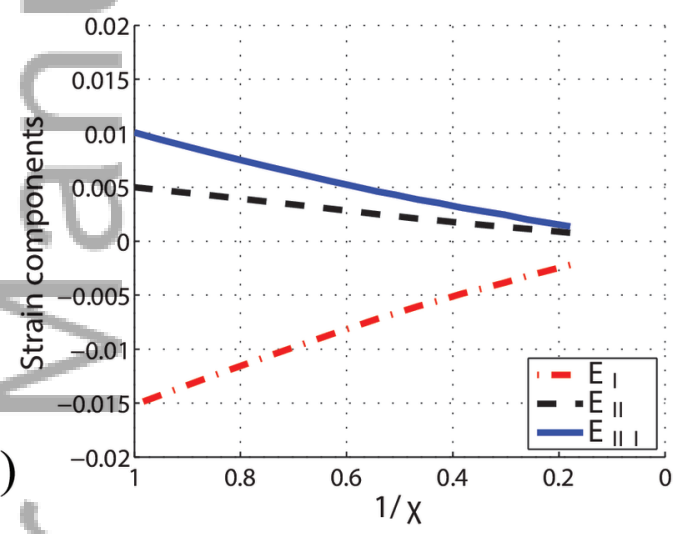

(c)
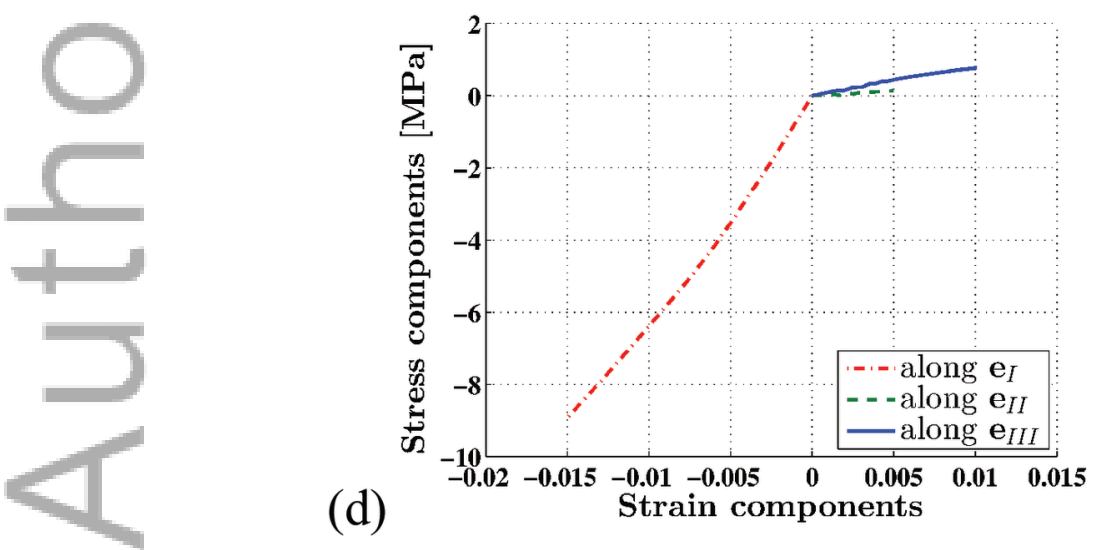

fig15_rev 

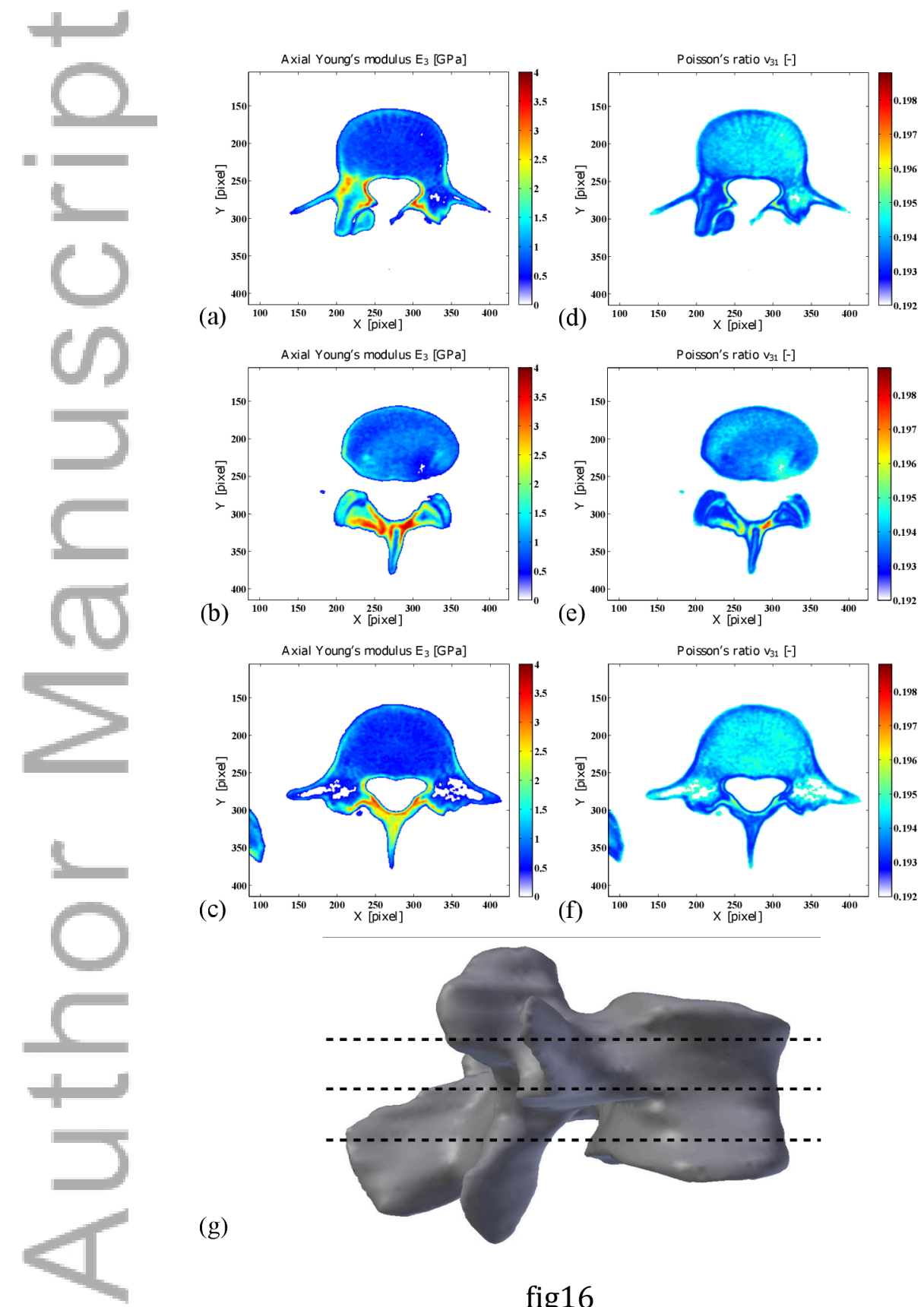

(e)

(c)

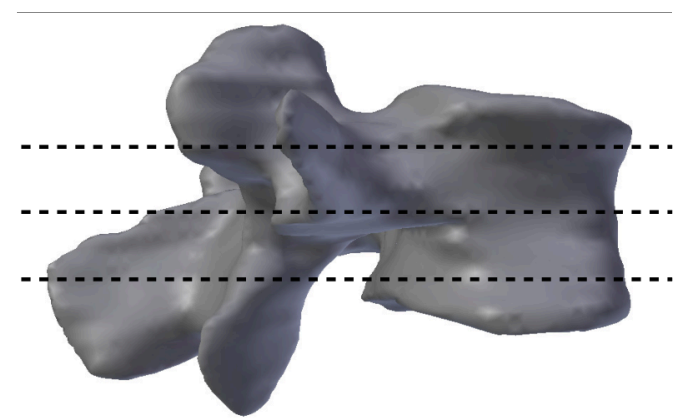

(g)

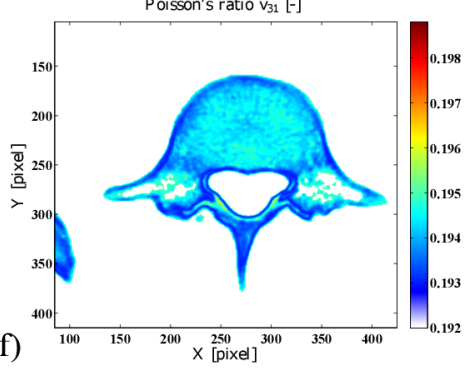

fig16

This article is protected by copyright. All rights reserved. 


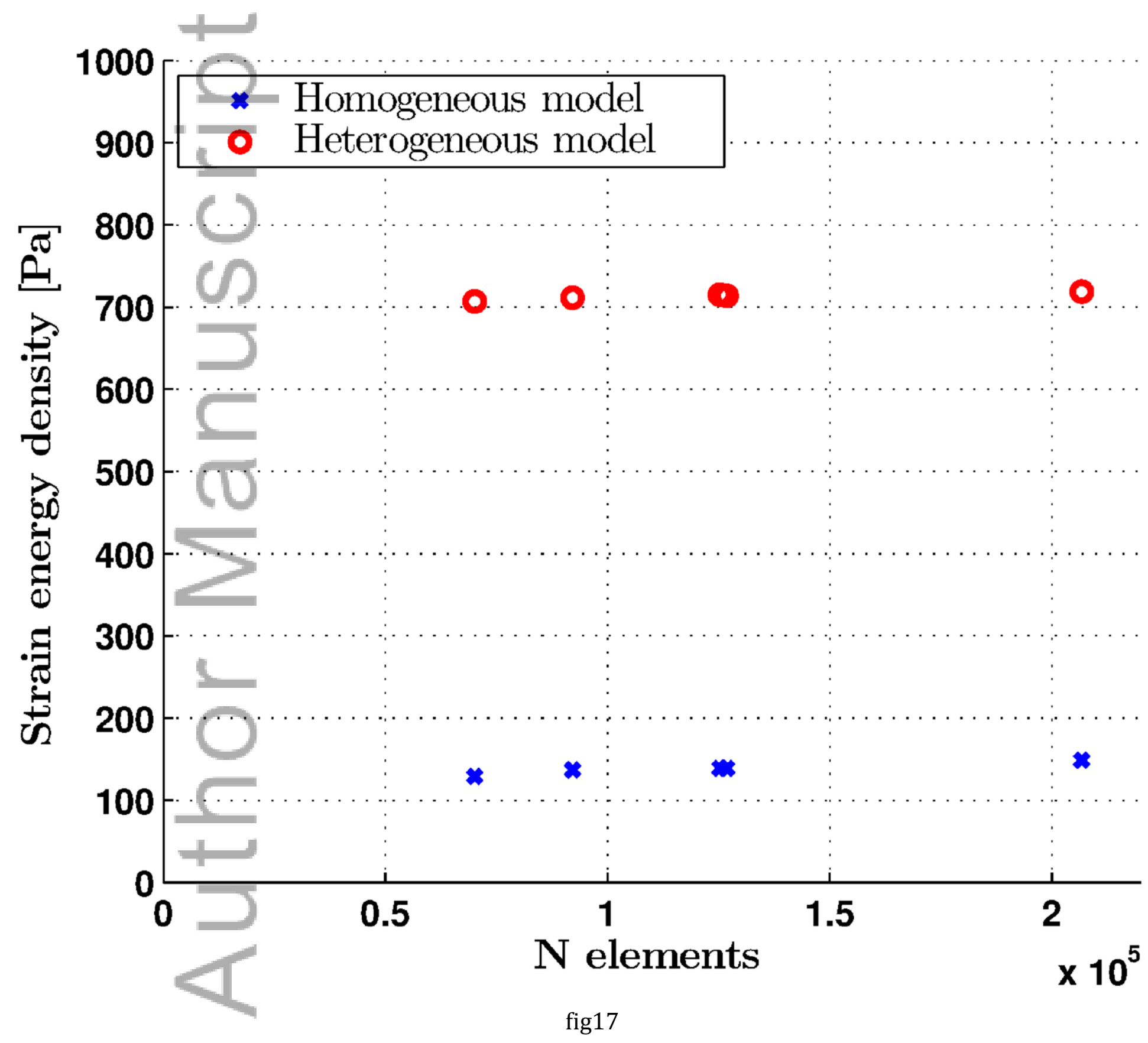




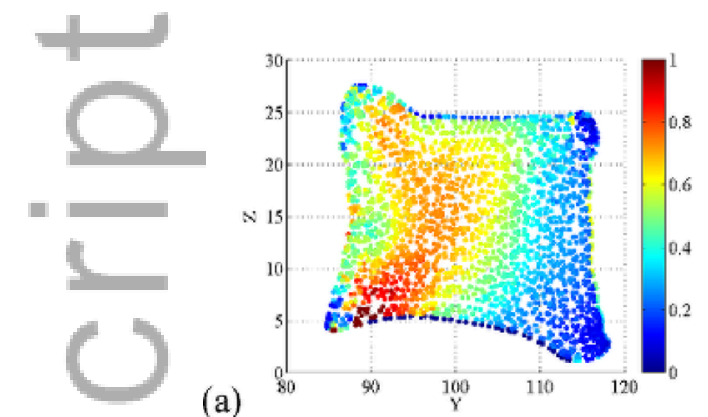

(a)
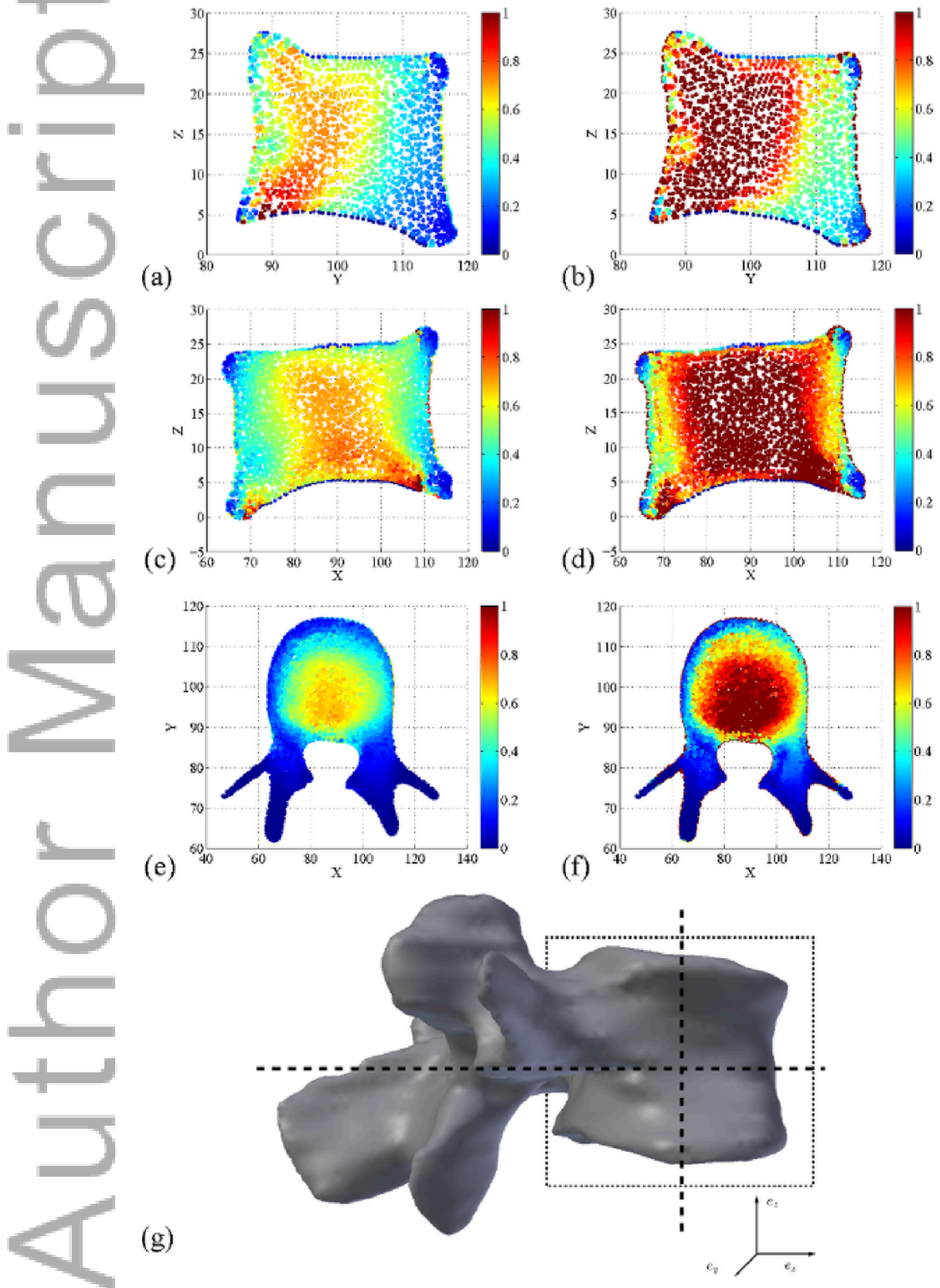

fig18

This article is protected by copyright. All rights reserved. 


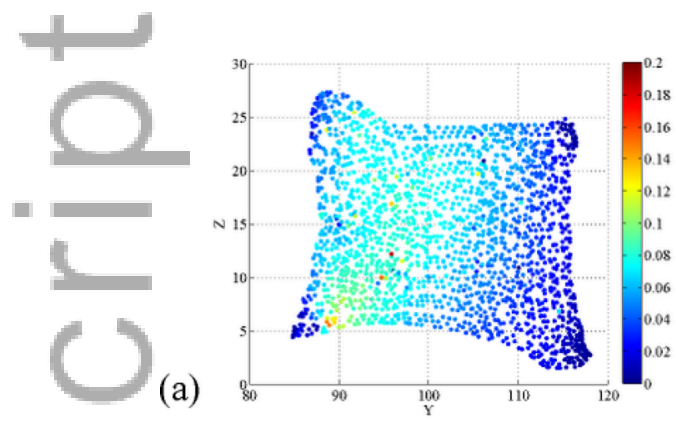

(b)

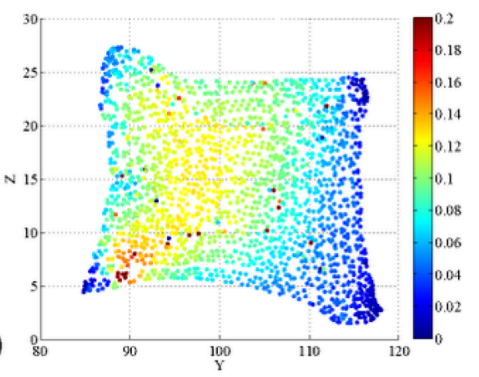

()

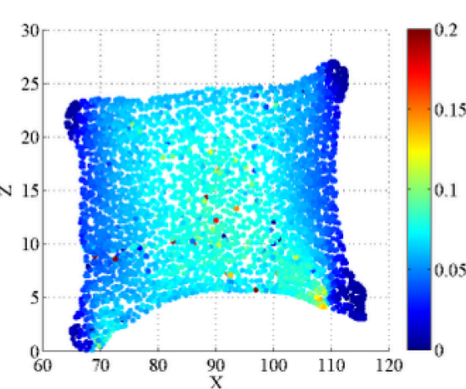

(d)

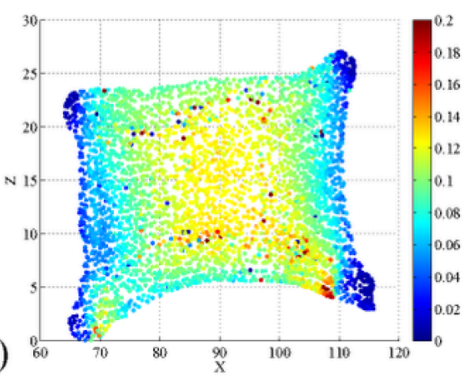

(e)

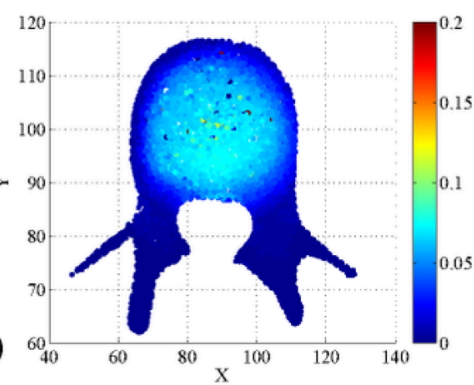

(f)
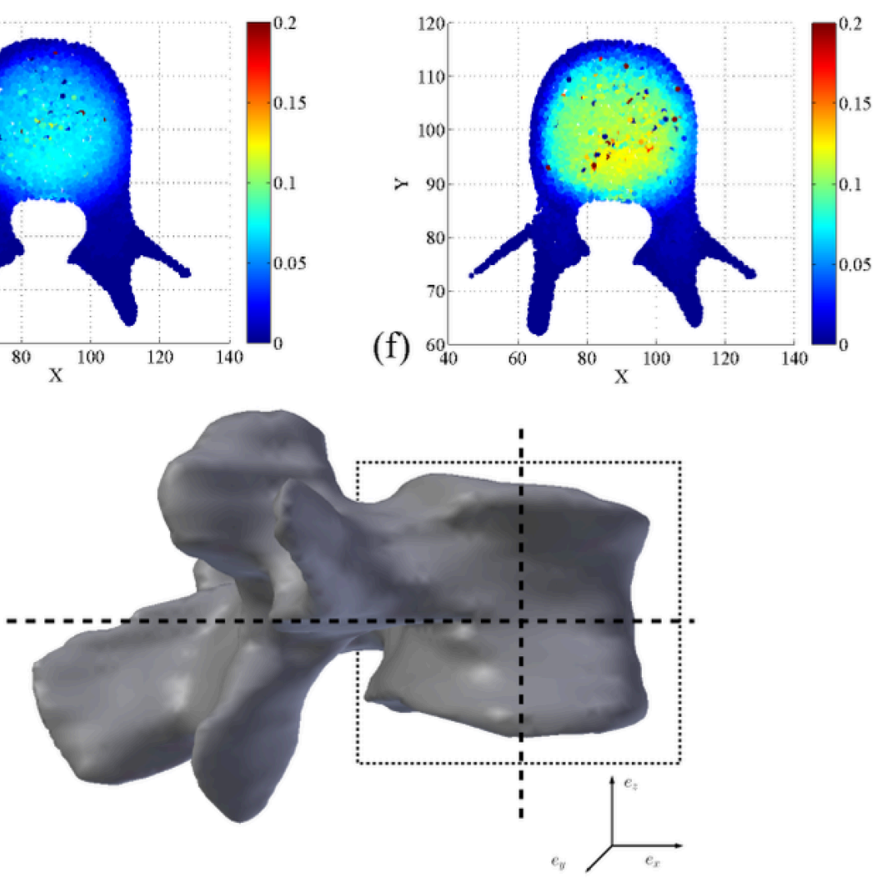

fig19

This article is protected by copyright. All rights reserved. 